B R I L L

brill.com/ctoz

\title{
Integrative systematics reveals the new land-snail genus Taphrenalla (Eupulmonata: Ariophantidae) with a description of nine new species from Thailand
}

\author{
Arthit Pholyotha \\ Biological Sciences Program, Faculty of Science, Chulalongkorn University, Bangkok 1033o, \\ Thailand \\ Animal Systematics Research Unit, Department of Biology, Faculty of Science, Chulalongkorn \\ University, Bangkok 10330, Thailand \\ Chirasak Sutcharit \\ Animal Systematics Research Unit, Department of Biology, Faculty of Science, Chulalongkorn \\ University, Bangkok 1033o, Thailand
}

Piyoros Tongkerd

Animal Systematics Research Unit, Department of Biology, Faculty of Science, Chulalongkorn University, Bangkok 1033o, Thailand

EkgachaiJeratthitikul

Animal Systematics and Molecular Ecology Laboratory, Department of Biology, Faculty of Science, Mahidol University, Bangkok 10330, Bangkok, Thailand

Somsak Panha

Animal Systematics Research Unit, Department of Biology, Faculty of Science, Chulalongkorn University, Bangkok 1033o, Thailand

somsak.pan@chula.ac.th

\begin{abstract}
The endemic terrestrial Crown Snail from Southern Thailand formerly in Macrochlamys Gray, 1847 is now described as Taphrenalla Pholyotha \& Panha gen. nov., based on comparative morphology and molecular data. Overall, eleven Taphrenalla species are now recognized, including two nominal species: T. asamurai and T. diadema. A total of nine new species are proposed: T. alba sp. nov., T. conformis sp. nov., T. corona sp. nov., T. dalli sp. nov., T. incilis sp. nov., T. macrosulcata sp. nov., T. parversa sp. nov., T. pygmaea sp. nov. and T. zemia sp. nov. The molecular phylogeny constructed from the mitochondrial cytochrome oxidase c subunit I (COI) and 16S rRNA gene fragments plus the nuclear $28 \mathrm{~S}$ rDNA gene fragments revealed that Taphrenalla

(C) PHOLYOTHA ET AL., 2020| DOI:10.1163/18759866-BJA10013

This is an open access article distributed under the terms of the CC BY 4.O License.
\end{abstract}


gen. nov. is monophyletic with a well-supported clade. The diagnostic characters of Taphrenalla gen. nov. are the shell sculpture with several radial grooves, body with well-developed colourful stripes running from the head to tail, and genitalia similar to Macrochamys but with an un-coiling epiphallic caecum. The spermatophore has one or two spines near the sperm sac and a spineless tail.

\section{Keywords}

Southeast Asia - limestone - endemic species - Limacoidei - Helicarionoidea - morphology anatomy - phylogeny

\section{Introduction}

Thailand, especially the southern part, is rich in biodiversity of malacofauna and is recognized as a biodiversity hotspot (Myers et al., 2000). The topography of Southern Thailand is a peninsula between the Gulf of Thailand and the Andaman Sea. The long ridge of two mountain ranges (Phuket Range and Nakhon Si Thammarat Range) separated by low-lying areas of less than $200 \mathrm{~m}$ above mean sea level (amsl) extend to this part. The Phuket Range runs parallel to the west coast of upper Southern Thailand which extends northwards to the Tenasserim Range, whereas the Nakhon Si Thammarat Ranges runs from Surat Thai southwards to the Malaysian border (Gupta, 2005; Ridd et al., 2011; Gardner et al., 2015; Department of Mineral Resources, 2018).

The diversity of land snails in Southern Thailand is due to several interrelated factors. There is a high relative humidity, a short dry season (2-4 months) and a great amount of rainfall (Thai Meteorological Department, 2015). According to the key zoogeographical position of Thailand, the snail fauna has dispersed from Indo-Himalayan, Indo-Chinese, and Malaysian regions (Naggs et al., 20o6). In addition, there are many extensive ranges of limestone karsts and outcrops scattered along this area. Limestones in Southern Thailand are formed from the Permian Ratburi Limestone and, to a lesser extent, the Ordovician-Devonian Satun
Group limestone (Gupta, 2005; Ridd et al., 2011; Gardner et al., 2015; Department of Mineral Resources, 2018). Many documents show that land snail diversity is associated with limestone karsts and outcrops (Clements et al., 2006; Naggs et al., 2006). The larger karsts probably contain a higher number and diversity of microhabitats that are conducive for land snail speciation and endemism (Clements et al., 2008; Foon et al., 2017).

The land snail family Ariophantidae Godwin-Austen, 1888 is recognized as one of the most diverse families and contains a remarkably high number of species with various shell characteristics from snails to semi-slugs (Blanford \& Godwin-Austen, 19o8; Schileyko, 2002, 2003). Ariophantid taxa are only characterized by the absence of the penial nerve fibres running through the cerebral ganglion (Hausdorf, 1998). Later, the definitions of Ariophantidae are given by Schileyko (2002), who made extensive changes to the classification of Limacoidea s.l. The characters of Ariophantidae are shell helicoid to plate-like, animal has no frontal organ, caudal foss and caudal horn well-developed, genitalia with various length flagellum, a straight, spirally coiled or missing epiphallic caecum attached by penial retractor, penis with or without verge, dart apparatus absent or present (when present, it is vaginal, with apical retractor). Ariophantidae is comprised of three subfamilies (Bouchet et al., 2017). 
Among these, the Macrochlamydinae is widely distributed throughout Asia, especially South and Southeast Asia (Blanford \& Godwin-Austen, 1908). Due to the similarity in their shell morphology (glossy, thin, and semi-transparent), early malacologists attributed most Asian species to Macrochlamys (Godwin-Austen, 1883, 1907; Blanford \& Godwin-Austen, 1908). The type genus of this subfamily is Macrochlamys Gray, 1847 , which is recognized as the most species-rich genus in Ariophantidae (Blanford \& Godwin-Austen, 1908; Pholyotha et al., 2018, 2020; Sajan et al., 2019). Subsequently, many genera, such as Taphrospira Blanford, 1905, Sarika GodwinAusten, 1907, Sakiella Godwin-Austen, 1908, Syama Godwin-Austen, 1908, and Rasama Laidlaw, 1932, have been described as different genera on the basis of their reproductive anatomy or some unique characters of their shells (Blanford, 1905; Blanford \& Godwin-Austen, 1908; Laidlaw, 1932).

Taxonomic studies of the two Crown Snails, Nanina (Macrochlamys) diadema Dall, 1897 and Macrochlamys asamurai (Panha, 1997), are still problematic in their generic placement because of the striking appearance of many radial grooves on their shell sculpture, leading to their name of "Crown Snails", and their remarkable body colouration. Early authors placed them in Macrochlamys (e.g., Dall, 1897; Panha, 1996, 1997; Maneevong, 2000; Hemmen \& Hemmen, 2001), while they were transferred to Sarika by later authors (e.g., Maassen, 2001; Sutcharit \& Panha, 2008; Pholyotha et al., 2018, 2020). Although Maassen (2001) suggested that a new genus should be established for these two species, Sutcharit \& Panha (2008) still included them in Sarika. During a re-examination of all specimens having remarkable radial grooves in our collection, many peculiar specimens were found that were distinct in their shell sculpture, animal colouration, and genital anatomy.
Moreover, molecular analysis suggested that they formed a monophyletic group of a different lineage to Sarika. Therefore, Maassen's suggestion was agreed upon.

Consequently, several studies have documented that an integrative taxonomic approach, including molecular, morphological, and anatomical data, and including information of the reproductive biology should be used when proposing species entities (Huang et al., 2019; Jeratthitikul et al., 2019; Jirapatrasilp et al., 2019). For inferring molecular phylogenies, the mitochondrial cytochrome $c$ oxidase subunit I (COI) and the large subunit ribosomal (r)RNA gene (16S) have been widely and successfully used to study putatively closely related land snails (Hyman et al., 2007, 2017; Wu et al., 2008; Liew et al., 2009; Köhler \& Criscione, 2015; Hyman \& Köhler, 2018). The partial $28 \mathrm{~S}$ nuclear rDNA (28S) sequences are more conserved and become useful to resolve deep relationships within the family (Wade et al., 2001, 2006; Páll-Gergely et al., 2017; Nantarat et al., 2019).

In this present study, several newly collected specimens of crown snails from Southern Thailand were examined. The new genus is proposed based on the distinct morphological characters and molecular data. The descriptions of nine new species are included herein and the status of two previously described species is updated. Additionally, phylogenetic trees constructed from concatenated sequences of three gene fragments (COI, $16 \mathrm{~S}$, and 28S) were used to infer the evolutionary relationship and distribution patterns among members of this genus in Southern Thailand.

\section{Materials and methods}

\section{Sampling and morphological studies}

This study is based on voucher specimens deposited in Chulalongkorn University 


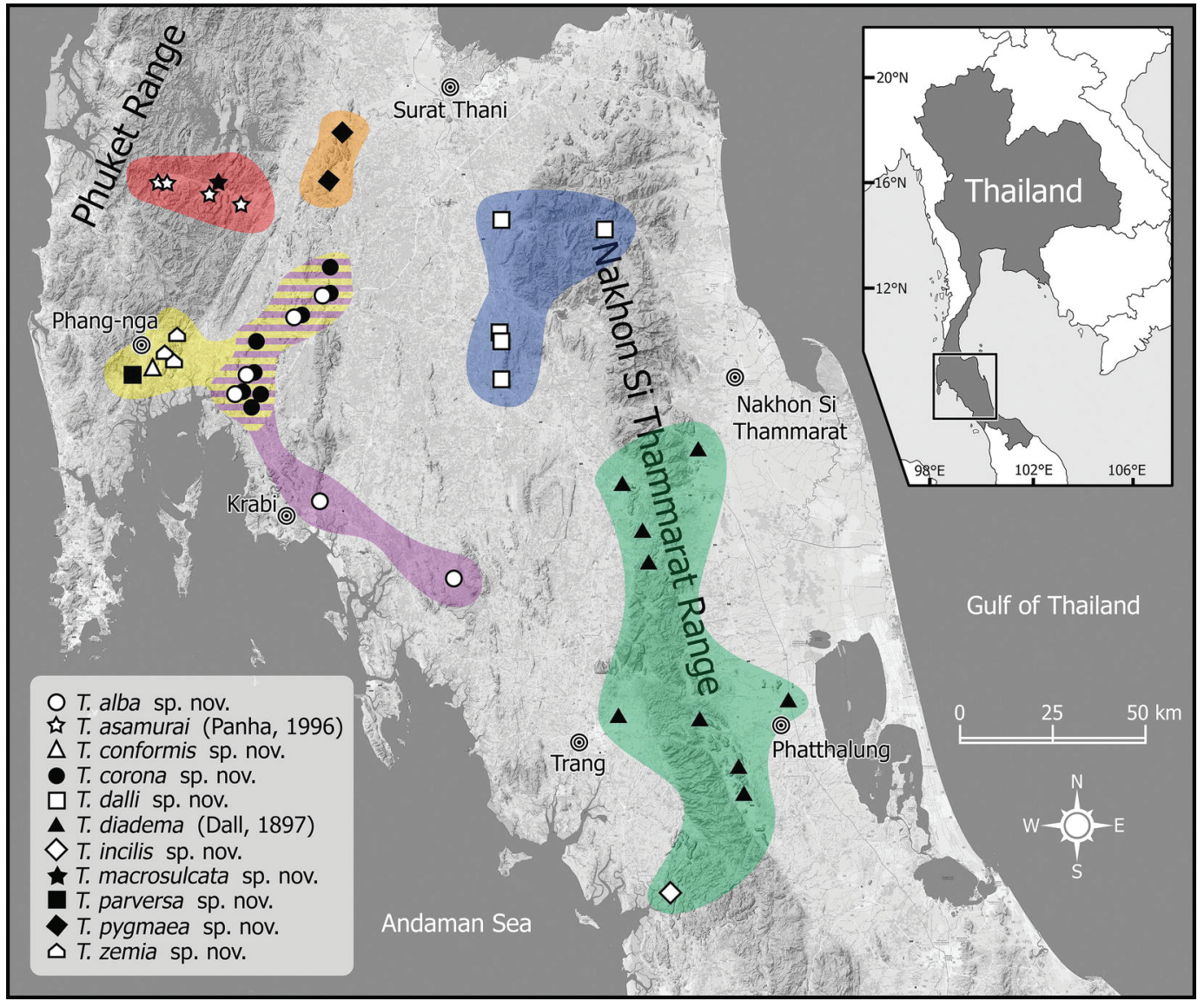

FIgURE $1 \quad$ Map showing the sampling sites of the 11 Taphrenalla species along Southern Thailand. Each colour of the distribution range follows the phylogenetic tree of all Taphrenalla species in fig. 3 .

Museum of Zoology (CUMZ) and new samples collected throughout Southern Thailand from 2015 to 2019 (fig. 1). The living snails were photographed and euthanised (American Veterinary Medical Association, 2013). Then, specimens from each locality were fixed and preserved in $70 \%(\mathrm{v} / \mathrm{v})$ ethanol for anatomical studies and duplicate specimens and/or tissues were preserved in $95 \%(\mathrm{v} / \mathrm{v})$ ethanol for molecular analysis. The genitalia of 3-10 specimens of each species were dissected and examined under an Olympus SZX2-TR3O stereoscopic light microscope. Shells and genitalia were imaged using a digital camera (DSLR D850 - Nikon) and a stereo microscope with Cell'D Imaging Software. Radulae were imaged by scanning electron microscopy (SEM; JEOL, JSM-6610 LV).

Species identification followed Dall (1897), Blanford \& Godwin-Austen (1908), Panha (1997), and Sutcharit \& Panha (2008), and was subsequently compared to the relevant type specimens. In the examined material sections, shells refer to empty shells, while specimens refer to specimens preserved in ethanol. Descriptions of a new genus and all new species herein are attributed to the first and fifth authors, Pholyotha \& Panha, respectively. The general vouchers and type specimens were deposited in the CUMZ and the Natural History Museum, London, United Kingdom (NHM). 


\section{Molecular studies}

DNA extraction, amplification, and sequencing

We extracted DNA from a total of 41 individuals of 11 Taphrenalla species. Our outgroup sampling included a total of 21 specimens representing six genera, including five ariophantid genera: Macrochlamys, Sarika, Hemiplecta Albers, 1850, Cryptozona Mörch, 1872 and
Megaustenia Cockerell, 1912, and one helicarionid genus Durgella Blanford, 1863 (table 1). We choose these genera because their distributions are in Thailand and some members of the genera Macrochlamys and Sarika had been hypothesized previously to be closely related genera (Blanford \& Godwin-Austen, 19o8; Solem, 1966; Sutcharit \& Panha, 2008) as well as to the new genus.

TABLE 1 Samples used in the molecular analyses with GenBank accession numbers

\begin{tabular}{llllll}
\hline Species & $\begin{array}{l}\text { Specimen } \\
\text { code }\end{array}$ & $\begin{array}{l}\text { Voucher } \\
\text { code }\end{array}$ & Locality name & & \multicolumn{2}{l}{ GenBank accession number } \\
\cline { 3 - 5 } & & & COI & $16 \mathrm{~S}$ & $28 \mathrm{~S}$ \\
\hline
\end{tabular}

Family Ariophantidae

Genus Taphrenalla gen. nov

\begin{tabular}{|c|c|c|c|c|c|c|}
\hline \multirow[t]{4}{*}{$\begin{array}{l}\text { T. alba } \\
\text { sp. nov. }\end{array}$} & S6 & CUMZ $_{7223}$ & $\begin{array}{l}\text { Limestone outcrops near } \\
\text { Than Bok Khorani, Ao } \\
\text { Luek, Krabi, Thailand }\end{array}$ & $\mathrm{MT}_{3} 64971$ & $\mathrm{MT}_{3} 65754$ & $\mathrm{MT}_{365698}$ \\
\hline & $\mathrm{S}_{45}$ & CUMZ $_{7219}$ & $\begin{array}{l}\text { Wat Tham Seua, Mueang, } \\
\text { Krabi, Thailand }\end{array}$ & $\mathrm{MT}_{3} 64972$ & $\mathrm{MT}_{3} 65755$ & $\mathrm{MT}_{3} 65699$ \\
\hline & $\mathrm{S}_{45-2}$ & CUMZ $_{7219}$ & $\begin{array}{l}\text { Wat Tham Seua, Mueang, } \\
\text { Krabi, Thailand }\end{array}$ & $\mathrm{MT}_{3} 64973$ & $\mathrm{MT}_{3} 6575^{6}$ & $\mathrm{MT}_{3} 65700$ \\
\hline & S127 & $\mathrm{CUMZ}_{7221}$ & $\begin{array}{l}\text { Limestone outcrops at Ao } \\
\text { Luek Tai, Ao Luek, Krabi, } \\
\text { Thailand }\end{array}$ & $\mathrm{MT}_{3} 64974$ & $\mathrm{MT}_{3} 65757$ & $\mathrm{MT}_{3} 65701$ \\
\hline
\end{tabular}

\begin{tabular}{|c|c|c|c|c|c|c|}
\hline \multirow[t]{3}{*}{ T. asamurai } & S18 & CUMZ7153 $_{715}$ & $\begin{array}{l}\text { Wat Tham Wararam, } \\
\text { Phanom, Surat Thani, } \\
\text { Thailand }\end{array}$ & $\mathrm{MT}_{3} 64934$ & $\mathrm{MT}_{3} 65723$ & $\mathrm{MT}_{3} 65667$ \\
\hline & $\mathrm{S}_{22}$ & $\mathrm{CUMZ}_{7159}$ & $\begin{array}{l}\text { Limestone outcrops at } \\
\text { Khlong Sok, Phanom, } \\
\text { Surat Thani, Thailand }\end{array}$ & $\mathrm{MT}_{3} 64935$ & $\mathrm{MT}_{3} 65724$ & $\mathrm{MT}_{3} 65668$ \\
\hline & $\mathrm{S}_{34}$ & $\mathrm{CUMZ}_{7153}$ & $\begin{array}{l}\text { Wat Tham Wararam, } \\
\text { Phanom, Surat Thani, } \\
\text { Thailand }\end{array}$ & $\mathrm{MT}_{3} 64936$ & $\mathrm{MT}_{3} 65725$ & $\mathrm{MT}_{3} 65669$ \\
\hline
\end{tabular}

\begin{tabular}{|c|c|c|c|c|c|c|}
\hline \multirow[t]{2}{*}{$\begin{array}{l}\text { T. conformis } \\
\text { sp. nov. }\end{array}$} & $S_{21}$ & $\mathrm{CUMZ}_{7203}$ & $\begin{array}{l}\text { Tham Phung Chang, } \\
\text { Mueang, Phang-nga, } \\
\text { Thailand }\end{array}$ & $\mathrm{MT}_{3} 64959$ & $\mathrm{MT}_{3} 65742$ & $\mathrm{MT}_{3} 65686$ \\
\hline & $\mathrm{S}_{120}$ & $\mathrm{CUMZ}_{7205}$ & $\begin{array}{l}\text { Tham Phung Chang, } \\
\text { Mueang, Phang-nga, } \\
\text { Thailand }\end{array}$ & $\mathrm{MT}_{3} 64960$ & $\mathrm{MT}_{3} 65743$ & $\mathrm{MT}_{3} 65687$ \\
\hline
\end{tabular}


TABLE 1 Samples used in the molecular analyses with GenBank accession numbers (cont.)

\begin{tabular}{|c|c|c|c|c|c|c|}
\hline \multirow[t]{3}{*}{ Species } & \multirow{2}{*}{$\begin{array}{l}\text { Specimen } \\
\text { code }\end{array}$} & \multirow{2}{*}{$\begin{array}{l}\text { Voucher } \\
\text { code }\end{array}$} & \multirow[t]{2}{*}{ Locality name } & \multicolumn{3}{|c|}{ GenBank accession number } \\
\hline & & & & COI & $16 S$ & $28 \mathrm{~S}$ \\
\hline & $\mathrm{S}_{126}$ & $\mathrm{CUMZ}_{7206}$ & $\begin{array}{l}\text { Tham Phung Chang, } \\
\text { Mueang, Phang-nga, } \\
\text { Thailand }\end{array}$ & $\mathrm{MT}_{3} 64961$ & $\mathrm{MT}_{3} 65744$ & $\mathrm{MT}_{3} 65688$ \\
\hline \multirow[t]{3}{*}{$\begin{array}{l}\text { T. corona } \\
\text { sp. nov. }\end{array}$} & $\mathrm{S}_{5}$ & $\mathrm{CUMZ}_{7192}$ & $\begin{array}{l}\text { Limestone outcrops near } \\
\text { Than Bok Khorani, Ao } \\
\text { Luek, Krabi, Thailand }\end{array}$ & $\mathrm{MT}_{3} 64953$ & $\mathrm{MT}_{3} 65736$ & $\mathrm{MT}_{3} 65680$ \\
\hline & $\mathrm{S}_{5-2}$ & $\mathrm{CUMZ}_{7192}$ & $\begin{array}{l}\text { Limestone outcrops near } \\
\text { Than Bok Khorani, Ao } \\
\text { Luek, Krabi, Thailand }\end{array}$ & $\mathrm{MT}_{3} 64954$ & $\mathrm{MT}_{3} 65737$ & $\mathrm{MT}_{365681}$ \\
\hline & $\mathrm{S}_{47}$ & $\mathrm{CUMZ}_{7195}$ & $\begin{array}{l}\text { Limestone outcrops at Ao } \\
\text { Luek Tai, Ao Luek, Krabi, } \\
\text { Thailand }\end{array}$ & $\mathrm{MT}_{3} 64955$ & $\mathrm{MT}_{3} 65738$ & $\mathrm{MT}_{365682}$ \\
\hline
\end{tabular}

T. dalli sp. nov. $\mathrm{S}_{52-2}$

S61

S65

$\mathrm{S}_{71}$

$\mathrm{S}_{73}$

$\mathrm{S} 63$

$\mathrm{S}_{70}$

T. diadema $\quad \mathrm{S}_{4} 6$

S62

s6
$\mathrm{CUMZ}_{7184}$

Nakhon Si Thammarat,

Thailand

CUMZ $_{7185}$ Wat Khiri Rat Phatthana, MT364949 -

Wiang Sa, Surat Thani,

Thailand

$\mathrm{CUMZ}_{7187}$ Wat Na San, Ban Na San, MT364950 -

Surat Thani, Thailand

CUMZ7189 Wat Tham Kanlayanamit, $_{\text {MT364951 }}$ MT365734 $_{3} \mathrm{MT}_{365678}$

Tham Phannara, Nakhon

Si Thammarat, Thailand

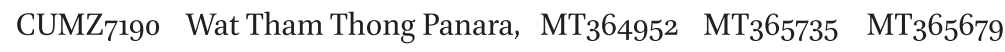

Tham Phannara, Nakhon

Si Thammarat, Thailand

$\mathrm{CUMZ}_{7175}$

Wat Tham Sumano,

$\mathrm{MT}_{3} 64940 \quad \mathrm{MT}_{3} 65729 \quad \mathrm{MT}_{3} 65673$

Srinagarindra,

Phatthalung, Thailand

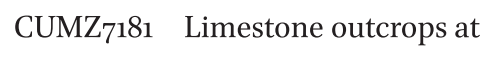

Khlong Chaloem, Kong

Ra, Phatthalung,

Thailand

CUMZ 7180 Tham Phaya Hong, Kong $\quad \mathrm{MT}_{3} 64942 \quad \mathrm{MT}_{3} 65731 \quad \mathrm{MT}_{3} 65675$

Ra, Phatthalung,

Thailand

$S_{70}$

CUMZ7167 Tham Rad, Thung Song, MT364943 -

Nakhon Si Thammarat,

Thailand 
TABLE 1 Samples used in the molecular analyses with GenBank accession numbers (cont.)

\begin{tabular}{|c|c|c|c|c|c|c|}
\hline \multirow[t]{2}{*}{ Species } & \multirow{2}{*}{$\begin{array}{l}\text { Specimen } \\
\text { code }\end{array}$} & \multirow{2}{*}{$\begin{array}{l}\text { Voucher } \\
\text { code }\end{array}$} & \multirow[t]{2}{*}{ Locality name } & \multicolumn{3}{|c|}{ GenBank accession number } \\
\hline & & & & COI & $16 S$ & $28 \mathrm{~S}$ \\
\hline & $\mathrm{S}_{72}$ & $\mathrm{CUMZ}_{7177}$ & $\begin{array}{l}\text { Khao Ok Talu Khuha } \\
\text { Sawan, Mueang, } \\
\text { Phatthalung, Thailand }\end{array}$ & $\mathrm{MT}_{3} 64944$ & $\mathrm{MT}_{3} 65732$ & $\mathrm{MT}_{3} 65676$ \\
\hline & $\mathrm{S}_{75}$ & CUMZ $_{7164}$ & $\begin{array}{l}\text { Wat Khuha Santayaram, } \\
\text { Ron Phibun, Nakhon Si } \\
\text { Thammarat }\end{array}$ & $\mathrm{MT}_{3} 64945$ & - & - \\
\hline & $\mathrm{S}_{7} 6$ & $\mathrm{CUMZ}_{7168}$ & $\begin{array}{l}\text { Wat Tham Phraphut, } \\
\text { Ratsada, Trang, Thailand }\end{array}$ & $\mathrm{MT}_{3} 64946$ & - & - \\
\hline & $S_{77}$ & $\mathrm{CUMZ}_{7165}$ & $\begin{array}{l}\text { Tham Talot, Thung Song, } \\
\text { Nakhon Si Thammarat, } \\
\text { Thailand }\end{array}$ & $\mathrm{MT}_{364947}$ & - & - \\
\hline
\end{tabular}

\begin{tabular}{|c|c|c|c|c|c|c|}
\hline \multirow[t]{3}{*}{$\begin{array}{l}\text { T. incilis } \\
\text { sp. nov. }\end{array}$} & $\mathrm{S}_{2}$ & $\mathrm{CUMZ}_{7208}$ & $\begin{array}{l}\text { Tham Khao Ting, Palian, } \\
\text { Trang, Thailand }\end{array}$ & $\mathrm{MT}_{3} 64962$ & $\mathrm{MT}_{3} 65745$ & $\mathrm{MT}_{3} 65689$ \\
\hline & S69 & CUMZ7209 $_{72}$ & $\begin{array}{l}\text { Tham Khao Ting, Palian, } \\
\text { Trang, Thailand }\end{array}$ & $\mathrm{MT}_{3} 64963$ & $\mathrm{MT}_{3} 65746$ & $\mathrm{MT}_{3} 65690$ \\
\hline & S69-2 & $\mathrm{CUMZ}_{7209}$ & $\begin{array}{l}\text { Tham Khao Ting, Palian, } \\
\text { Trang, Thailand }\end{array}$ & $\mathrm{MT}_{3} 64964$ & $\mathrm{MT}_{3} 65747$ & $\mathrm{MT}_{3} 65691$ \\
\hline \multirow[t]{3}{*}{$\begin{array}{l}\text { T. macrosulcata } \\
\text { sp. nov. }\end{array}$} & $\mathrm{S}_{3} 8$ & $\mathrm{CUMZ}_{7162}$ & $\begin{array}{l}\text { Limestone outcrops at } \\
\text { Khlong Sok, Phanom, } \\
\text { Surat Thani, Thailand }\end{array}$ & $\mathrm{MT}_{3} 64937$ & $\mathrm{MT}_{3} 65726$ & $\mathrm{MT}_{3} 65670$ \\
\hline & $\mathrm{S}_{3} 8-2$ & $\mathrm{CUMZ}_{7162}$ & $\begin{array}{l}\text { Limestone outcrops at } \\
\text { Khlong Sok, Phanom, } \\
\text { Surat Thani, Thailand }\end{array}$ & $\mathrm{MT}_{3} 64938$ & $\mathrm{MT}_{3} 65727$ & $\mathrm{MT}_{3} 65^{671}$ \\
\hline & $\mathrm{S}_{3} 8-3$ & $\mathrm{CUMZ}_{7162}$ & $\begin{array}{l}\text { Limestone outcrops at } \\
\text { Khlong Sok, Phanom, } \\
\text { Surat Thani, Thailand }\end{array}$ & $\mathrm{MT}_{3} 64939$ & $\mathrm{MT}_{3} 65728$ & $\mathrm{MT}_{3} 65672$ \\
\hline \multirow[t]{3}{*}{$\begin{array}{l}\text { T. parversa } \\
\text { sp. nov. }\end{array}$} & $\mathrm{S}_{40}$ & $\mathrm{CUMZ}_{7200}$ & $\begin{array}{l}\text { Tham Suwan Khuha, } \\
\text { Takua Thung, Phang-nga, } \\
\text { Thailand }\end{array}$ & $\mathrm{MT}_{3} 64956$ & $\mathrm{MT}_{3} 65739$ & $\mathrm{MT}_{3} 65^{68} 3$ \\
\hline & $\mathrm{S}_{40-2}$ & $\mathrm{CUMZ}_{7200}$ & $\begin{array}{l}\text { Tham Suwan Khuha, } \\
\text { Takua Thung, Phang-nga, } \\
\text { Thailand }\end{array}$ & $\mathrm{MT}_{3} 64957$ & $\mathrm{MT}_{3} 65740$ & $\mathrm{MT}_{3} 65684$ \\
\hline & $\mathrm{S}_{40-3}$ & $\mathrm{CUMZ}_{7200}$ & $\begin{array}{l}\text { Tham Suwan Khuha, } \\
\text { Takua Thung, Phang-nga, } \\
\text { Thailand }\end{array}$ & $\mathrm{MT}_{3} 64958$ & $\mathrm{MT}_{3} 65741$ & $\mathrm{MT}_{3} 65685$ \\
\hline $\begin{array}{l}\text { T. pygmaea } \\
\text { sp. nov. }\end{array}$ & S67 & $\mathrm{CUMZ}_{7212}$ & $\begin{array}{l}\text { Wat Sathit Khirirom, } \\
\text { Khiri Rat Nikhom, Surat } \\
\text { Thani, Thailand }\end{array}$ & $\mathrm{MT}_{3} 64965$ & $\mathrm{MT}_{3} 65748$ & $\mathrm{MT}_{3} 65^{6} 9^{2}$ \\
\hline
\end{tabular}


TABLE 1 Samples used in the molecular analyses with GenBank accession numbers (cont.)

\begin{tabular}{|c|c|c|c|c|c|c|}
\hline \multirow[t]{2}{*}{ Species } & \multirow{2}{*}{$\begin{array}{l}\text { Specimen } \\
\text { code }\end{array}$} & \multirow{2}{*}{$\begin{array}{l}\text { Voucher } \\
\text { code }\end{array}$} & \multirow[t]{2}{*}{ Locality name } & \multicolumn{3}{|c|}{ GenBank accession number } \\
\hline & & & & COI & $16 S$ & $28 \mathrm{~S}$ \\
\hline & S119 & CUMZ $_{7211}$ & $\begin{array}{l}\text { Tham Wang Badan } \\
\text { Priest's Camp Site, Khiri } \\
\text { Rat Nikhom, Surat Thani, } \\
\text { Thailand }\end{array}$ & $\mathrm{MT}_{3} 64966$ & $\mathrm{MT}_{3} 65749$ & $\mathrm{MT}_{3} 65693$ \\
\hline & S119-2 & $\mathrm{CUMZ}_{7211}$ & $\begin{array}{l}\text { Tham Wang Badan } \\
\text { Priest's Camp Site, Khiri } \\
\text { Rat Nikhom, Surat Thani, } \\
\text { Thailand }\end{array}$ & $\mathrm{MT}_{3} 64967$ & $\mathrm{MT}_{3} 65750$ & $\mathrm{MT}_{3} 65694$ \\
\hline \multirow[t]{3}{*}{$\begin{array}{l}\text { T. zemia } \\
\text { sp. nov. }\end{array}$} & S64 & $\mathrm{CUMZ}_{7214}$ & $\begin{array}{l}\text { Wat Khiriwong, Thap } \\
\text { Put, Phang-nga, Thailand }\end{array}$ & $\mathrm{MT}_{3} 64968$ & $\mathrm{MT}_{3} 6575^{1}$ & $\mathrm{MT}_{3} 65695$ \\
\hline & S66 & $\mathrm{CUMZ}_{7216}$ & $\begin{array}{l}\text { Wat Tham Bang Toei, } \\
\text { Mueang, Phang-nga, } \\
\text { Thailand }\end{array}$ & $\mathrm{MT}_{3} 64969$ & $\mathrm{MT}_{3} 6575^{2}$ & $\mathrm{MT}_{3} 65696$ \\
\hline & S68 & $\mathrm{CUMZ}_{7215}$ & $\begin{array}{l}\text { Tham Pha Sua Bureau of } \\
\text { Monks, Mueang, } \\
\text { Phang-nga, Thailand }\end{array}$ & $\mathrm{MT}_{3} 64970$ & $\mathrm{MT}_{3} 65753$ & $\mathrm{MT}_{3} 65697$ \\
\hline
\end{tabular}

Genus Macrochlamys

\begin{tabular}{|c|c|c|c|c|c|c|}
\hline M. aspides & MY8 & $\mathrm{CUMZ}_{7135}$ & $\begin{array}{l}\text { Lun-Nya Mountain, } \\
\text { Hpa-an, Kayin, Myanmar }\end{array}$ & $\mathrm{MT}_{3} 64986$ & $\mathrm{MT}_{3} 65761$ & $\mathrm{MT}_{3} 65705$ \\
\hline \multirow[t]{3}{*}{ M. caverna } & $\mathrm{C}_{1}$ & CUMZ7109 & $\begin{array}{l}\text { Wat Khao Samo Khon, } \\
\text { Tha Wung, Lopburi, } \\
\text { Thailand }\end{array}$ & $\mathrm{MT}_{3} 64989$ & $\mathrm{MT}_{3} 6575^{8}$ & $\mathrm{MT}_{3} 65702$ \\
\hline & $\mathrm{C}_{15}$ & CUMZ $_{7113}$ & $\begin{array}{l}\text { Khao Mon Ing Dharma } \\
\text { Practice Place, Ban Mi, } \\
\text { Lopburi, Thailand }\end{array}$ & $\mathrm{MT}_{3} 64988$ & $\mathrm{MT}_{3} 65759$ & $\mathrm{MT}_{3} 65703$ \\
\hline & $\mathrm{C} 16$ & $\mathrm{CUMZ}_{7111}$ & $\begin{array}{l}\text { Wat Tham Chang Pueak, } \\
\text { Tha Wung, Lopburi, } \\
\text { Thailand }\end{array}$ & $\mathrm{MT}_{3} 64987$ & $\mathrm{MT}_{3} 65760$ & $\mathrm{MT}_{3} 65704$ \\
\hline M. tanymentulo & $\mathrm{W}_{16}$ & $\mathrm{CUMZ}_{7119}$ & $\begin{array}{l}\text { Limestone outcrops at } \\
\text { Khao Lok, Thong Pha } \\
\text { Phum, Kanchanaburi, } \\
\text { Thailand }\end{array}$ & $\mathrm{MT}_{3} 64985$ & $\mathrm{MT}_{3} 65762$ & $\mathrm{MT}_{3} 65706$ \\
\hline
\end{tabular}

\section{Genus Sarika}

\begin{tabular}{|c|c|c|c|c|c|}
\hline S. heptagyra & W19 & $\mathrm{CUMZ}_{7231}$ & $\begin{array}{l}\text { Tham Khao Noi Bureau } \\
\text { of Monks, Thong Pha } \\
\text { Phum, Kanchanaburi, } \\
\text { Thailand }\end{array}$ & $\mathrm{MT}_{3} 64980$ & $\mathrm{MT}_{3} 65765$ \\
\hline
\end{tabular}


TABLE 1 Samples used in the molecular analyses with GenBank accession numbers (cont.)

\begin{tabular}{|c|c|c|c|c|c|c|}
\hline \multirow[t]{3}{*}{ Species } & \multirow{2}{*}{$\begin{array}{l}\text { Specimen } \\
\text { code }\end{array}$} & \multirow{2}{*}{$\begin{array}{l}\text { Voucher } \\
\text { code }\end{array}$} & \multirow[t]{2}{*}{ Locality name } & \multicolumn{3}{|c|}{ GenBank accession number } \\
\hline & & & & $\mathrm{COI}$ & $16 S$ & $28 \mathrm{~S}$ \\
\hline & $\mathrm{W}_{25}$ & $\mathrm{CUMZ}_{7232}$ & $\begin{array}{l}\text { Tham Dao Wadung, Sai } \\
\text { Yok, Kanchanaburi, } \\
\text { Thailand }\end{array}$ & $\mathrm{MT}_{3} 64981$ & $\mathrm{MT}_{3} 65766$ & $\mathrm{MT}_{3} 65710$ \\
\hline \multirow[t]{3}{*}{ S. obesior } & MY2 & CUMZ $_{7141}$ & $\begin{array}{l}\text { Forest on Kala Island, } \\
\text { Myeik, Tanintharyi, } \\
\text { Myanmar }\end{array}$ & $\mathrm{MT}_{3} 64979$ & $\mathrm{MT}_{3} 65769$ & $\mathrm{MT}_{3} 65713$ \\
\hline & MY2-2 & $\mathrm{CUMZ}_{7141}$ & $\begin{array}{l}\text { Forest on Kala Island, } \\
\text { Myeik, Tanintharyi, } \\
\text { Myanmar }\end{array}$ & $\mathrm{MT}_{3} 64978$ & $\mathrm{MT}_{3} 65770$ & $\mathrm{MT}_{3} 65714$ \\
\hline & W65 & $\mathrm{CUMZ}_{7233}$ & $\begin{array}{l}\text { Wat Nong Phlap, Hua } \\
\text { Hin, Prachuap Khiri } \\
\text { Khan, Thailand }\end{array}$ & $\mathrm{MT}_{3} 64977$ & $\mathrm{MT}_{3} 65768$ & $\mathrm{MT}_{3} 65712$ \\
\hline \multirow[t]{2}{*}{ S. resplendens } & $\mathrm{W}_{4}$ & $\mathrm{CUMZ}_{7234}$ & $\begin{array}{l}\text { Khao Cha Ngum, } \\
\text { Photharam, Ratchaburi, } \\
\text { Thailand }\end{array}$ & $\mathrm{MT}_{3} 64982$ & $\mathrm{MT}_{3} 65763$ & $\mathrm{MT}_{3} 65707$ \\
\hline & $\mathrm{W}_{23}$ & $\mathrm{CUMZ}_{7235}$ & $\begin{array}{l}\text { Limestone outcrops near } \\
\text { Song Karia, Sangkhla } \\
\text { Buri, Kanchanaburi, } \\
\text { Thailand }\end{array}$ & $\mathrm{MT}_{3} 64983$ & $\mathrm{MT}_{3} 65764$ & $\mathrm{MT}_{3} 65708$ \\
\hline Sarika sp. 1 & Sul6 & $\mathrm{CUMZ}_{7236}$ & $\begin{array}{l}\text { Wat Sathit Khirirom, } \\
\text { Khiri Rat Nikhom, Surat } \\
\text { Thani, Thailand }\end{array}$ & $\mathrm{MT}_{3} 64975$ & $\mathrm{MT}_{3} 65771$ & $\mathrm{MT}_{3} 65715$ \\
\hline Sarika sp. 2 & E2-2 & $\mathrm{CUMZ}_{7237}$ & $\begin{array}{l}\text { Pang Sida Waterfall, } \\
\text { Watthana Nakhon, Sa } \\
\text { Kaeo, Thailand }\end{array}$ & $\mathrm{MT}_{3} 64984$ & $\mathrm{MT}_{3} 65772$ & $\mathrm{MT}_{3} 65716$ \\
\hline Sarika sp. 3 & $\mathrm{~W}_{5} 8$ & $\mathrm{CUMZ}_{723} 8$ & $\begin{array}{l}\text { Tham Khao Ma-Rong, } \\
\text { Bang Saphan, Prachuap } \\
\text { Khiri Khan, Thailand }\end{array}$ & $\mathrm{MT}_{3} 64976$ & $\mathrm{MT}_{3} 65767$ & $\mathrm{MT}_{3} 65711$ \\
\hline \multicolumn{7}{|c|}{ Genus Cryptozona } \\
\hline C. siamensis & $\mathrm{NE}_{7}$ & $\mathrm{CUMZ}_{7239}$ & $\begin{array}{l}\text { Garden in Khon Kaen } \\
\text { University, Mueang, } \\
\text { Khon Kaen, Thailand }\end{array}$ & $\mathrm{MT}_{3} 64993$ & $\mathrm{MT}_{3} 65773$ & $\mathrm{MT}_{3} 65717$ \\
\hline & S129 & $\mathrm{CUMZ}_{7240}$ & $\begin{array}{l}\text { Wat Tha Mai Lai, } \\
\text { Mueang, Chumphon, } \\
\text { Thailand }\end{array}$ & $\mathrm{MT}_{3} 64992$ & $\mathrm{MT}_{3} 65774$ & $\mathrm{MT}_{3} 65718$ \\
\hline
\end{tabular}


Samples used in the molecular analyses with GenBank accession numbers (cont.)

\begin{tabular}{|c|c|c|c|c|c|c|}
\hline \multirow[t]{2}{*}{ Species } & \multirow{2}{*}{$\begin{array}{l}\text { Specimen } \\
\text { code }\end{array}$} & \multirow{2}{*}{$\begin{array}{l}\text { Voucher } \\
\text { code }\end{array}$} & \multirow[t]{2}{*}{ Locality name } & \multicolumn{3}{|c|}{ GenBank accession number } \\
\hline & & & & COI & $16 S$ & $28 \mathrm{~S}$ \\
\hline \multicolumn{7}{|c|}{ Genus Hemiplecta } \\
\hline $\begin{array}{l}\text { H. } \\
\text { humphreysiar }\end{array}$ & $\mathrm{H}_{7}$ & CUMZ & Singapore & $\mathrm{MT}_{3} 64994$ & $\mathrm{MT}_{3} 65775$ & $\mathrm{MT}_{3} 65719$ \\
\hline H. pluto & $\mathrm{H} 63$ & CUMZ & Laos & $\mathrm{MT}_{3} 64995$ & $\mathrm{MT}_{3} 65776$ & $\mathrm{MT}_{3} 65720$ \\
\hline \multicolumn{7}{|c|}{ Genus Megaustenia } \\
\hline $\begin{array}{l}\text { Megaustenia } \\
\text { sp. }\end{array}$ & C19 & $\mathrm{CUMZ}_{7241}$ & $\begin{array}{l}\text { Pa Ma-muang Bureau of } \\
\text { Monks, Noen Maprang, } \\
\text { Phitsanulok, Thailand }\end{array}$ & $\mathrm{MT}_{3} 64990$ & $\mathrm{MT}_{3} 65778$ & $\mathrm{MT}_{3} 65722$ \\
\hline
\end{tabular}

Family Helicarionidae

Genus Durgella

\begin{tabular}{|c|c|c|c|c|c|c|}
\hline Durgella sp. & $\mathrm{N} 15$ & $\mathrm{CUMZ}_{7242}$ & $\begin{array}{l}\text { Tham Lom Tham Wang, } \\
\text { Si Samrong, Sukhothai, } \\
\text { Thailand }\end{array}$ & $\mathrm{MT}_{3} 64991$ & $\mathrm{MT}_{3} 65777$ & $\mathrm{MT}_{3} 65721$ \\
\hline
\end{tabular}

Whole genomic DNA was extracted from a small piece of the foot muscle tissue using the NucleoSpin Tissue Kit (Macherey-Nagel, Germany), following the manufacturer's standard instructions. The two partial mitochondrial genes (COI and 16S rRNA) were amplified using the LCO1491 and $\mathrm{HCO}_{2198}$ universal primers for COI (Folmer et al., 1994) and the 16Sar and $16 \mathrm{Sbr}$ universal primers for $16 \mathrm{~S}$ (Palumbi et al., 1991), while the $28 \mathrm{~S}$ rDNA was amplified using the $\mathrm{LSU}_{2}$ and $\mathrm{LSU}_{4}$ primers (Wade \& Mordan, 2000). The PCR thermal cycling was performed under the following conditions: (i) COI: initial $94^{\circ} \mathrm{C}$ for 2 min followed by 36 cycles of $94^{\circ} \mathrm{C}$ for $30 \mathrm{~s}$, $5^{\circ}$ or $5^{\circ} \mathrm{C}$ for $120 \mathrm{~s}$, and $72^{\circ} \mathrm{C}$ for $120 \mathrm{~s}$, and then followed by a final $72^{\circ} \mathrm{C}$ for $5 \mathrm{~min}$; (ii) $16 \mathrm{~S}$ rRNA: $94^{\circ} \mathrm{C}$ for $2 \mathrm{~min}$, followed by 40 cycles of $94^{\circ} \mathrm{C}$ for 3 o s, $50^{\circ} \mathrm{C}$ for 6 o s, and $72^{\circ} \mathrm{C}$ for 120 $\mathrm{s}$, and then followed by a final $72^{\circ} \mathrm{C}$ for $5 \mathrm{~min}$; (iii) $28 \mathrm{~S}$ rDNA: $94^{\circ} \mathrm{C}$ for $1 \mathrm{~min}$, followed by 36 cycles of $94^{\circ} \mathrm{C}$ for $30 \mathrm{~s}, 62^{\circ} \mathrm{C}$ for 9 o s, and $72^{\circ} \mathrm{C}$ for $120 \mathrm{~s}$, and then followed by a final $72^{\circ} \mathrm{C}$ for $5 \mathrm{~min}$. The size of the PCR products was checked under UV transillumination after gel electrophoresis. The PCR products were sent for commercial sequencing at Bioneer Co., Korea.

Sequence alignment and phylogenetic analyses

Chromatograms were manually corrected for misreads using MEGA v. 7.0 (Kumar et al., 2016). To achieve a single consensus sequence, individual forward and reverse sequence traces were aligned and edited using MUSCLE, as implemented in MEGA v. 7.0. The newly generated sequences have been deposited in the GenBank databases with accession numbers: MT364934-MT364995 and MT365667MT365778 (table 1).

The sequence alignments of the COI, $16 \mathrm{~S}$ rRNA, and 28S rDNA gene fragments were performed separately using MAFFT v. 7 in 
the MAFFT online service (https://mafft.cbrc. jp/alignment/server/index.html) with the default options (Katoh et al., 2017). The regions of ambiguous alignment were checked and cleaned with Gblocks v. o.91b using relaxed parameters and allowing all gap positions (Castresana, 200o; Talavera \& Castresana, 2007). To check for substitution saturation, we performed the test implemented in DAMBE (Xia, 2013). The phylogenetic trees were then constructed using maximum likelihood (ML) and Bayesian inference (BI). Prior to the ML and BI analyses, the best-fit models of nucleotide substitution were identified for each gene separately with five partitions (16S rRNA, $28 \mathrm{~S}$ rDNA and the three codon positions of COI) using Kakusan4 (Tanabe, 2007, 2011). The ML phylogenetic analysis was performed by applying the GTRGAMMA model to all three genes at the default settings of RAxMLHPC2 on XSEDE v. 8.2.10 (Stamatakis, 2014) in the CIPRES Science Gateway (Miller, Pfeiffer \& Schwartz, 2010). Nodal support values of ML were assessed with 1000 bootstrap (BS) replicates.

The BI analysis was performed using MrBayes on XSEDE v. 3.2.6 (Ronquist et al., 2012) in the CIPRES Science Gateway. The analysis was performed using two simultaneous runs consisted of running four simultaneous chains for 10 million generations. Every 500 generations were sampled and the first $50 \%$ of sampled trees were discarded as burn-in. The other settings of the analysis followed the developer's recommendation (Ronquist et al., 2012). For ML, BS support values of $\geq 70 \%$ were considered highly supported and BI posterior probabilities (PP) of $\geq 0.95$ were considered statistically significant (Hillis \& Bull, 1993; Felsenstein, 2004; Huelsenbeck \& Rannala, 2004; Mauro \& Agorreta, 2010; Hirano et al., 2018). Pairwise genetic distances based on the $\mathrm{COI}$ and $16 \mathrm{~S}$ sequences were calculated using Kimura's two-parameter model ( $\left.\mathrm{K}_{2} \mathrm{P}\right)$ in MEGA v. 7 .

\section{Molecular species delimitation}

We conducted species delimitation analyses using two methods: (i) the Automatic Barcode Gap Discovery (ABGD) method (Puillandre et al., 2012) as a distance-based method and (ii) the Poisson Tree Processes (PTP) method (Zhang et al., 2013; Kapli et al., 2017) as a phylogeny-based method. We applied two approaches only to the COI dataset because COI-based DNA barcoding can delimit diverse animal species (Hebert et al., 2003). To apply ABGD, the sequence alignment of the COI gene was uploaded at https://bioinfo.mnhn.fr/abi/public/abgd/abgdweb.html (last modification date: 7 December 2018) and then the $\mathrm{K}_{2} \mathrm{P}$ model was chosen as the distance type with the following settings: Pmin $=0.001$, Pmax $=0.1$, Steps $=$ 40, $\mathrm{X}$ (relative gap width) $=1$, and $\mathrm{Nb}$ bins (for distance distribution $)=20$. The analysis with Jukes-Cantor distance (JC69) was employed with the same settings, except for the relative gap width $(\mathrm{X}=0.8)$. The PTP species delimitation analyses using the single-rate PTP (sPTP) were processed thorough the online PTP web server (http://mptp.h-its.org). A phylogenetic input tree was obtained from the ML analysis, which was conducted based on an alignment of the 41 COI sequences from all Taphrenalla species with an additional two sequences of Sarika resplendens as the out-group using RAxMLHPC2 on XSEDE v. 8.2.10. The molecular operational taxonomic units (MOTUs) delimited by the two species delimitation analyses were regarded as preliminary hypothesis, then the distinction based on morphological and anatomical characters were observed to treat them as either distinct species or conspecific lineages.

\section{Abbreviations}

In the descriptions of the reproductive organs, 'proximal' refers to the region closest to the genital pore and 'distal' refers to the region furthest away. The genital terminology and 
abbreviations follow Blanford \& GodwinAusten (1908) and Pholyotha et al. (2018, 2020): ant-ldl, anterior left dorsal lobe; an, anus; at, atrium; da, dart apparatus; ch, caudal horn; e, epiphallus; ec, epiphallic caecum; $\mathrm{fl}$, flagellum; fo, free oviduct; gd, gametolytic duct; gs, gametolytic sac; h, heart; hf, head filament; hg, hindgut; kd, kidney; lsl, left shell lobe; mc, mantle collar; ov, oviduct; p, penis; pc, penial caecum; pg, prostate gland; post-ldl, posterior left dorsal lobe; pp, penial pilaster; ppv, principal pulmonary vein; prm, penial retractor muscle; pv, penial verge; rdl, right dorsal lobe; rsl, right shell lobe; ss, sperm sac; tf, tail filament; ur, ureter; v, vagina, and vd, vas deferens.

\section{Collections}

CUMZ, Chulalongkorn University Museum of Zoology, Bangkok; NHM, The Natural History Museum, London; SMF, Forschungsinstitut und Naturmuseum Senckenberg, Frankfurt am Main; USNM, National Museum of Natural History, Smithsonian Institution, Washington, DC.

\section{Results}

\section{Molecular phylogeny}

From a total of 56 individuals used (including outgroups), we obtained COI, 16S, and 28S sequences for 35 specimens from all Taphrenalla species. The final concatenated dataset of the aligned sequences of the three gene fragments had a total length of $1672 \mathrm{bp}$ (COI: 655 bp, 16S: 478 bp, and 28S: 539 bp), after $41 \mathrm{bp}$ were excluded as ambiguously aligned by Gblocks (COI: 1 bp, 16S: 40 bp). Using DAMBE, no substitution saturation was detected in all datasets (Iss < Iss.c with $\mathrm{p}<0.01)$. The best-fit models of evolution for each gene fragment $\left(1^{\text {st }} \mathrm{COI} ; 2^{\text {nd }} \mathrm{COI} ; 3^{\text {rd }} \mathrm{COI}\right.$; 16S; 28S) based on the Bayesian Information
Criterion (BIC) test were the Kimura 1980 model with gamma distribution $(\mathrm{K} 8 \mathrm{O}+\mathrm{G})$ for the $1^{\text {st }}$ COI codon, the Felsenstein (1981) model with gamma distribution $(\mathrm{F} 81+\mathrm{G})$ for the $2^{\text {nd }}$ COI codon, and the general time reversible model with time-reversible gamma distribution $(\mathrm{GTR}+\mathrm{G})$ for the $3^{\text {rd }} \mathrm{COI}$ codon, the $16 \mathrm{~S}$ gene, and the $28 \mathrm{~S}$ gene.

\section{Phylogenetic relationships}

The phylogenetic trees (fig. 2) based on the concatenated datasets using ML and BI methods recovered 11 species of Taphrenalla forming a well-supported clade $(\mathrm{BS}=89 \%, \mathrm{PP}=$ 1). Focusing on the sister-group relationships among genera, M. tanymentula Pholyotha \& Panha, 2018 was retrieved as the closest sister group to Taphrenalla, but with poor support $(\mathrm{BS}=67 \%, \mathrm{PP}=0.88)$. The two other Macrochlamys species in this analysis, which are endemic in Thailand and Myanmar, formed a sister clade to the Taphrenalla $+M$. tanymentula clade with strong support (BS = 96\%, PP = o.99). The genera Sarika and the Cryptozona were retrieved as monophyletic with very strong support $(\mathrm{BS}=100 \%, \mathrm{PP}=1)$. The Cryptozona + Sarika clade was also a sister group to the Taphrenalla + Macrochlamys clade with high support ( $\mathrm{BS}=97 \%, \mathrm{PP}=1)$. In addition, compared with the other outgroups, the large land snail genus Hemiplecta and the semi-slug genus Megaustenia positioned as basal clades with strong support (BS $=94 \%$, $\mathrm{PP}=1$ ).

With respect to the monophyly of all Taphrenalla species, the phylogenetic trees (figs 2, 3) were clearly divided into two well-separated clades (clade A and B). Clade A contained $T$. diadema and eight new species with good support ( $\mathrm{BS}=85 \%, \mathrm{PP}=0.99$ ), while clade B contained T. macrosulcata and T. asamurai with very strong support (BS = 100\%, PP = 1). Although the species relationships among clade A were not well resolved, 


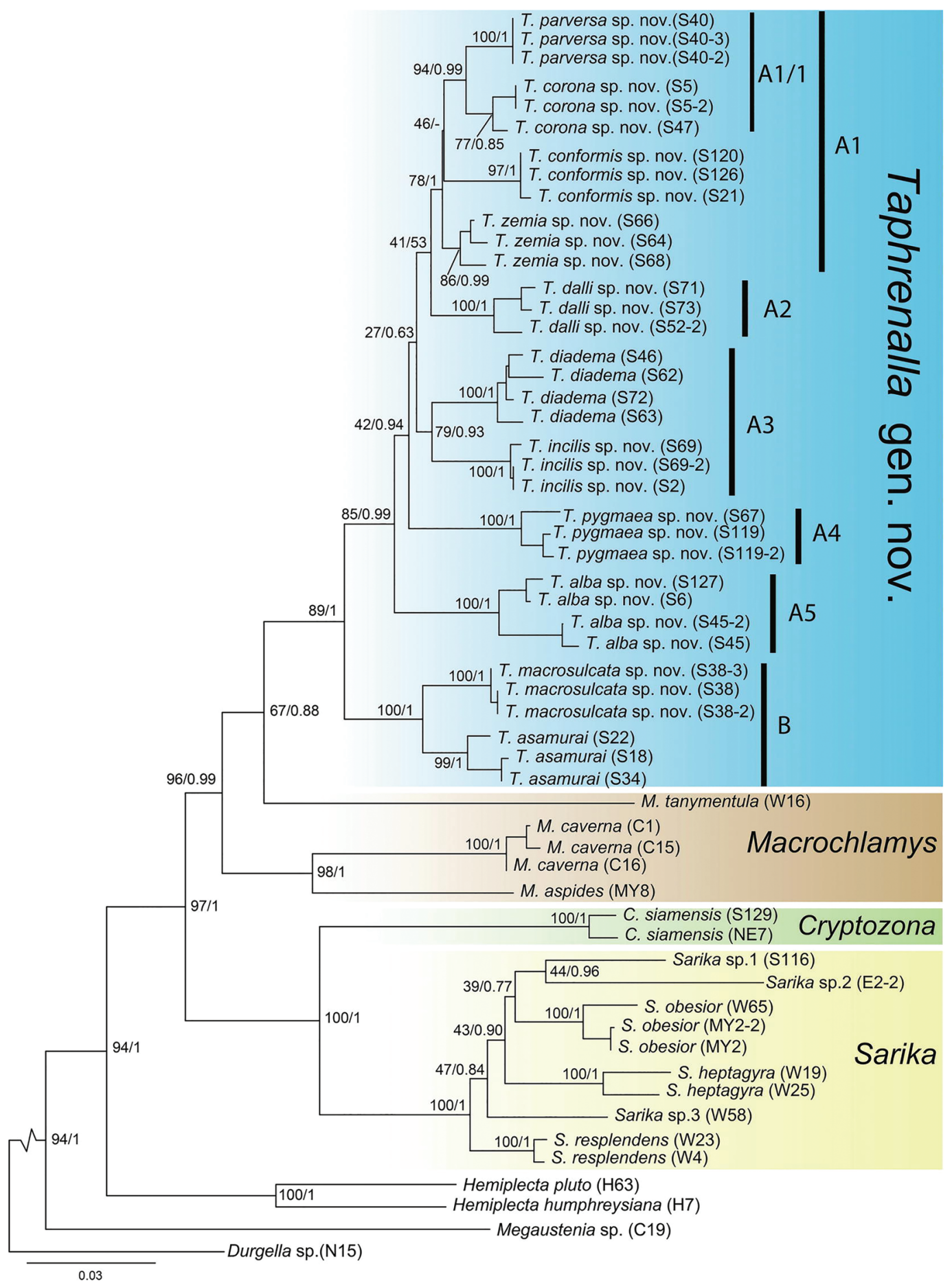

FIGURE 2 Representative ML tree of the Taphrenalla gen. nov., Macrochlamys, Sarika, Cryptozona, Hemiplecta, Megaustenia, and Durgella based on the combined partial sequences of the COI, 16S, and 28S genes. The code in the parenthesis next to the species name refers to voucher numbers of the analysed samples. Numbers on the branches indicate the ML BS and BI PP values. 


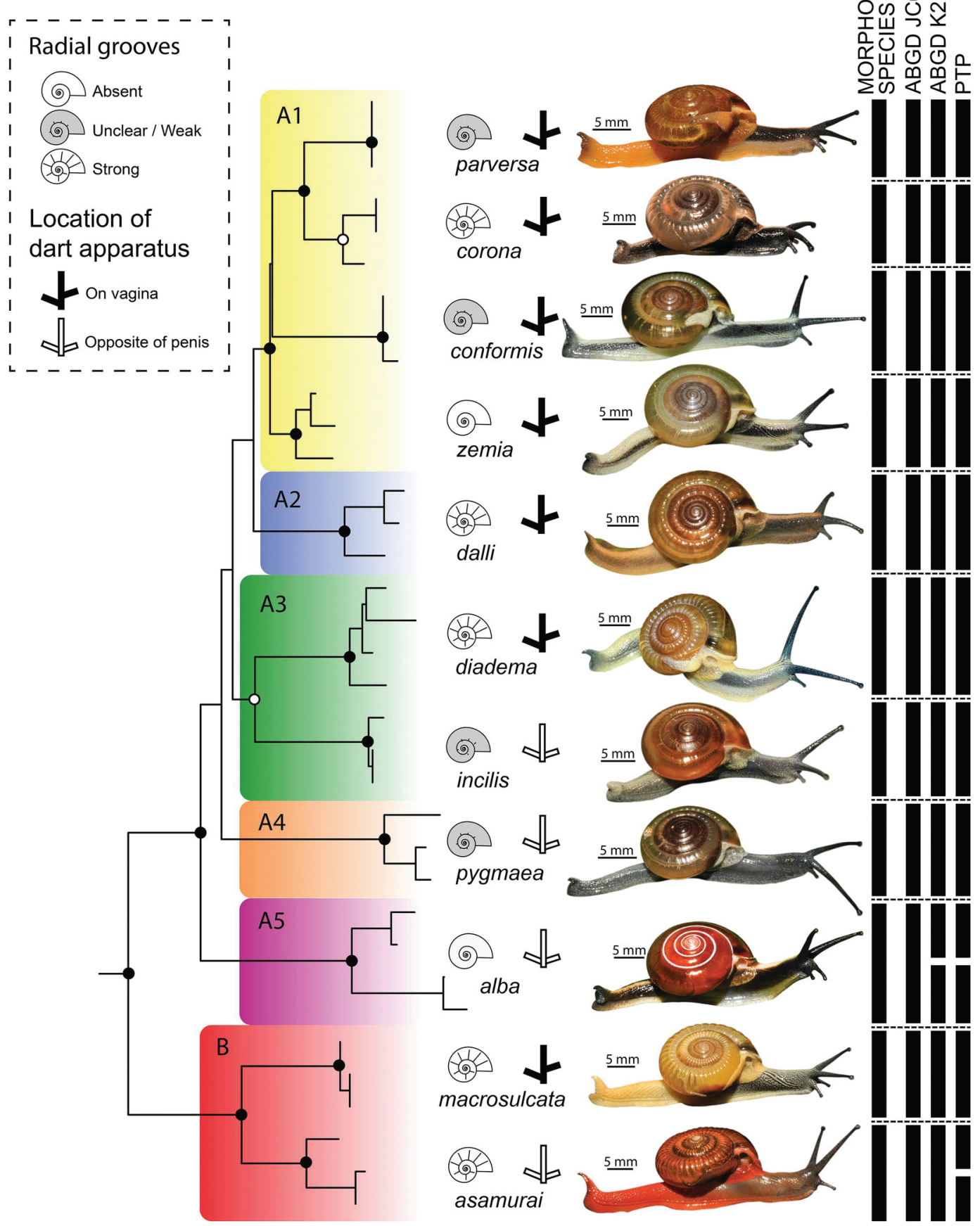

FIgURE 3 A representative ML tree showing only the Taphrenalla clade. The synopsis of the radial groove on shell sculpture, genitalia showing location of dart apparatus, and live specimens of Taphrenalla spp. Results of species delimitation analyses based on the COI gene using ABGD and PTP. Black circles represent nodes with both ML (when $\geq 70 \%$ ) and BI (when $\geq 0.95$ ) support. White circles represent nodes with ML BS support but no BI PP support (when < 0.95). Each clade colour refers to the distribution range in fig. 1. 
this clade was further divided into five subclades (A1 to A5). Four new species (T. parversa, T. corona, T. zemia, and T. conformis) formed clade A1 with good support $(\mathrm{BS}=78 \%$, $\mathrm{PP}=1$ ). Moreover, within clade A1, T. parversa was very closely related to $T$. corona with high support (clade A1/1; BS = 94\%, PP = o.99). Interestingly, clade A1 showed various degrees of the radial grooves on shell sculpture, ranging from distinct to absent. The strongly supported clade A2 (BS = 100\%, PP = 1) consisted of one species, T. dalli. Within clade $\mathrm{A}_{3}$, the type species $T$. diadema was the sister lineage of T. incilis with moderate support (BS = $79 \%, \mathrm{PP}=0.93)$. Clades $\mathrm{A}_{4}$ and $\mathrm{A}_{5}$ consisted of T. pygmaea and T. alba, respectively, both of which were highly supported $(\mathrm{BS}=100 \%, \mathrm{PP}=$ 1). Taxa with a similar shell morphology were not always retrieved as monophyletic, e.g. T. dalli (clade A2) and T. diadema (clade A3).

\section{Pairwise genetic distances}

The aligned COI sequence data matrix of 62 specimens, including 41 specimens of Taphrenalla species, and the $16 \mathrm{~S}$ data matrix of 56 specimens, including 35 specimens of Taphrenalla species, were used to calculate the mean sequence divergences. The mean genetic divergence observed among the genera of the family Ariophantidae ranged between 10.0$16.7 \%$ in COI and $12.2-19.5 \%$ in $16 \mathrm{~S}$ (table 2 ), while the interspecific divergences among the 11 species of Taphrenalla ranged from $3.4-7.7 \%$ for COI and from 1.0-9.2\% for $16 \mathrm{~S}$ (table 3 ). The Taphrenalla intraspecific divergences ranged from $0-2.4 \%$ for COI and from $0-1.5 \%$ for 16S (table 4). The highest intraspecific mean sequence divergence of COI and $16 \mathrm{~S}$ within Taphrenalla was observed in T. alba. No variation in the COI was observed in T. parversa. and no variation in the $16 \mathrm{~S}$ was observed in T. parversa, T. incilis, and T. conformis.

\section{Species delimitation}

A total of $41 \mathrm{COI}$ sequences, representing all Taphrenalla species were assembled for the molecular species delimitation to identify species boundaries. The results of the ABGD species delimitation approach using the JC69 model and the $\mathrm{K}_{2} \mathrm{P}$ model recovered 11 and 12 MOTUs, respectively (fig. 3). The other method, the single-rate PTP analysis recovered 13 MOTUs (fig. 3). Therefore, the two species delimitation analyses (ABGD and PTP) suggested there were between 11 and 13 MOTUs in Taphrenalla gen. nov. By comparing them with morphology-based delimitation, we concluded that there were 11 confirmed candidate species being treated as distinct species, and the two remaining MOTUs were treated as the conspecific lineages of T. asamurai and T. alba sp. nov., respectively.

TABLE 2 Mean genetic divergences between Taphrenalla gen. nov. and other genera estimated by the K2P model from the mitochondrial COI (lower-left) and ${ }_{16 S}$ (upper-right) gene sequences

\begin{tabular}{llllllll}
\hline Genera & 1 & 2 & 3 & 4 & 5 & 6 & 7 \\
\hline 1 Taphrenalla gen. nov. & & 0.123 & 0.142 & 0.136 & 0.131 & 0.195 & 0.214 \\
2 Macrochlamys & 0.100 & & 0.136 & 0.139 & 0.134 & 0.173 & 0.222 \\
3 Sarika & 0.122 & 0.116 & & 0.122 & 0.150 & 0.158 & 0.190 \\
4 Cryptozona & 0.134 & 0.127 & 0.114 & & 0.155 & 0.147 & 0.205 \\
5 Hemiplecta & 0.120 & 0.123 & 0.136 & 0.150 & & 0.149 & 0.172 \\
6 Megaustenia & 0.141 & 0.134 & 0.144 & 0.167 & 0.144 & & 0.196 \\
7 Durgella & 0.148 & 0.145 & 0.144 & 0.145 & 0.145 & 0.173 & \\
\hline
\end{tabular}


TABLE 3 Mean intra- and inter-specific genetic divergences among species within Taphrenalla gen. nov. from the mitochondrial COI (lower-left) and $16 \mathrm{~S}$ (upper-right) gene sequences estimated by the K2P model. Taxa in bold are the new species described herein

\begin{tabular}{llllllllllll}
\hline Taphrenalla spp. & 1 & 2 & 3 & 4 & 5 & 6 & 7 & 8 & 9 & 10 & 11 \\
\hline 1 asamurai & & 0.026 & 0.086 & 0.087 & 0.078 & 0.080 & 0.077 & 0.088 & 0.083 & 0.079 & 0.089 \\
2 macrosulcata & 0.045 & & 0.085 & 0.079 & 0.077 & 0.079 & 0.082 & 0.092 & 0.081 & 0.078 & 0.085 \\
3 diadema & 0.075 & 0.066 & & 0.050 & 0.035 & 0.036 & 0.033 & 0.028 & 0.055 & 0.038 & 0.068 \\
4 dalli & 0.061 & 0.063 & 0.051 & & 0.044 & 0.051 & 0.047 & 0.042 & 0.068 & 0.047 & 0.083 \\
5 corona & 0.068 & 0.063 & 0.052 & 0.045 & & 0.010 & 0.014 & 0.025 & 0.055 & 0.014 & 0.063 \\
6 parversa & 0.076 & 0.073 & 0.057 & 0.046 & 0.035 & & 0.017 & 0.030 & 0.062 & 0.013 & 0.070 \\
7 conformis & 0.060 & 0.070 & 0.056 & 0.045 & 0.043 & 0.053 & & 0.030 & 0.060 & 0.019 & 0.061 \\
8 incilis & 0.055 & 0.064 & 0.051 & 0.052 & 0.046 & 0.055 & 0.046 & & 0.052 & 0.031 & 0.059 \\
9 pygmaea & 0.071 & 0.067 & 0.072 & 0.059 & 0.062 & 0.070 & 0.069 & 0.073 & & 0.056 & 0.073 \\
10 zemia & 0.062 & 0.053 & 0.044 & 0.034 & 0.034 & 0.038 & 0.037 & 0.047 & 0.057 & & 0.065 \\
11 alba & 0.077 & 0.077 & 0.068 & 0.058 & 0.057 & 0.067 & 0.058 & 0.068 & 0.075 & 0.054 & \\
\hline
\end{tabular}

TABLE 4 Mean intra- and inter-specific genetic divergences among species within Taphrenalla gen. nov. from the mitochondrial COI (lower-left) and $16 \mathrm{~S}$ (upper-right) gene sequences estimated by the K2P model. Taxa in bold are the new species described herein

asamurai macro- diadema dalli corona parversa conformis incilis pygmaea zemia alba sulcata

\begin{tabular}{|c|c|c|c|c|c|c|c|c|c|c|c|}
\hline $\mathrm{COI}$ & 0.016 & 0.001 & 0.018 & 0.017 & 0.009 & 0 & 0.001 & 0.004 & 0.015 & 0.011 & 0.024 \\
\hline $16 S$ & 0.005 & 0.002 & 0.005 & 0.011 & 0.003 & o & o & o & 0.011 & 0.008 & 0.015 \\
\hline
\end{tabular}

In general, the results from the ABGD and PTP approaches recognized higher number of species than morphological distinctiveness (Jirapatrasilp et al., 2019; Nantarat et al., 2019). The ABGD analysis using the $\mathrm{K}_{2} \mathrm{P}$ model also yielded higher numbers of MOTUs than the JC69 model (Jirapatrasilp et al., 2019), which is similar to this study. Therefore, the $\mathrm{K}_{2} \mathrm{P}$ model, which is popular for COI barcoding may yield biased results (Collins et al., 2012; Srivathsan \& Meier, 2012; Jirapatrasilp et al., 2019). Also similar to our study, in the recent analysis of the operculated land snails, Nantarat et al. (2019) reported that the PTP species delimitation revealed additional MOTUs relative to the ABGD method.

\section{Discussion}

\section{Phylogeny and taxonomic implications}

Based on two mitochondrial and one nuclear gene fragments, the phylogenetic analyses supported that both Taphrenalla gen. nov. and all the recognized species were monophyletic (fig. 2). Previously, the two species of the Crown Snail (T. asamurai and T. diadema) were placed in the genus Macrochlamys s.l. because of their resemblance in having a depressed and thin shell with a shiny shell surface (Dall, 1897; Panha, 1996). Generally, taxonomic confusion in ariophantid snails has arisen when principally relying on shell morphology, since this is highly similar between 
TABLE 5 Comparison of the shell sculpture and genitalia of Taphrenalla gen. nov. and the related genera. Data are taken from the original descriptions and additional references: Blanford \& Godwin-Austen (1908) and Schileyko (2002, 2003)

\begin{tabular}{|c|c|c|c|c|c|c|}
\hline \multirow[t]{2}{*}{ Genera } & \multirow[t]{2}{*}{ Type species } & \multicolumn{2}{|l|}{ Shell } & \multicolumn{3}{|l|}{ Genitalia } \\
\hline & & $\begin{array}{l}\text { Shell } \\
\text { width }(\mathrm{mm})\end{array}$ & Sculpture & $\begin{array}{l}\text { Penial } \\
\text { verge }\end{array}$ & $\begin{array}{l}\text { Epiphallic } \\
\text { caecum }\end{array}$ & $\begin{array}{l}\text { Dart } \\
\text { apparatus }\end{array}$ \\
\hline $\begin{array}{l}\text { Taphrenalla } \\
\text { gen. nov. }\end{array}$ & $\begin{array}{l}\text { Nanina diadema } \\
\text { Dall, } 1897\end{array}$ & $9.6-21.3$ & $\begin{array}{l}\text { Radial grooves / } \\
\text { rarely smooth }\end{array}$ & Present & $\begin{array}{l}\text { Straight or } \\
\text { bent }\end{array}$ & Present \\
\hline $\begin{array}{l}\text { Macrochlamys } \\
\text { Gray, } 1847\end{array}$ & $\begin{array}{l}\text { Helix vitrinoides } \\
\text { Deshayes, } 1831\end{array}$ & $7.0-27.0$ & $\begin{array}{l}\text { Generally } \\
\text { smooth }\end{array}$ & Present & $\begin{array}{l}\text { Spirally } \\
\text { coiled }\end{array}$ & Present \\
\hline $\begin{array}{l}\text { Sarika } \\
\text { Godwin-Austen, } \\
1907\end{array}$ & $\begin{array}{l}\text { Helix resplendens } \\
\text { Philippi, } 1846\end{array}$ & $14.0-25.5$ & $\begin{array}{l}\text { Generally } \\
\text { smooth }\end{array}$ & $\begin{array}{l}\text { Absent / } \\
\text { rarely } \\
\text { present }\end{array}$ & Straight & Present \\
\hline $\begin{array}{l}\text { Syama } \\
\text { Godwin-Austen, } \\
1908\end{array}$ & $\begin{array}{l}\text { Macrochlamys prona } \\
\text { Nevill, } 1878\end{array}$ & $10.0-23.0$ & $\begin{array}{l}\text { Generally } \\
\text { smooth }\end{array}$ & Present & $\begin{array}{l}\text { Spirally } \\
\text { coiled }\end{array}$ & Absent \\
\hline $\begin{array}{l}\text { Taphrospira } \\
\text { Blanford, } 1905\end{array}$ & $\begin{array}{l}\text { Macrochlamys } \\
\text { convallata } \\
\text { Benson, } 1856\end{array}$ & $10.0-15.0$ & $\begin{array}{l}\text { Generally } \\
\text { smooth }\end{array}$ & Present & Straight & Absent \\
\hline $\begin{array}{l}\text { Rasama } \\
\text { Laidlaw, } 193^{2}\end{array}$ & $\begin{array}{l}\text { Macrochlamys kala } \\
\text { Godwin-Austen, } 1883\end{array}$ & $7 \cdot 0-8.5$ & $\begin{array}{l}\text { Generally } \\
\text { smooth }\end{array}$ & Present & Absent & Absent \\
\hline $\begin{array}{l}\text { Cryptozona } \\
\text { Mörch, } 1872\end{array}$ & $\begin{array}{l}\text { Helix ligulata } \\
\text { Ferussac, } 1819\end{array}$ & $20.0-40.0$ & $\begin{array}{l}\text { Spiral and } \\
\text { radial striae }\end{array}$ & Absent & Straight & Present \\
\hline $\begin{array}{l}\text { Hemiplecta } \\
\text { Albers, } 185^{\circ}\end{array}$ & $\begin{array}{l}\text { Helix humphreysiana } \\
\text { Lea, } 1841\end{array}$ & $37.0-5^{6.0}$ & $\begin{array}{l}\text { Smooth / } \\
\text { spiral wrinkles / } \\
\text { spiral striae }\end{array}$ & $\begin{array}{l}\text { Present / } \\
\text { absent }\end{array}$ & Straight & Present \\
\hline
\end{tabular}

species. The snail's anatomy is now required in later taxonomic works, especially the reproductive organs that show a significant difference among genera and species (Blanford \& Godwin-Austen, 19o8; Schileyko, 2002, 2003). For example, Macrochlamys has a spirally coiled epiphallic caecum, Sarika has a straight epiphallic caecum, Taphrenalla gen. nov. has a straight or slightly bent epiphallic caecum and Rasama has no epiphallic caecum (Blanford \& Godwin-Austen, 1908). Thus, T. asamurai and T. diadema were then transferred to Sarika based on their straight epiphallic caecum (Sutcharit \& Panha, 2008).
However, Taphrenalla gen. nov. and Sarika did not appear to be closely related in this study (fig. 2). Two anatomical features supported that this new genus is closer to the Indochinese Macrochlamys even though they have a straight epiphallic caecum. The shared characters between them are a penial verge and penial caecum in the male genitalia. Interestingly, $T$. corona sp. nov. and $T$. parversa sp. nov. do not develop the penial caecum as well as $M$. tanymentula (Pholyotha et al., 2018). On the other hand, Cryptozona siamensis is closer to Sarika in the molecular phylogeny. 
The genitalia without penial verge and penial caecum of $C$. siamensis showed a strong similarity with Sarika, even though the shell with a reticulated sculpture was an obvious difference (Godwin-Austen, 1907; Pholyotha et al., 2020). Several reports (e.g., Hausdorf, 1998; Hirano et al., 2014; Hyman et al., 2017) have suggested that genital traits are more likely to reflect the actual phylogenetic relationships than morphological appearances. On one hand, phenotypic plasticity in snail shells is a well-documented phenomenon and is probably a response to environmental variation (Emberton, 1991, 1995; Gustafson et al., 2014; Proćków et al., 2017). The other is convergence and parallelism in the character states of the shell morphology and other anatomical structures that are generally known in land snails (Hirano et al., 2014, 2015; Köhler \& Criscione, 2015; Hyman et al., 2017). On the other hand, if they are sister relationships based on molecular data, the result of the similarity in shell morphology in the close species groups is best explained by retention of the ancestral characters (Köhler \& Criscione, 2015).

In addition, our results suggested that the shell features with radial grooves on the shell sculpture of Taphrenalla gen. nov., appeared to be suitable for differentiating them from ariophantid genera. Moreover, the anatomical characters of (i) having a penial verge and straight to bent epiphallic caecum, (ii) one or two spines on tail filament of the spermatophore, and (iii) well-developed colourful lateral stripes are the important diagnostic characters found in this new genus (table 6). Even though T. zemia sp. nov. and T. alba sp. nov. have no radial grooves, they have the other unique features of this new genus. The comparative information of genitalia of these genera is mentioned in the remarks of the genus.

The spermatophore morphology is unique in this new genus. Variation can only be found in the tail filament close to the sperm sac bearing one or two spines, whereas the other parts and head filament are spineless. In contrast, the spermatophore of the Sarika, Macrochlamys, and Cryptozona species have a series of complex spine arrangements on the tail filament (Blanford \& Godwin-Austen, 1908; Maneevong, 200o; Pholyotha et al., 2018; Pholyotha, unpubl. data).

In the case of the soft-body colouration, most of the ariophantid snails generally have a black or dark grey to milky colour even though some species have a bright (attractive) colour, such as red, orange, or yellow (Blanford \& Godwin-Austen, 19o8; Pholyotha et al., 2018; Inkhavilay et al., 2019; Sajan et al., 2019). For example, the Indochina M. aurantia Pholyotha \& Panha, 2018 and Hemiplecta pluto (Pfeiffer, 1863) have a bright reddish-orange soft-body colour (Pholyotha et al., 2018; Inkhavilay et al., 2019). Remarkably, colourful stripes on the body only occurrs in Taphrenalla species.

\section{Endemism and biogeographical patterns}

Interestingly, Taphrenalla nov. gen. is one of the high endemism genera and is found in limestone areas along the two main mountain ranges of Southern Thailand. Our results also found that (i) the species distributed near the Phuket and Nakhon Si Thammarat mountain ranges are likely to present strong radial grooves (T. asamurai, T. diadema, T. macrosulcata sp. nov., and T. dalli sp. nov.), while (ii) the species distributed further away or near the coastal areas may be prone to independent reduction (T. parversa sp. nov., T. conformis sp. nov., T. incilis sp. nov., and T. pygmaea sp. nov.) or loss (T. zemia sp. nov. and T. alba sp. nov.) of the radial grooves on the shell sculpture. However, all Taphrenalla species are conspicuous in this hypothesis presented here except for $T$. corona sp. nov. This new species has strong radial grooves but can be found on 


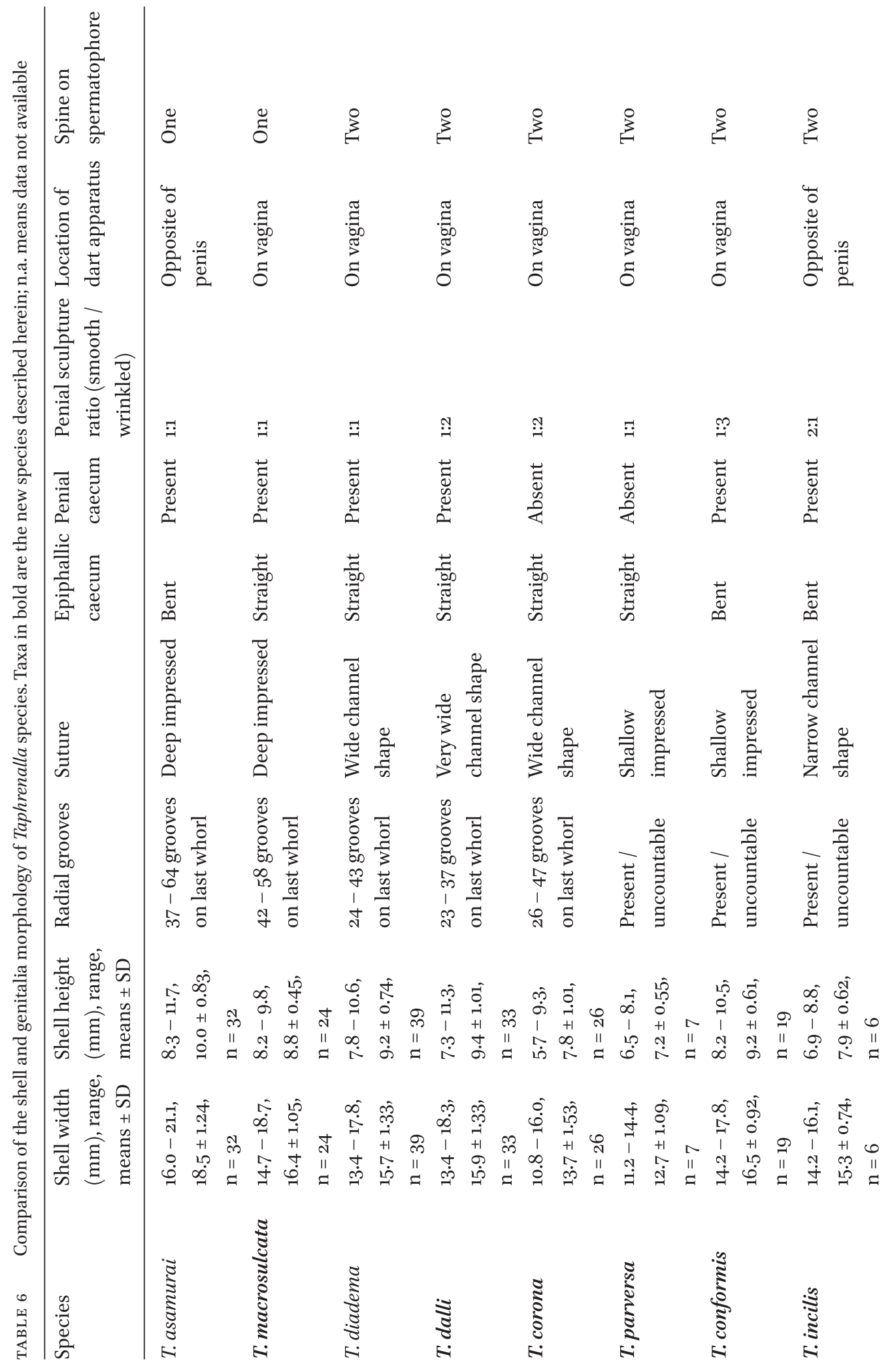




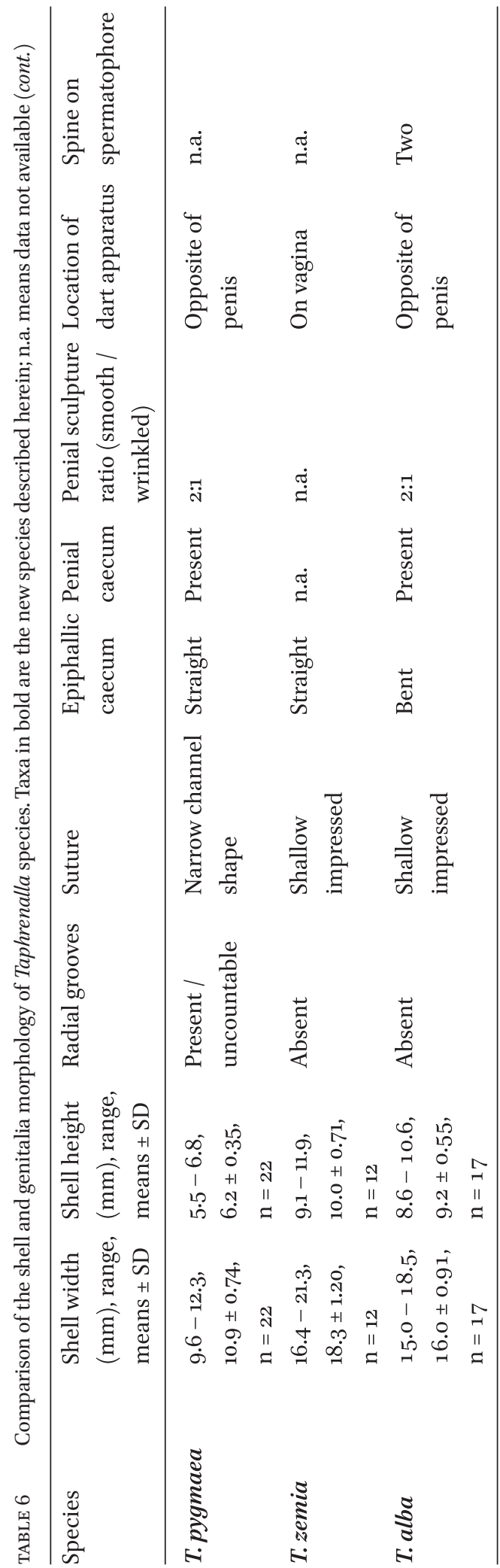

limestone outcrops near the Andaman sea northwards to the southern part of the Phuket Range.

In support, firstly the populations of $T$. diadema, found on limestone outcrops in Phatthalung close to the Gulf of Thailand, have shallower radial grooves on the shell sculpture and are smaller than the other populations distributed along the Nakhon Si Thammarat Range. Secondly, T. incilis sp. nov. is distributed near the southern part of Nakhon Si Thammarat Range but its localities are close (within $7 \mathrm{~km}$ ) to coastal areas. Thirdly, the isolated limestone outcrops of the southern part of the Phuket Range, not far from the Andaman sea, contain three allopatric species with a different form of radial groove; two species with a weak radial groove (T. parversa sp. nov. and T. conformis sp. nov.) and one species without a radial groove (T. zemia sp. nov.). Fourthly, the smooth-shelled species T. alba sp. nov. was found in the limestone hills along the shore of the Andaman sea at Krabi.

In general, the influence of convergent shifts in the morphology of terrestrial gastropod shells is possibly caused by several factors, such as habitat, isolation, surrounding soil type, natural predators, moisture levels, and geological age (Voris, 2000; Nekola, 2003; Chiba, 2004; Clements et al., 2008; Woodruff, 2010; Stankowski, 2011; Köhler \& Criscione, 2015; Nantarat et al., 2019). Furthermore, several studies have also documented that occupying similar ecological niches with similar selective forces can cause species in the same area to undergo convergent evolution (Alizon et al., 2008; Clements et al., 2008; Wu et al., 2008; Hirano et al., 2014; Nantarat et al., 2019). The mechanism of diversification may be related to adaptation to new environmental conditions (Wellborn \& Langerhans, 2015; Cameron, 2016), or may simply be the result of habitat fragmentation and isolation (Delicado et al., 2013). 
In tropical landmasses, limestone forests are considered de facto habitat islands because of their isolation from one another by habitats without limestone substrata, and this spatial configuration limits gene flow and induces high levels of species endemism (Clements et al., 2008; Foon et al., 2017). However, it is not clear whether the high level of endemic species or the degree of radial grooves on the sculpture of Taphrenalla shells are also caused by adaptation to these factors because insufficient environmental data was obtained in the present work. To fill this gap, further analyses incorporating the habitat condition of these Taphrenalla species are needed.

\section{Acknowledgements}

The authors are grateful to all members of the Animal Systematics Research Unit, Chulalongkorn University for their kind help during field trips. We are indebted to J. Ablett and F. Naggs (NHM, London) and E.E. Strong (NMNH, Washington, D.C.) for allowing us to examine the collections and photographs. We express our sincere gratitude to Dr. Frank Köhler, Dr. Bernhard Hausdorf, and an anonymous reviewer for valuable comments. We also thank R. Butcher for English polishing. The main financial research support came from The Thailand Research Fund, TRF-DPG628001, and Center of Excellence on Biodiversity (BDC-PG2-161002) to SP. This project was also supported by the $90^{\text {th }}$ Anniversary of Chulalongkorn University Fund (Ratchadaphiseksomphot Endowment Fund), the Overseas Research Experience Scholarship for Graduate Students and the Human Resource Development in Science Project (Science Achievement Scholarship of Thailand, SAST) to AP. This study has been approved by The Animal Care and Use Protocol Review No. 1723018.

\section{References}

Abbott, R.T. (1989) Compendium of Land Shells. American Malacologists, Inc. VMC Graphics, Hong Kong.

Alizon, S., Kucera, M. \& Jansen, V.A.A. (2008) Competition between cryptic species explains variations in rates of lineage evolution. Proc. Natl. Acad. Sci. U.S.A., 105, 12382-12386.

American Veterinary Medical Association. (2013) AVMA Guidelines for the Euthanasia of Animals. Available online at https://www.avma.org/KB/ Policies/Documents/euthanasia.pdf. [Accessed on 2 February 2018].

Blanford, W.T. \& Godwin-Austen, H.H. (1908) Mollusca: Testacellidae and Zonitidae. In: C.T. Bingham (Ed.) The Fauna of British India including Ceylon and Burma. Taylor and Francis, London.

Blanford, W.T. (1905) Descriptions of Indian and Burmese land-shells referred to the genera Macrochlamys, Bensonia, Taphrospira (gen. nov.), Microcystina, Euplecta, and Polita. Proc. Zool. Soc. Lond., 72, 441-447.

Boss, K.J., Rosewater, J. \& Ruhoff, F.A. (1968) The zoological taxa of William Healey Dall. United States National Museum Bulletin, 287, 1-427.

Bouchet, P., Rocroi, J.P., Hausdorf, B., Kaim, A., Kano, Y., Nützel, A., Parkhaev, P., Schrödl, M. \& Strong, E.E. (2017) Revised classification, nomenclator and typification of gastropod and monoplacophoran families. Malacologia, 61, 1-526. doi:10.4002/040.061.0201.

Cameron, R. (2016) Slugs and Snails. HarperCollins Publishers, London.

Castresana, J. (2000) Selection of conserved blocks from multiple alignments for their use in phylogenetic analysis. Mol. Biol. Evol., 17, 540552. doi:10.1093/oxfordjournals.molbev.ao26334.

Chiba, S. (2004) Ecological and morphological patternsincommunities oflandsnails of thegenus Mandarina from the Bonin Islands. J. Evol. Biol., 17, 131-143. doi:10.1046/j.1420-9101.2004.0o639.x. Clements, R., Ng, P.K.L., Lu, X.X., Ambu, S., Schilthuizen, M. \& Bradshaw, C.J.A. (2008) 
Using biogeographical patterns of endemic land snails to improve conservation planning for limestone karsts. Biol. Conserv., 141, 27512764. doi:10.1016/j.biocon.2008.o8.o11.

Clements, R., Sodhi, N.S., Schilthuizen, M. \& Ng, P.K.L.(2006) Limestone karsts of Southeast Asia: imperiledarks of biodiversity.Bioscience, 56,733 742. doi:10.1641/ooo6-3568(2006)56[733:LKOSA I]2.o.CO;2.

Collins, R.A., Boykin, L.M., Cruickshank, R.H. \& Armstrong, K.F. (2012) Barcoding's next top model: an evaluation of nucleotide substitution models for specimen identification. Methods Ecol. Evol., 3, 457-465. doi:10.1111/j.2041-210X.2011.00176.x.

Dall, W.H. (1897) Note on land shells from the Malay Peninsula. The Nautilus, 11, 37-38.

Dall, W.H. (1902) Illustrations and descriptions of new, unfigured, or imperfectly know shells, chiefly American, in the U.S. National Museum. Proc. U.S. Nat. Mus., 24, 499-566.

Delicado, D., Machordom, A. \& Ramos, M.A. (2013) Living on the mountains: patterns and causes of diversification in the springsnail subgenus Pseudamnicola (Corrosella) (Mollusca: Caenogastropoda: Hydrobiidae). Mol. Phylogenet. Evol., 68, 387-397. doi:10.1016/j.ympev.2013.04.022.

Department of Mineral Resources. (2018) Geology of Thailand. Available online at http://www. dmr.go.th/n_more_news_en.php?nid=109504. [Accessed 22 August 2019].

Emberton, K.C. (1991) Ecology of a shell convergence between subfamilies of polygyrid land snails. Biol. J. Linn. Soc., 44, 105-120. doi:10.1111/j.1095-8312.1991.tboo610.x.

Emberton, K.C. (1995) Sympatric convergence and environmental correlation between two land-snail species. Evolution, 49, 469-475. doi:10.1111/j.1558-5646.1995.tbo2279.x.

Felsenstein, J. (2004) Inferring Phylogenies. Sinauer Associates Inc., Sunderland, MA.

Folmer, O., Black, M., Hoeh,W.,Lutz, R. \& Vrijenhoek, R. (1994) DNA primers for amplification of mitochondrial cytochrome $c$ oxidase subunit I from diverse metazoan invertebrates. Mol. Mar. Biol. Biotechnol., 3, 294-299.

Foon, J.K., Clements, G.R. \& Liew, T-S. (2017) Diversity and biogeography of land snails (Mollusca, Gastropoda) in the limestone hills of Perak, Peninsular Malaysia. ZooKeys, 682, 1-94. doi:10.3897/zookeys.682.12999.

Gardner, S., Sidisunthorn, P. \& Chayamarit, K. (2015) Forest Trees of Southern Thailand Volume 1 (Acanthaceae to Escalloniaceae). Kobfai Publishing Project, Bangkok.

Godwin-Austen, H.H. (1883-1907) Land and Freshwater Mollusca of India, including South Arabia, Baluchistan, Afghanistan, Kashmir, Nepal, Burmah, Pegu, Tenasserim, Malay Peninsula, Ceylon, and other Islands of the Indian Ocean. Supplementary to Messrs. Theobald and Hanley's Conchologia Indica. Taylor and Francis, London.

Gray, J.E. (1847) A list of the genera of recent Mollusca, their synonyma and types. Proc. Zool. Soc. Lond., 15, 129-182.

Gude, G.K. (1903) A classified list of the Helicoild land shells of Asia, Part VI.J. Malacol., 10, 45-62. Gupta, A. (2005) Landforms of Southeast Asia. In: A. Gupta A (Ed.) The Physical Geography of Southeast Asia, pp. 38-64. Oxford University Press, New York.

Gustafson, K.D., Kensinger, B.J., Bolek, M.G. \& Luttbeg, B. (2014) Distinct snail (Physa) morphotypes from different habitats converge in shell shape and size under common garden conditions. Evol. Ecol. Res., 16, 77-89.

Hausdorf,B.(1998) Phylogeny of the Limacoideasensu lato (Gastropoda: Stylommatophora).J. Molluscan Stud., 64, 35-66. Doi1o.1o93/mollus/64.1.35.

Hebert, P.D.N., Ratnasingham, S. \& DeWaard, J.R. (2003) Barcoding animal life: cytochrome c oxidase subunit 1 divergences among closely related species. Proc. R. Soc. B: Biol. Lett., 270, S96-S99. doi:10.1098/rsbl.2003.0025.

Hemmen, J. \& Hemmen, C. (2001) Aktualisierte liste der terrestrischen gastropoden Thailands. Sch.r Malakozool. Haus. Nat. Cismar, 18, 35-70. 
Hillis, D.M. \& Bull, J.J. (1993) An empirical test of bootstrapping as a method for assessing confidence in phylogenetic analysis. Syst. Biol., 42, 182-192. doi:10.1093/sysbio/42.2.182.

Hirano, T., Kameda, Y., Kimura, K. \& Chiba, S. (2014) Substantial incongruence among the morphology, taxonomy, and molecular phylogeny of the land snails Aegista, Landouria, Trishoplita, and Pseudobuliminus (Pulmonata: Bradybaenidae) occurring in East Asia. Mol. Phylogenet. Evol., 70, 171-181. doi:10.1016/j.ympev.2013.o9.o20.

Hirano, T., Kameda, Y., Kimura, K. \& Chiba, S. (2015) Divergence in the shell morphology of the land snail genus Aegista (Pulmonata: Bradybaenidae) under phylogenetic constraints. Biol. J. Linn. Soc., 114, 229-241. doi:10.1111/bij.12407.

Hirano, T., Wada, S., Mori, H., Uchida, S., Saito, T. \& Chiba, S. (2018) Genetic and morphometric rediscovery of an extinct land snail on oceanic islands. J. Molluscan Stud., 84, 148-156. doi:10.1093/mollus/eyyoo3.

Huang, X-C., Su, J-H., Ouyang, J-X., Ouyang, S., Zhou, C-H. \& Wu, X-P. (2019) Towards a global phylogeny of freshwater mussels (Bivalvia: Unionida): species delimitation of Chinese taxa, mitochondrial phylogenomics, and diversification patterns. Mol. Phylogenet. Evol., 13o, 45-59. doi:10.1016/j.ympev.2018.o9.o19.

Huelsenbeck, J.P. \& Rannala, B. (2004) Frequentist properties of bayesian posterior probabilities of phylogenetic trees under simple and complex substitution models. Syst. Biol., 53, 904-913. doi:10.1080/10635150490522629.

Hyman, I.T., Ho, S.Y.W. \& Jermiin, L.S. (2007) Molecular phylogeny of Australian Helicarionidae, Euconulidae and related groups (Gastropoda: Pulmonata: Stylommatophora) based on mitochondrial DNA. Mol. Phylogenet. Evol.,45,792-812.doi:10.1016/j.ympev.2007.08.018.

Hyman, I.T. \& Köhler, F. (2018) Reconciling comparative anatomy and mitochondrial phylogenetics in revising species limits in the Australian semislug Helicarion Férussac, 1821 (Gastropoda: Stylommatophora).
Zool. J. Linn. Soc., 184, 933-968. doi:10.1093/ zoolinnean/zlyo17.

Hyman, I.T., Lamborena, I. I. \& Köhler, F. (2017) Molecularphylogenetics and systematic revision of the south-eastern Australian Helicarionidae (Gastropoda, Stylommatophora). Contrib. Zool., 86, 51-95. doi:10.1163/18759866-o86o10o4.

Inkhavilay, K., Sutcharit, C., Bantaowong, U., Chanabun, R., Siriwut, W., Srisonchai, R., Pholyotha, A., Jirapatrasilp, P. \& Panha, S. (2019) Annotated checklist of the terrestrial molluscs from Laos (Mollusca, Gastropoda). ZooKeys, 834, 1-166. doi:10.3897/zookeys.834.288oo.

Jeratthitikul, E., Phuangphong, S., Sutcharit, C., Prasankok, P., Kongim, B. \& Panha, S. (2019) Integrative taxonomy reveals phenotypic plasticity in the freshwater mussel Contradens contradens (Bivalvia: Unionidae) in Thailand, with a description of a new species. Syst. Biodivers., 17, 134-147. doi:10.108o/14772000.2018.15546o7.

Jirapatrasilp, P., Backeljau, T., Prasankok, P., Chanabun, R. \& Panha, S. (2019) Untangling a mess of worms: Species delimitations reveal morphological crypsis and variability in Southeast Asian semi-aquatic earthworms (Almidae, Glyphidrilus). Mol. Phylogenet. Evol., 139, 106531. doi:10.1016/j.ympev.2019.106531.

Kapli, P., Lutteropp, S., Zhang, J., Kobert, K., Pavlidis, P., Stamatakis, A. \& Flouri, T. (2017). Multi-rate Poisson tree processes for single-locus species delimitation under maximum likelihood and Markov chain Monte Carlo. Bioinformatics, 33, 1630-1638. doi:10.1093/bioinformatics/btxo25.

Katoh, K., Rozewicki, J. \& Yamada, K.D. (2017) MAFFT online service: multiple sequence alignment, interactive sequence choice and visualization. Brief. Bioinform., bbx1o8. doi:10.1093/bib/bbxio8.

Köhler, F. \& Criscione, F. (2015) A molecular phylogeny of camaenid land snails from north-western Australia unravels widespread homoplasy in morphological characters (Gastropoda, Helicoidea). Mol. Phylogenet. Evol., 83, 44-55. doi:10.1016/j.ympev.2014.11.oo9. 
Kumar, S., Stecher, G. \& Tamura, K. (2016) MEGA7: molecular evolutionary genetics analysis version 7.0 for bigger datasets. Mol. Biol. Evol., 33, 1870-1874. doi:10.1093/molbev/mswo54.

Laidlaw, F.F. (1932) New name for Sarama G.-A. J. Conchol., 19, 259.

Liew, T-S., Schilthuizen, M. \& Vermeulen, J.J. (2009) Systematic revision of the genus Everettia Godwin-Austen, 1891 (Mollusca: Gastropoda: Dyakiidae) in Sabah, northern Borneo. Zool. J. Linn. Soc., 157, 515-550. doi:10.1111/j.1096-3642.2009.00526.x.

Maassen, W.J.M. (2001) A preliminary checklist of the non-marine molluscs of West-Malaysia. "A Handlist". De Kreukel, Extra Editie, 2001, 1-155.

Maneevong, A. (2000) Taxonomic revision of terrestrial snails genera Macrochlamys, Cryptozona and Hemiplecta in Thailand. Master Thesis, Department of Biology, Faculty of Science, Chulalongkorn University, Bangkok.

Mauro, D.S. \& Agorreta, A. (2010) Molecular systematics: a synthesis of the common methods and the state of knowledge. Cell. Mol. Biol. Lett., 15, 311-341. doi:10.2478/s11658-o10-0o10-8.

Miller, M.A., Pfeiffer, W. \& Schwartz, T. (2010) Creating the CIPRES Science Gateway for inference of large phylogenetic trees. In: Proceedings of the Gateway Computing Environments Workshop (GCE), 14 Nov. 2010, New Orleans, LA, USA.

Myers, N., Mittermeier, R.A., Mittermeier, C.G., da Fonseca, G.A.B. \& Kent, J. (2000) Biodiversity hotspots for conservation priorities. Nature, 403, 853-858. doi:10.1038/35002501.

Naggs, F., Panha, S. \& Raheem, D. (2006) Developing land snail expertise in South and Southeast Asia, a new Darwin Initiative Project. The Natural History Journal of Chulalongkorn University, 6, 43-46.

Nantarat, N., Sutcharit, C., Tongkerd, P., Wade, C.M., Naggs, F. \& Panha, P. (2019) Phylogenetics and species delimitations of the operculated land snail Cyclophorus volvulus (Gastropoda:
Cyclophoridae) reveal cryptic diversity and new species in Thailand. Sci. Rep., 9, 7041. doi:10.1038/ s41598-019-43382-5.

Nekola, J.C. (2003) Large-scale terrestrial gastropod community composition patterns in the Great Lakes region of North America. Divers. Distrib., 9, 55-71. doi:10.1046/j.1472-4642.2003.00165.x.

Páll-Gergely, B., Fehér, Z., Otani, J.U., \& Asami, T. (2017) An integrative taxonomic approach to infer the systematic position of Chalepotaxis Ancey, 1887 (Gastropoda: Stylommatophora: Helicarionidae). Molluscan Res., 37, 113-119. doi: 10.108o/13235818.2016.1234996.

Palumbi, S.R., Martin, A., Romano, S., McMillan, W.O., Stice, L. \& Grabowski, G. (1991) The Simple Fools Guide to PCR. University of Hawaii Press, Honolulu.

Panha, S. (1996) A checklist and classification of the terrestrial pulmonate snail of Thailand. Walkerana, 8, 31-40.

Panha, S. (1997) A new species of Macrochlamys from Thailand (Stylommatophora: Ariophantidae). Malacological Review, 29, 101-105.

Pholyotha, A., Sutcharit, C. \& Panha, S. (2018) The land snail genus Macrochlamys Gray, 1847 from Thailand, with descriptions of five new species (Pulmonata: Ariophantidae). Raffles Bull. Zool., $66,763-781$.

Pholyotha, A., Sutcharit, C., Tongkerd, P., Lin, A. \& Panha, S. (2020) Taxonomic revision of the land snail genera Macrochlamys Gray, 1847 and Sarika Godwin-Austen, 1907 (Eupulmonata: Ariophantidae) from south-eastern Myanmar, with descriptions of three new species. Molluscan Res., 40(2), 183-204. doi:10.1080/1323 5818.2020.1723041.

Proćków, M., Kuźnik-Kowalska, E. \& Mackiewicz, P. (2017) Phenotypic plasticity can explain evolution of sympatric polymorphism in the hairy snail Trochulus hispidus (Linnaeus, 1758). Curr. Zool., 63, 389-402. doi:10.1093/cz/zowo82.

Puillandre, N., Lambert, A., Brouillet, S. \& Achaz, G. (2012) ABGD, Automatic Barcode Gap Discovery 
for primary species delimitation. Mol. Ecol., 21, 1864-1877. doi:10.1111/j.1365-294X.2011.05239.x.

Ridd, M.F., Barber, A.J. \& Crow, M.J. (2011) Introduction to the geology of Thailand. In: M.F. Ridd, A.J. Barber, M.J. Crow (Eds.) The Geology of Thailand, pp. 1-18. Geological Society, London. Ronquist, F., Teslenko, M., Mark, Pvd., Ayres, D.L., Darling, A., Höhna, S., Larget, B., Liu, L., Suchard, M.A. \& Huelsenbeck, J.P. (2012) MrBayes 3.2: Efficient Bayesian phylogenetic inference and model choice across a large model space. Syst. Biol., 61, 539-542. doi:10.1093/sysbio/syso29.

Sajan, S., Tripathy, B., Chandra, K. \& Sivakumar, K. (2019) A new species of the genus Macrochlamys Gray, 1847 (Stylommatophora: Ariophantidae) from Western Himalaya, India. J. Nat. Hist., 53, 797-813. doi:10.108o/oo222933.2019.1615566.

Schileyko, A.A. (2002) Treatise on recent terrestrial pulmonate mollusks. Part 9. Helicarionidae, Gymnarionidae, Rhysotinidae, Ariophantidae. Ruthenica, supplement 2, 1167-1307.

Schileyko, A.A. (2003) Treatise on recent terrestrial pulmonate mollusks. Part 10. Ariophantidae, Ostracolethidae, Ryssotidae, Milacidae, Dyakiidae, Staffordiidae, Gastrodontidae, Zonitidae, Daudebardiidae, Parmacellidae. Ruthenica, supplement 2, 1309-1466.

Solem, A. (1966) Some non-marine mollusks from Thailand, with notes on classification of the Helicarionidae. Spolia Zoologica Musei Hauniensis, 24, 1-110.

Srivathsan,A.\&Meier,R.(2012)Ontheinappropriate use of Kimura-2-parameter $\left(\mathrm{K}_{2} \mathrm{P}\right)$ divergences in the DNA-barcoding literature. Cladistics, 28, 190-194. doi:10.1111/j.1096-0031.2011.00370.x.

Stamatakis, A. (2014) RAxML Version 8: A tool for phylogenetic analysis and post-analysis of large phylogenies. Bioinformatics, 30, 1312-1313. doi:10.1093/bioinformatics/btuo33.

Stankowski, S. (2011) Extreme, continuous variation in an island snail: local diversification and association of shell form with the current environment. Biol. J. Linn. Soc., 104, 756-769. doi:10.1111/j.1095-8312.2011.01748.x.
Sutcharit, C., \& Panha, S. (2008) Taxonomic re-evaluation of Sarika diadema (Dall, 1897) and S. asamurai (Panha, 1997), two endemic land snails from Thailand (Pulmonata: Ariophantidae: Macrochlamydinae). Raffles Bull. Zool., 56, 95-100.

Talavera, G. \& Castresana, J. (2007) Improvement of phylogenies after removing divergent and ambiguously aligned blocks from protein sequence alignments. Syst. Biol., 56, 564-577. doi:10.108o/10635150701472164.

Tanabe, A.S. (2007) Kakusan: a computer program to automate the selection of a nucleotide substitution model and the configuration of a mixed model on multilocus data. Mol. Ecol. Notes, 7, 962-964. doi:10.1111/j.1471-8286.2007.01807.x.

Tanabe, A.S. (2011) Kakusan4 and Aminosan: two programs for comparing nonpartitioned, proportional and separate models for combined molecular phylogenetic analyses of multilocus sequence data. Mol. Ecol. Resour., 11, 914-921. doi:10.1111/j.1755-0998.2011.03021.x.

Thai Meteorological Department (2015) The Climate of Thailand. Available online at https:// www.tmd.go.th/en/archive/thailand_climate. pdf. [Accessed 22 August 2019].

Voris, H.K. (2000) Maps of Pleistocene sea levels in Southeast Asia: shorelines, river systems and time durations. J. Biogeogr., 27, 1153-1167. doi:10.1046/j.1365-2699.200o.00489.x.

Wade, C.M., Mordan, P.B. \& Clarke, B. (2001) A phylogeny of the land snails (Gastropoda: Pulmonata). Proc. R. Soc. Lond. B 268, 413-422. doi:10.1098/rspb.200o.1372.

Wade, C.M., Mordan, P.B. \& Naggs, F. (2006) Evolutionary relationships among the Pulmonata land snails and slugs (Pulmonata, Stylommatophora). Biol. J. Linn. Soc., 87, 593610. doi:10.1111/j.1095-8312.2006.00596.x.

Wade, C.M. \& Mordan, P.B. (2000) Evolution within the gastropod molluscs; using the ribosomal RNA gene-cluster as an indicator of phylogenetic relationships. J. Molluscan Stud., 66, 565-570. doi:10.1093/mollus/66.4.565. 
Wellborn, G.A. \& Langerhans, R.B. (2015) Ecological opportunity and the adaptive diversification of lineages. Ecol. Evol., 5, 176-195. doi:10.1002/ ece3.1347.

Woodruff, D.S. (2010) Biogeography and conservation in Southeast Asia: how 2.7 million years of repeated environmental fluctuations affect today's patterns and the future of the remaining refugial-phase biodiversity. Biodivers. Conserv., 19, 919-941.

Wu, S-P., Hwang, C-C. \& Lin, Y-S. (2008) Systematic revision of the arboreal snail Satsuma albida species complex (Mollusca: Camaenidae) with descriptions of 14 new species from Taiwan. Zool. J. Linn. Soc., 154, 437-493. doi:10.1111/j.1096-3642.2008.00415.x.
Xia, X. (2013) DAMBE5: a comprehensive software package for data analysis in molecular biology and evolution. Mol. Biol. Evol., 30, 1720-1728. doi:10.1093/molbev/msto64.

Zhang, J., Kapli, P., Pavlidis, P. \& Stamatakis, A. (2013) A general species delimitation method with applications to phylogenetic placements. Bioinformatics, 29, 2869-2876. doi:10.1093/ bioinformatics/btt499.

RECEIVED: 18 FEBRUARY 2020 | REVISED AND ACCEPTED: 15 MAY 2020

EDITOR: T. DE WINTER 


\section{APPENDIX}

\section{Systematics}

Family: Ariophantidae Godwin-Austen, 1888 Subfamily: Macrochlamydinae Godwin-Austen, 1888

Genus Taphrenalla Pholyotha \& Panha, gen. nov.

\section{Type species. Nanina (Macrochlamys) diadema} Dall, 1897

Etymology. Taphrenalla is derived from 'Taphr' (the Greek word 'Taphros') meaning 'trench or ditch' and 'enalla' (the Greek word 'enallax') meaning crosswise. Therefore, the generic name means the snail with transverse ditches or radial grooves on the shell sculpture. The gender of the new generic name is feminine.

\section{Description}

Shell. Shell dextral, depressed to globosely depressed, thin, translucent, corneous to dark brown colour. Shell surface shiny, smooth (fig. 4A), with very fine growth lines or sculptured, very weak (fig. 4B) to strong (figs $4 \mathrm{C}, \mathrm{D}$ ) radial grooves starting from suture. Suture shallow impressed (figs $4 \mathrm{~A}, \mathrm{~B}$ ), deep impressed (fig. 4C), or wide and deep channel-shaped (fig. 4D). Whorls $5^{-6}$, increasing regularly. Last whorl rounded to slightly shouldered. Aperture crescentic with simple lip. Columellar margin simple and little expanded near umbilicus. Umbilicus perforate, narrowly opened.

Genital organs. Genitalia with short to long penis; thick or thin penial sheath. Epiphallic caecum usually straight, rarely a little bent at tip (not spirally coiled); penial retractor muscle attached to head of epiphallic caecum (rarely attached near the head). Flagellum relatively short and enlarged at base. Penial verge well-developed and small to large; penial caecum usually present and short or rarely absent. Female genital organ well-developed; dart apparatus located on vagina or at vagina and penis junction. Spermatophore long, needle-shaped and translucent. Head filament smooth, shorter than sperm sac and gradually thinning to terminal point. Sperm sac enlarged, capsule-shaped and contained whitish sperm mass. Tail filament very long and thin tube; region close to sperm sac bearing one or two spines.

Radula. Teeth arranged in U-shape with very wide angle. Central tooth symmetrical tricuspid; mesocone lanceolated-shaped; ectocones short and located at middle of tooth height. Lateral teeth asymmetrical tricuspid; mesocone triangular shaped; endocone smaller than ectocone; ectocone located below endocone. Marginal teeth with obliquely bicuspid, elongate and narrower teeth, and outermost teeth shorter and smaller than inner teeth (fig. $4 \mathrm{H}$ ).

External features. Living snails usually covered with reticulated skin; three colourful stripes running from head to tail (one at middle of body and two on each side of body near foot sole). Eye stalks and head usually with dark colour; tail region usually with lighter colour than head region. Pallial cavity and some internal organs visible through translucent shell (figs $4 \mathrm{~F}, \mathrm{G}$ ).

Mantle collar large, well developed and composed of two shell lobes and three dorsal lobes (figs $4 \mathrm{E}-\mathrm{G}$ ); shell lobes usually slender and longer than dorsal lobes. Right shell lobe placed on upper shell surface and longer than left shell lobe placed below periphery. Right dorsal lobe larger than left dorsal lobe; left dorsal lobe divided into anterior left dorsal lobe and posterior left dorsal lobe. Foot sole tripartite; caudal foss long and narrow; caudal horn raised and large. Colouration of soft body usually variable from reddish, orange, yellow, milky-white to greyish, and colour disappeared in preserved specimens. 


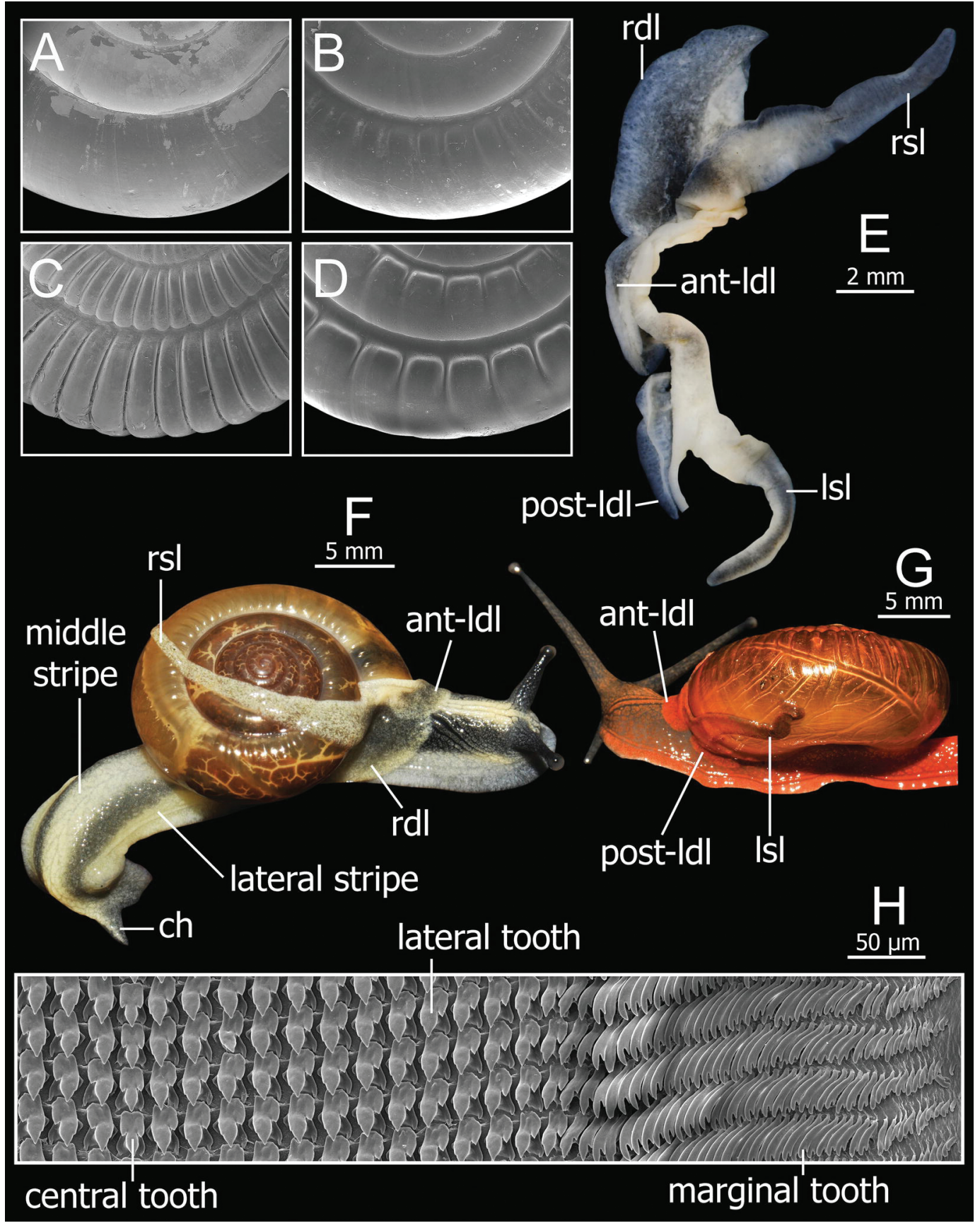

FIGURE 4 Schematic of shell sculpture, mantle lobes, body terminology and radular of Taphrenalla gen. nov. A-D. radial grooves and suture types on upper shell surface: A. no radial grooves with shallow impressed suture. B. weak to nearly absent radial grooves with impressed suture. C. deep radial grooves with deep impressed suture. D. deep radial grooves with wide and deep channel shaped suture. E. dorsal view of mantle collar. F. right-hand side of snail shows mantle lobes and colour stripes on body. G. left-hand side of snail shows mantle lobes. H. representative SEM images of radular. 
Distribution range. Endemic to Malay Peninsula: Southern Thailand (fig. 1) and probably in Peninsular Malaysia.

Remarks. Taphrenalla diadema is the type species of the new genus because this species somewhat represents the morphology in general among congeneric species and is also the oldest valid species. Although the absence of radial grooves is evolved in T. zemia sp. nov. and T. alba sp. nov., they present the other characteristics of yellowish stripes on the body and a simple spermatophore. The spermatophore of T. alba sp. nov. has two spines near the sperm sac but is spineless in other regions. In addition, the molecular analysis grouped them within the Taphrenalla clade with strong support.

For comparison with the other closely related ariophantid genera, Taphrenalla gen. nov. can be distinguished from Sarika, Macrochlamys, Taphrospira, Syama, and Rasama by the shell sculpture having radial grooves, while the others have a smooth shell without radial grooves (table 5). The shell morphology of Hemiplecta and Cryptozona are clearly different from the new genus in being much larger, with a smooth shell surface and without a radial groove. Regarding the genitalia anatomy, Taphrenalla gen. nov. have a penial verge, dart apparatus, and straight or slightly bent epiphallic caecum. Compared to the other genera, Macrochlamys and Syama both have a spirally coiled epiphallic caecum, but only Syama has no dart apparatus. The genus Taphrospira also has a straight epiphallic caecum and is without a dart apparatus, while the genus Rasama has neither an epiphallic caecum nor a dart apparatus (Blanford \& Godwin-Austen, 1908; Schileyko, 2002, 2003). Thus, the genitalia of the genus Sarika is similar to Taphrenalla gen. nov. However, all species of the genus Sarika, except for $S$. consepta (Benson, 186o), have no penial verge (Pholyotha et al., 202O), while this character is present in all Taphrenalla species. The taxonomic status of $S$. consepta is needed to be investigated in the future using a molecular approach.

In addition, most Taphrenalla species have bright body colouration patterns of the left, middle, and right stripes, either restricted to the head section or running from head to tail, while all Sarika species have a monochrome greyish to blackish body colour (Pholyotha et al., 2020).

\section{Taphrenalla asamurai (Panha, 1997)}

(figs 1, 3, 5, 6A, 7A-C, table 6)

Macrochlamys asamurai Panha, 1997: 101-105, figs 2a, 2b1, 3-4. Type locality: Takun Village, Suratthani, Thailand.

Macrochlamys asamurai: Maneevong, 2000:26-27, fig. 4-1.

Sarika asamurai: Sutcharit \& Panha, 2008: 95-100, figs $2 c, d, 3^{f-i}, 4 d-f$.

Material examined. Type material: not examined. Non-type material: Wat Tham Wararam, Phanom District, Surat Thani $\left(98^{\circ} 53^{\prime} \mathrm{O} 7.3^{\prime \prime} \mathrm{N} 98^{\circ} 40^{\prime} \mathrm{O} . \mathrm{o}^{\prime \prime} \mathrm{E}\right)$ : CUMZ 7153 (fig. 6A; 26 shells and 15 specimens in ethanol), CUMZ 7154 (six specimens in ethanol), CUMZ 7155 (14 shells and eight specimens in ethanol), and CUMZ 7156 (four shells). Limestone outcrops at Khlong Sok, Phanom District, Surat Thani ( $8^{\circ} 53^{\prime} 39.3$ "N $\left.98^{\circ} 33^{\prime} 10.7^{\prime \prime} \mathrm{E}\right)$ : CUMZ 7157 (three shells) and CUMZ 7158 (one shell). Limestone outcrops at Khlong Sok, Phanom District, Surat Thani ( $\left.8^{\circ} 50^{\prime} 51.2^{\prime \prime} \mathrm{N} \quad 98^{\circ} 44^{\prime} 18.0^{\prime \prime} \mathrm{E}\right)$ : CUMZ 7159 (31 shells and 12 specimens in ethanol). Wat Tham Phanthurat, Phanom District, Surat Thani ( $8^{\circ} 54^{\prime}$ o1.3"N 98 ${ }^{\circ} 31^{\prime} 3$ o.2"E): CUMZ 7160 (three specimens in ethanol).

Remarks. Taphrenalla asamurai had been re-described and illustrated by Sutcharit \& Panha (2008). The unique characters are a depressed conic shell of medium size (width up to $21.1 \mathrm{~mm}$; height up to $11.7 \mathrm{~mm}$ ), deep and narrow impressed suture, and long radial grooves that appeared on 


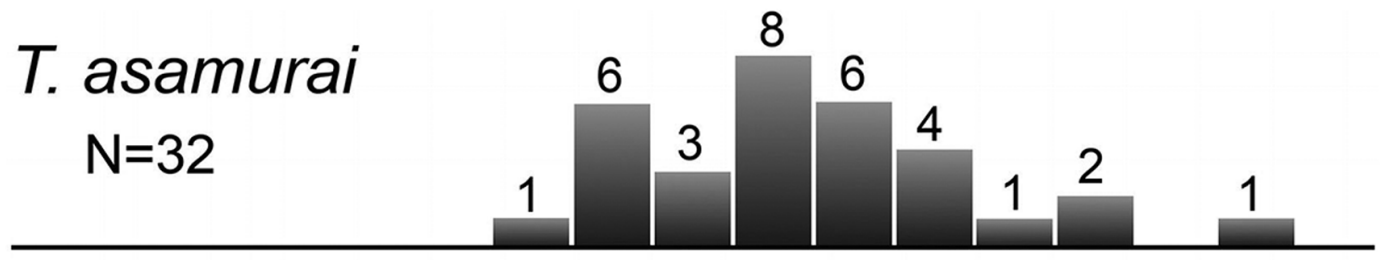

T. macrosulcata sp. nov.
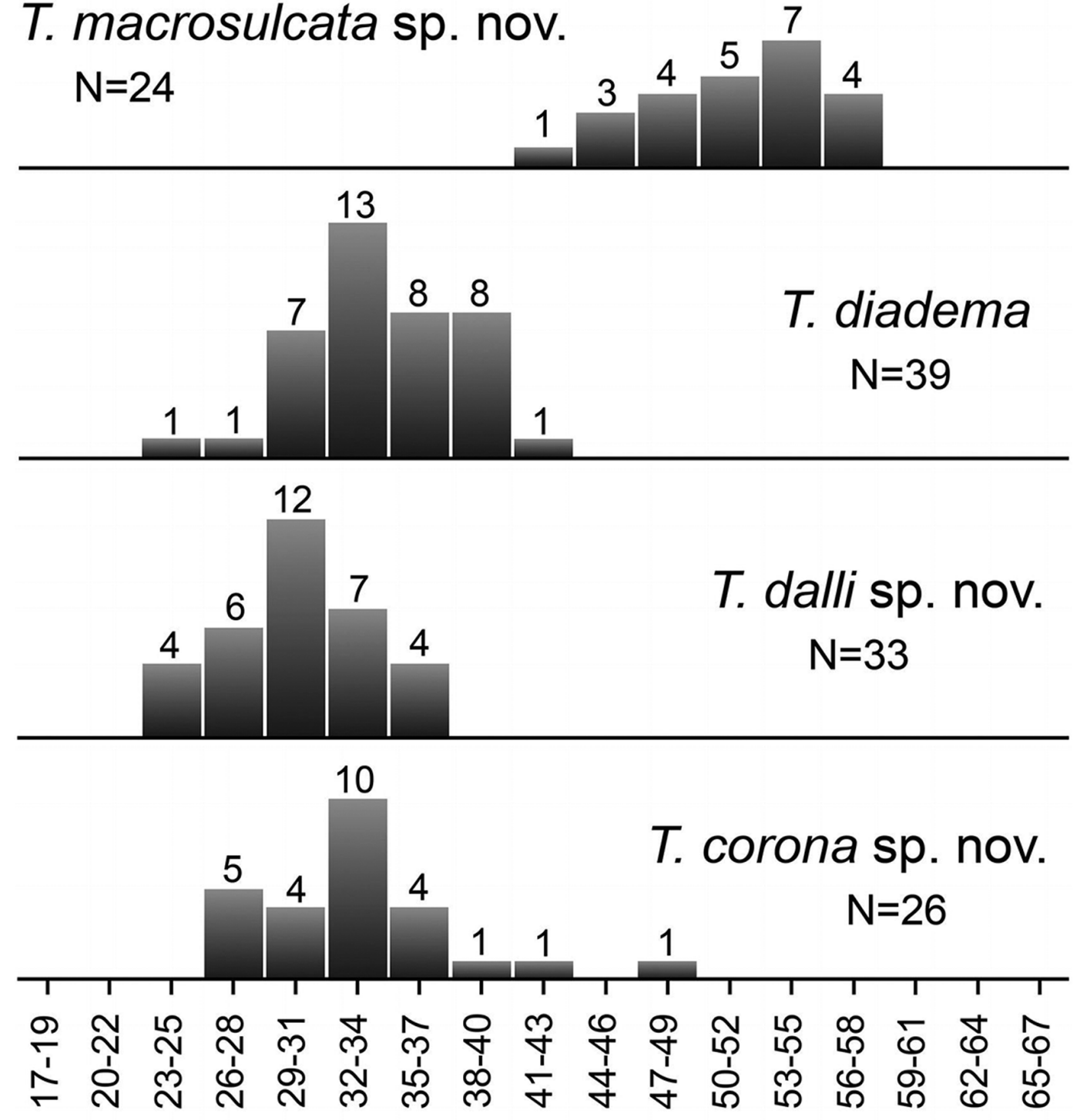

\section{No. radial grooves per last whorl}

FIgURE 5 Frequency of radial grooves numbers on the last whorl of Taphrenalla asamurai, T. macrosulcata sp. nov., T. diadema, T. dalli sp. nov., and T. corona. sp. nov. 


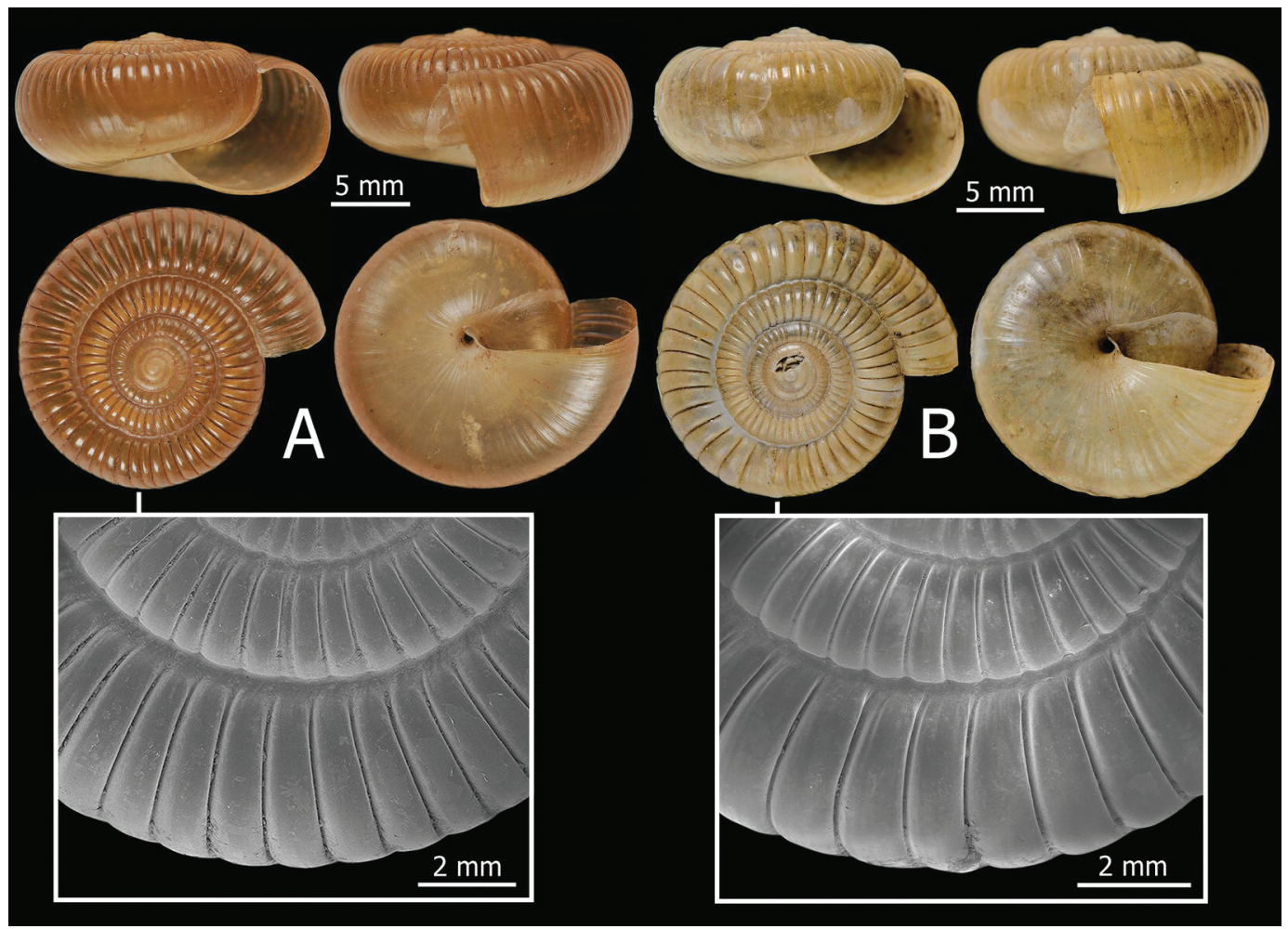

FIgURE 6 Shells. A. Taphrenalla asamurai specimen CUMZ 7153. B. T. macrosulcata sp. nov. holotype CUMZ 7161. Inset SEM image showing shell sculpture of each species.

the last $37-64$ grooves $(\mathrm{n}=32$; figs $5,6 \mathrm{~A})$. The genitalia are bent at the epiphallic caecum, and the proximal part of dart apparatus is with a thick and swollen sac-like structure (figs $7 \mathrm{~A},{ }_{7} \mathrm{~B}$ ). Spermatophore has one spine on the tail filament close to the sperm sac (fig. $7 \mathrm{C}$ ). Living snails have monochrome red to dark red on tail (fig. 3).

Taphrenalla macrosulcata Pholyotha \& Panha, sp. nov.

(figs 1, 3, 5, 6B, 7D-F, table 6)

Type material examined. Holotype: CUMZ 7161 (fig. 6B). Paratypes. Same data as holotype: CUMZ 7162 (15 shells and five specimens in ethanol), CUMZ 7163 (three shells and nine specimens in ethanol), NHMUK (two shells) and SMF (two shells).
Type locality. Limestone outcrops at Khlong Sok, Phanom District, Surat Thani, Thailand $\left(8^{\circ} 53^{\prime} 20.5^{\prime \prime} \mathrm{N} 98^{\circ} 40^{\prime} 27 \cdot 7^{\prime \prime} \mathrm{E}\right)$.

Etymology. The specific epithet is derived from 'macro' (the Greek word 'makros') meaning 'long' and 'sulcata' (the Latin word 'sulcus') meaning 'furrow, groove' with reference to the characteristic of having numerous long radial grooves on shell sculpture.

Diagnosis. Shell with a narrow and deep impressed suture and deep and long radial grooves. Epiphallic caecum straight and short. Penial caecum short. Inner sculpture of proximal penis with fine wrinkled longitudinal folds; distally with oblique longitudinal folds and transverse-folded surrounding penial verge. Dart apparatus located on vagina. 


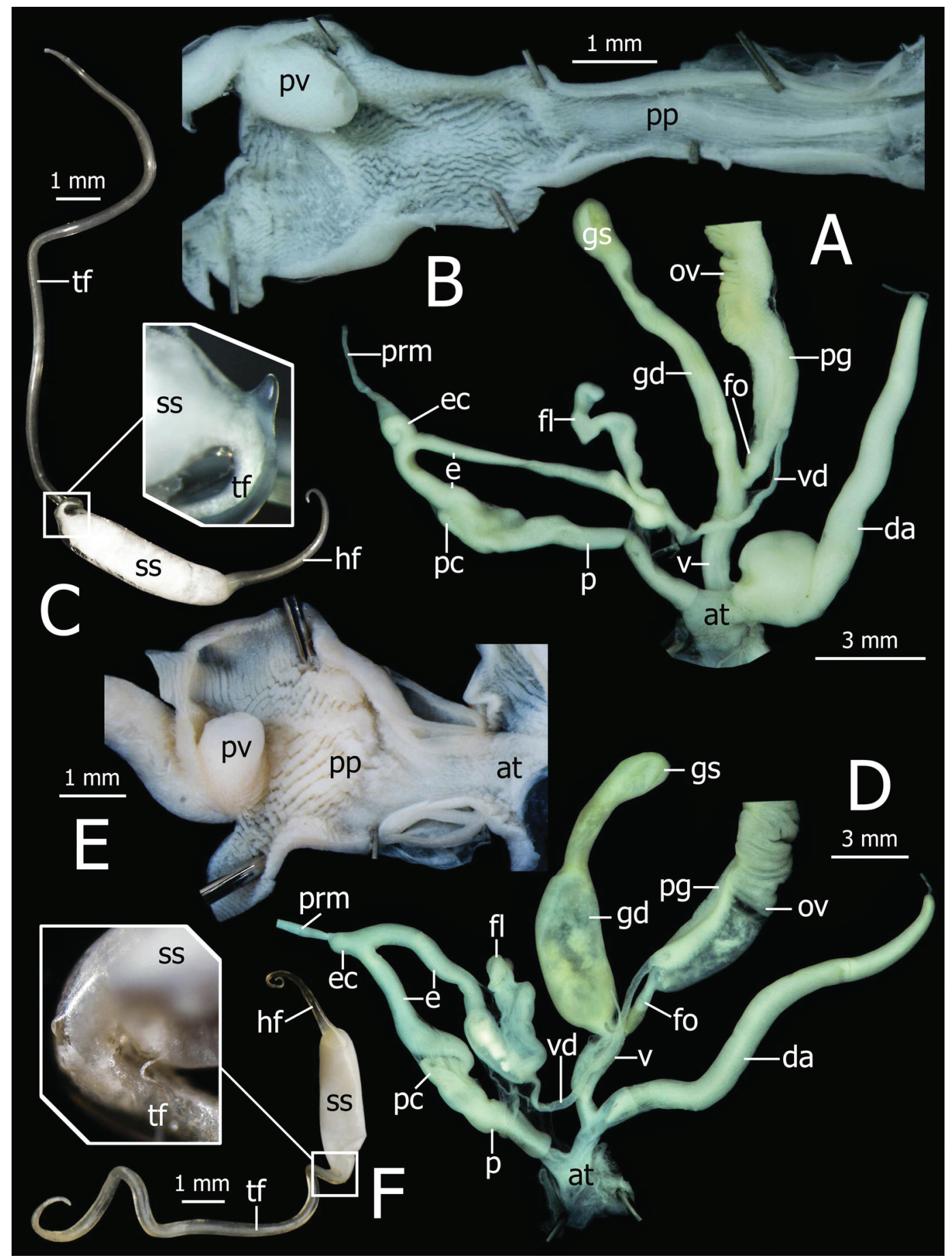

FIgURE $7 \quad$ Genitalia and spermatophore. A-C. Taphrenalla asamurai specimen CUMZ 7153. A. whole reproductive system. B. internal wall of penis with penial verge. C. spermatophore; inset showing one spine located close to the sperm sac. D-F. T. macrosulcata sp. nov. paratype CUMZ 7162. D. whole reproductive system. E. internal wall of penis with penial verge. F. spermatophore; inset showing one spine located close to the sperm sac. 
Spermatophore with one spine on tail filament close to sperm sac.

\section{Description}

Shell (fig. 6B). Shell comparatively depressed conic, medium-sized (width up to $18.7 \mathrm{~mm}$; height up to $9.8 \mathrm{~mm}$ ) and pale brown. Whorls $5^{-6}$; suture deep and narrow impressed. Upper shell surface with strong and long radial grooves continuing from suture, gradually inconspicuous and then disappear below periphery. Radial grooves starting between whorl 3 to 4 and with $42-58$ grooves at last whorl ( $n=24$; fig. 5 ). Spire depressed conic; apex raised with a spire angle of about $143-164^{\circ}$. Last whorl shouldered and well-rounded at periphery. Aperture lip simple; umbilicus narrowly opened.

Genital organs (figs ${ }_{7} \mathrm{D}-\mathrm{F}$ ). Atrium short. Penis elongate cylindrical and same length as total vagina length; penial caecum present. Inner sculpture of proximal penial wall has very fine wrinkled, longitudinal penial pilasters, with thick and oblique longitudinal folds in middle, and then transformed to a thin, transverse-folded, surrounded penial verge. Epiphallus slender tube and about two times total penis length. Epiphallic caecum very short; thick penial retractor muscle attached at tip. Flagellum large and irregular slender tube. Vas deferens thin tube. Vagina long and cylindrical tube. Dart apparatus located on vagina away from penis joining to atrium. Spermatophore long and needle-shaped. Tail filament very long tube; region close to sperm sac bearing a very small spine.

External features (fig. 3). Animal dark gray mixed with pale yellow on head and body and monochrome bright yellowish on tail.

Remarks. Taphrenalla macrosulcata sp. nov. is similar to T. asamurai in shell morphology but can be differentiated by a paler brown shell and a pale yellowish soft body. Whereas, T. asamurai has a dark brown shell and reddish to dark red soft body.
Regarding the genital anatomy, this new species has a short flagellum, straight epiphallic caecum, and dart apparatus connecting to the vagina away from the penis junction and without thick connective tissue surrounding the proximal end. For comparison, T. asamurai has a long flagellum, bent epiphallic caecum, and dart apparatus located opposite the penis junction and with thick connective tissue at the proximal end.

The presence of one spine on the tail filament of the spermatophore is the remarkable character of T. macrosulcata sp. nov. and T. asamurai, while other Taphrenalla species have two spines.

Taphrenalla diadema (Dall, 1897)

(figs 1, 3, 5, 8A-C, 9A-C, table 6)

Nanina (Macrochlamys) diadema Dall, 1897: 37-38. Type locality: Prang, Malay Peninsula; Dall, 1902: 499, pl. 27 figs 1-3; Boss, Rosewater, \& Ruhoff, 1968: 104.

Macrochlamys diadema: Gude, 1903: 50.

Syama diadema: Abbott, 1989: 23, 133 (text figure); Panha, 1996: 102-104, fig. 2b2 (Holotype, USNM 150277); Maneevong, 2000: 28-29, fig. 4-2.

Sarika diadema: Sutcharit \& Panha, 2008: 95-100, figs $2 a, b, 3 a-e, 4 a-c$.

Material examined. Type material: holotype USNM 150277. Non-type material: Wat Khuha Santayaram (Wat Tham Khao Daeng), Ron Phibun District, Nakhon Si Thammarat $\left(8^{\circ} 14^{\prime} 39.5\right.$ "N 99 ${ }^{\circ} 2^{\prime}$ 'Oo.1”E): CUMZ 7164 (one specimen in ethanol). Tham Talot, Thung Song District, Nakhon Si Thammarat ( $8^{\circ} \circ 9^{\prime} 32.3^{\prime \prime} \mathrm{N} 99^{\circ} 40^{\prime} 41.6$ "E): CUMZ 7165 (16 shells and three specimens in ethanol). Tham Rad, Thung Song District, Nakhon Si Thammarat (8॰ $\left.{ }^{\circ} 47.2^{\prime \prime} \mathrm{N} 99^{\circ} 43^{\prime} 45.0^{\prime \prime} \mathrm{E}\right)$ : CUMZ 7166 (10 shells) and CUMZ 7167 (11 specimens in ethanol). Wat Tham Phraphut, Ratsada District, Trang ( $7^{\circ} 57^{\prime} 57 \cdot 3^{\prime \prime} \mathrm{N} \quad 99^{\circ} 44^{\prime} 41.3^{\prime \prime}$ ): CUMZ 7168 (four shells and two specimens in ethanol). Tham Chang Hai, Mueang District, Trang $\left(7^{\circ} 35^{\prime} 26.6^{\prime \prime} \mathrm{N}\right.$ $99^{\circ} 40^{\prime} \circ 5 \cdot 3^{\prime \prime E}$ ): CUMZ 7169 (nine shells) and CUMZ 


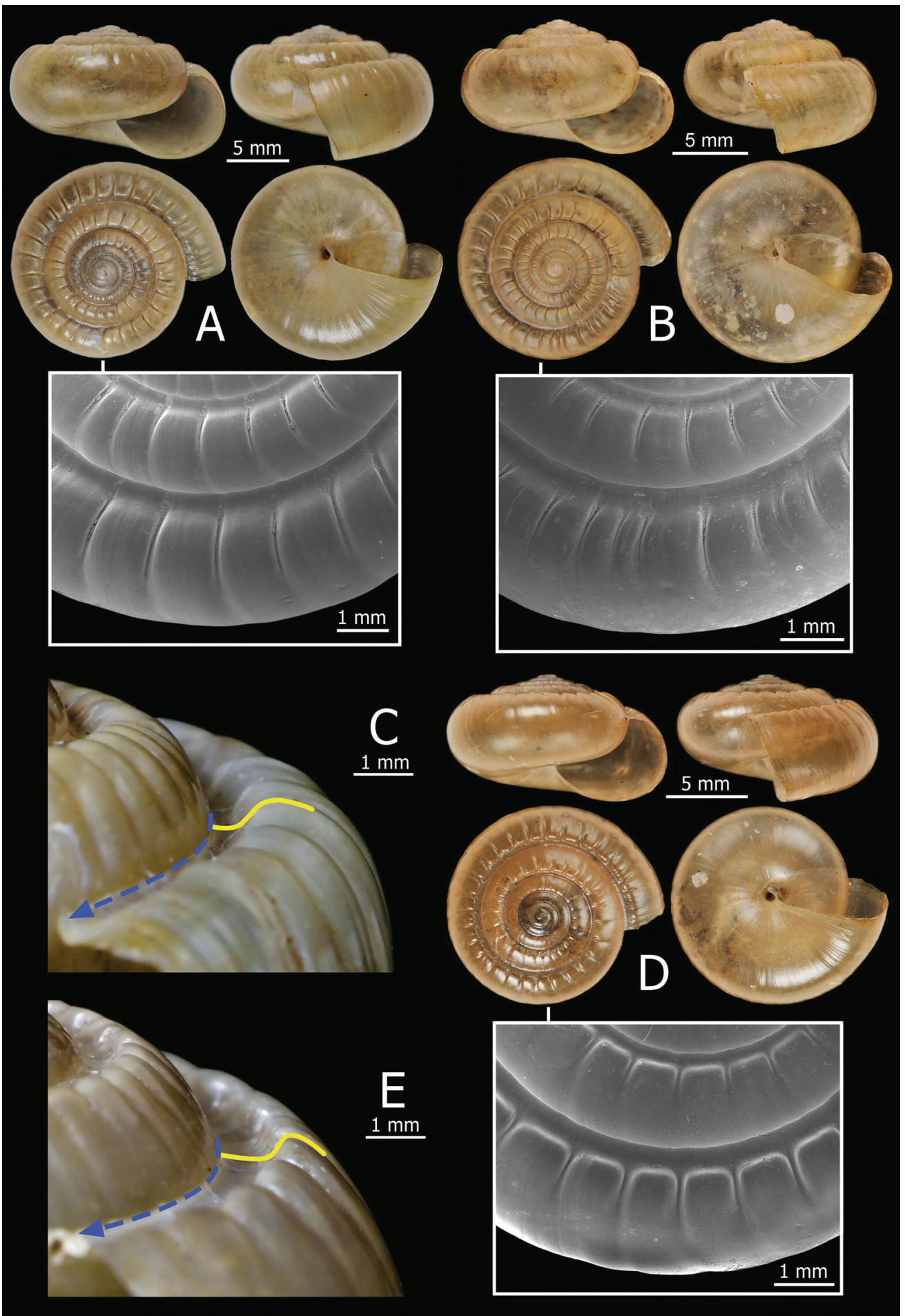

FIGURE 8 Shells. A-C. Taphrenalla diadema. A. specimen CUMZ 7175. B. specimen CUMZ 7177. C. specimen CUMZ 717 showing channel-shaped suture with wide bottom. D, E. T. dalli sp. nov. D. holotype CUMZ 7183. E. specimen CUMZ 7189 showing channel-shaped suture with very wide bottom. Inset SEM image showing shell sculpture of each species. 


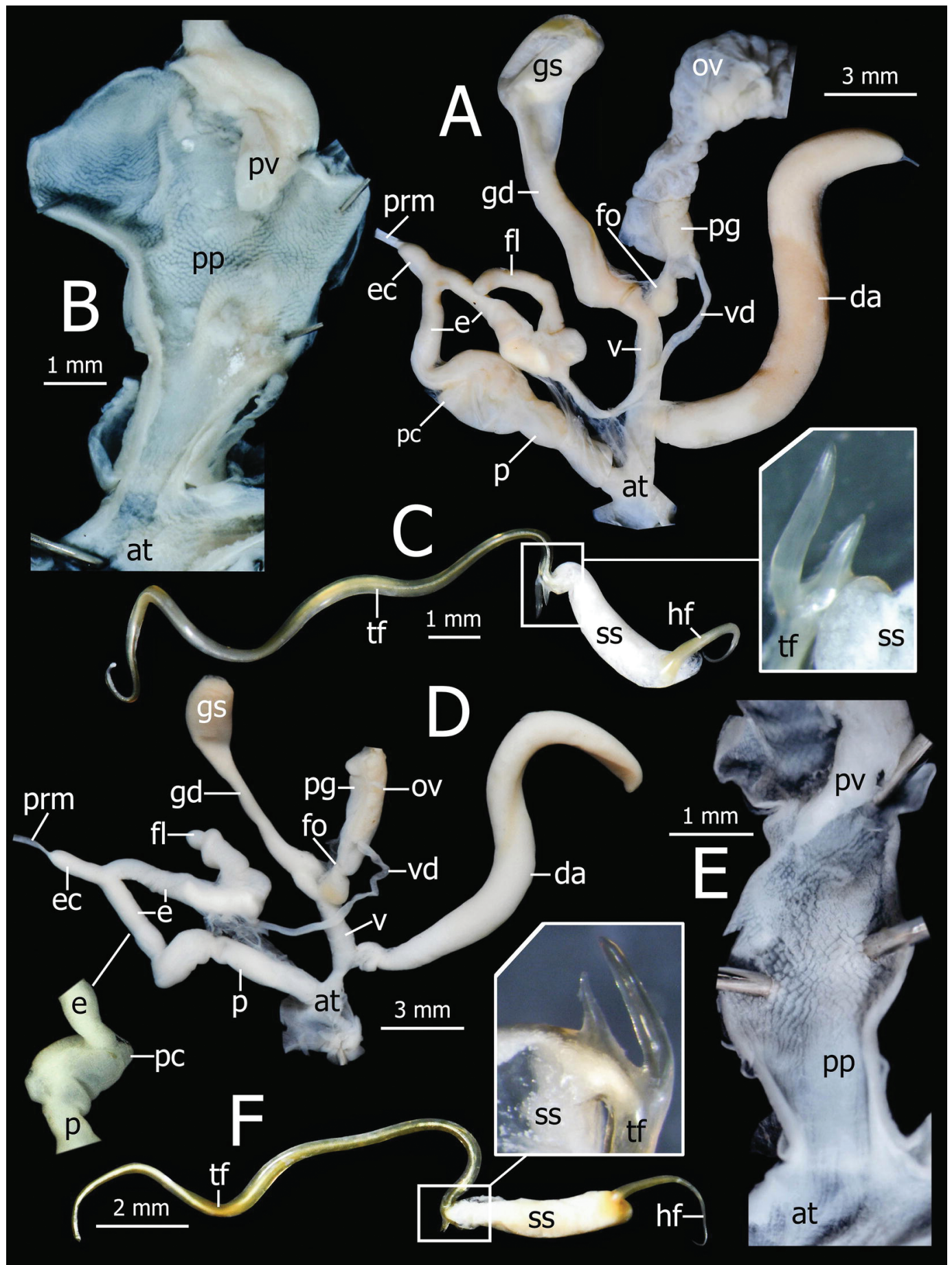

FIgURE 9 Genitalia and spermatophore. A-C. Taphrenalla diadema specimen CUMZ 718o. A. whole reproductive system, B, internal wall of penis with penial verge. C. spermatophore; inset showing two spines located close to sperm sac. D-F. T. dalli sp. nov. paratype CUMZ 7184. D. whole reproductive system; inset showing a small penial caecum. E. internal wall of penis with penial verge. F. spermatophore of T. dalli sp. nov. specimen CUMZ 7186; inset showing two spines located close to the sperm sac. 
7170 (two shells). Khao Pu Chao Bureau of Monks, Na Yong District, Trang ( $7^{\circ} 333^{\prime} 53.0^{\prime \prime} \mathrm{N} 99^{\circ} 46^{\prime}{ }_{3} 6.2$ 'E): CUMZ 7171 (fig. 8C; 18 shells) and CUMZ 7172 (four shells). Wat Khao Huai Haeng, Huai Yot District, Trang ( $\left.7^{\circ} 47^{\prime} 36.5^{\prime \prime} \mathrm{N} \quad 99^{\circ} 3^{\prime} 37.0^{\prime \prime} \mathrm{E}\right)$ : CUMZ 7173 (16 specimens in ethanol). Wat Tham Sumano, Srinagarindra District, Phatthalung $\left(7^{\circ} 35^{\prime} 14.0^{\prime \prime} \mathrm{N}\right.$ $99^{\circ} 52^{\prime} \circ 6.8$ "E): CUMZ 7174 (10 specimens in ethanol) and CUMZ 7175 (fig. 8A; four shells and 33 specimens in ethanol). Khao Ok Talu Khuha Sawan, Mueang District, Phatthalung ( $7^{\circ} 37^{\prime} 33 \cdot 7^{\prime \prime} \mathrm{N}$ $100^{\circ} 05^{\prime 23.7 " E): ~ C U M Z ~} 7176$ (three shells) and CUMZ 7177 (fig. 8B; 55 shells and 18 specimens in ethanol). Wat Khuha Sawan, Mueang District, Phatthalung ( $7^{\circ} 37^{\prime} 15.0^{\prime \prime} \mathrm{N} 100^{\circ} 04^{\prime} 48.7^{\prime \prime E}$ ): CUMZ 7178 (one shell). Tham Phaya Hong, Kong Ra District, Phatthalung $\left(7^{\circ} 27^{\prime} 48.4^{\prime \prime} \mathrm{N} 99^{\circ} 57^{\prime} 53 \cdot 3^{\prime \prime} \mathrm{E}\right)$ : CUMZ 7179 ( 36 shells) and CUMZ 7180 (22 shells and 137 specimens in ethanol). Limestone outcrops at Khlong Chaloem, Kong Ra District, Phatthalung ( $\left.{ }^{\circ} 23^{\prime} 50.6^{\prime \prime} \mathrm{N} \quad 99^{\circ} 5^{\prime} 45 \cdot 2^{\prime \prime E}\right)$ : CUMZ 7181 (five shells and 31 specimens in ethanol). Tham Phra Non, Mueang District, Phatthalung ( $7^{\circ} 40^{\prime} 52.1^{\prime \prime} \mathrm{N}$ 100 ${ }^{\circ} 3^{\prime} 42.4 " \mathrm{E}$ ): CUMZ 7182 (10 shells).

Remarks. Taphrenalla diadema had been recently re-described and illustrated by Sutcharit \& Panha (2008). The distinguishing characters are a depressed conic shell, medium-sized (width up to $17.8 \mathrm{~mm}$; height up to $10.6 \mathrm{~mm}$ ), a wide and deep channel-shaped suture, and short radial grooves appeared on last about 24-43 grooves ( $\mathrm{n}=39$; figs $5,8 \mathrm{~A}-\mathrm{C})$. The genitalia have a short and straight epiphallic caecum, and dart apparatus located on vagina away from vagina and penis junction (figs 9A, B). Spermatophore has one short spine on tail filament close to sperm sac (fig. 9C). Living snail has yellowish stripes on head and tail (fig. 3).

The specimens from Khao Ok Talu, Phatthalung Province (fig. 8B) tended to have a smaller diameter and shallower radial grooves than the other populations (figs 8A, C). However, all the genital characters and spermatophores from all localities appear to be identical. In addition, the molecular data also confirmed that the shell variations were all grouped within the T. diadema clade.

Taphrenalla dalli Pholyotha \& Panha, sp. nov. (figs 1, 3, 5, 8D, E, 9D-F, table 6)

Type material examined. Holotype: CUMZ 7183 (fig. 8D). Paratypes. Same data as holotype: CUMZ 7184 (31 shells and nine specimens in ethanol), CUMZ 7188 (one shell), NHMUK (two shells) and SMF (two shells).

Other material examined. Wat Khiri Rat Phatthana, Wiang Sa District, Surat Thani $\left(8^{\circ} 31^{\prime} 36.5^{\prime \prime} \mathrm{N} \quad 99^{\circ} 23^{\prime}\right.$ oo.2"E): CUMZ $7185 \quad(63$ shells and 88 specimens in ethanol). Wat $\mathrm{Na}$ San, Ban Na San District, Surat Thani, Thailand (848'30.7”N 99 22'16.1”E): CUMZ 7186 (four shells and 11 specimens in ethanol) and CUMZ 7187 (11 shells and 24 specimens in ethanol). Wat Tham Kanlayanamit, Tham Phannara District, Nakhon Si Thammarat ( $8^{\circ} 30^{\prime} 49.3^{\prime \prime} \mathrm{N}$ 99 ${ }^{\circ} 22^{\prime} 53.9$ "E): CUMZ 7189 (fig 8E; 39 shells and 27 specimens in ethanol). Wat Tham Thong Panara, Tham Phannara District, Nakhon Si Thammarat $\left(8^{\circ} 25^{\prime} 19.1{ }^{\prime \prime} \mathrm{N} 99^{\circ}{ }^{22}\right.$ '48.4"E): CUMZ 719 o (20 shells and one specimen in ethanol).

Type locality. Limestone outcrop at Tham Lord, Nopphitam District, Nakhon Si Thammarat, Thailand $\left(8^{\circ} 47^{\prime} 16.7^{\prime \prime} \mathrm{N} 99^{\circ} 3^{\prime} 29.9^{\prime \prime} \mathrm{E}\right)$.

Etymology. This species is named after William Healey Dall, an American malacologist, who discovered the first species of Crown Snail, T. diadema.

Diagnosis. Shell with a very wide channel-shaped suture and with deep and short radial grooves. Epiphallic caecum straight. Penial caecum very short. Inner sculpture of proximal penis with very small, irregular and longitudinal folds, and then with obliquely and wrinkled to very fine pilasters distally. Dart apparatus connected on vagina. 
Spermatophore with two spines on tail filament close to sperm sac.

\section{Description}

Shell (figs 8D, E). Shell depressed conic to globosely depressed, medium-sized (width up to $18.3 \mathrm{~mm}$; height up to $11.3 \mathrm{~mm}$ ) and pale to dark brown. Whorls $5^{-6}$; suture very wide, deep and channeled-shape. Upper shell surface with strong and short radial grooves continuing from suture to inconspicuous at periphery and then disappear below periphery. Radial grooves beginning between whorl 3 to 4 and having 23-37 grooves at last whorl ( $\mathrm{n}=33$; fig. 5$)$. Spire depressed conic; apex raised with a spire angle of about $135^{-155^{\circ}}$. Last whorl shouldered and well-rounded at periphery. Aperture lip simple; umbilicus narrowly opened.

Genital organs (figs 9D-F). Atrium slightly short. Penis elongate cylindrical and nearly two times that of total vagina length; penial caecum present. Inner sculpture of proximal penial wall supported by penial pilasters starting proximally with very small irregular longitudinal folds, then gradually, obliquely, wrinkled pilasters in middle, to very fine pilasters surrounding penial verge. Epiphallus slender tube, approximately one and a half times total penis length. Epiphallic caecum slightly prolonged, and attached with thick penial retractor muscle (prm). Flagellum enlarged at base and tapering with irregular shape to tip. Vas deferens slender tube. Vagina long and cylindrical tube. Dart apparatus located on proximal vagina away from penis joining to atrium. Spermatophore long and needle-shaped. Tail filament very long tube; region close to sperm sac bearing two spines; spine close to sperm sac shorter than the other.

External features (fig. 3). Animal dark gray in body colour with three pale orange stripes running from head to caudal horn. One stripe at middle of the body and others two stripes on side of body close to foot sole; stripes on tail wider than anterior.
Remarks. Shell morphology of this new species looks similar to T. diadema, but can be distinguished by having a wider base of the suture than in T. diadema. In comparison, $T$. dalli sp. nov. shows a small penial caecum, shorter flagellum, and large and coarse penial sculpture pilaster at the middle of penis. Whereas, T. diadema has a large penial caecum, longer flagellum, and inner wall of penis is sculptured with very fine wrinkled pilasters. In addition, the penial sculpture at the middle of the penis of T. dalli sp. nov. has larger, more obliquely wrinkled pilasters than $T$. diadema.

This new species shows variation in size and shell sculpture, the like of which also appears in T. diadema. However, the shell suture and genitalia of all variants are identical, and are also clustered together in the $T$. dalli clade in the molecular analysis.

Taphrenalla corona Pholyotha \& Panha, sp. nov. (figs 1, 3, 5, 10A, 11A-C, table 6)

Type material examined. Holotype: CUMZ 7191 (fig. 10A). Paratypes. Same data as holotype: CUMZ 7192 (two shells and nine specimens in ethanol), CUMZ 7193 (21 shells), CUMZ 7194 (one specimen in ethanol), NHMUK (two shells), and SMF (two shells).

Other material examined. Limestone outcrops at Ao Luek Tai, Ao Luek District, Krabi $\left(8^{\circ} 24^{\prime}\right.$ 'og.9"N, 98 $8^{\circ} 4^{\prime} 16.3^{\prime \prime E}$ ): CUMZ 7195 (five specimens in ethanol). Tham Sa Yuan Thong, Ao Luek District, Krabi $\left(8^{\circ} 21^{\prime} 44.6^{\prime \prime} \mathrm{N}, 98^{\circ} 44^{\prime} 45.9^{\prime \prime} \mathrm{E}\right)$ : CUMZ 7196 (one shell). Tham Phet, Ao Luek District, Krabi $\left(8^{\circ} 23^{\prime} 33.9^{\prime \prime} \mathrm{N}, \quad 98^{\circ} 46^{\prime} 24.0^{\prime \prime} \mathrm{E}\right)$ : CUMZ 7197 (one shell). Wat Khao Hua Sing, Plai Phraya District, Krabi ( $\left.8^{\circ} 30^{\prime} 47 \cdot 7^{\prime \prime} \mathrm{N} 98^{\circ} 45^{\prime} 30.1^{\prime \prime E}\right)$ : CUMZ 7198 (29 shells). Tham Nalakiring Bureau of Monks, Plai Phraya District, Krabi ( $8^{\circ} 33$ '35.3” $\left.3^{\prime} 8^{\circ} 51^{\prime} 37 \cdot 5^{\prime \prime} \mathrm{E}\right)$ : CUMZ 7225 (eight shells and three specimens in ethanol). Wat Khao Phra, Phrasaeng District, Surat Thani $\left(8^{\circ} 37^{\prime} 33.0^{\prime \prime} \mathrm{N} 98^{\circ} 56^{\prime} 53.5^{\prime \prime} \mathrm{E}\right)$ : CUMZ 


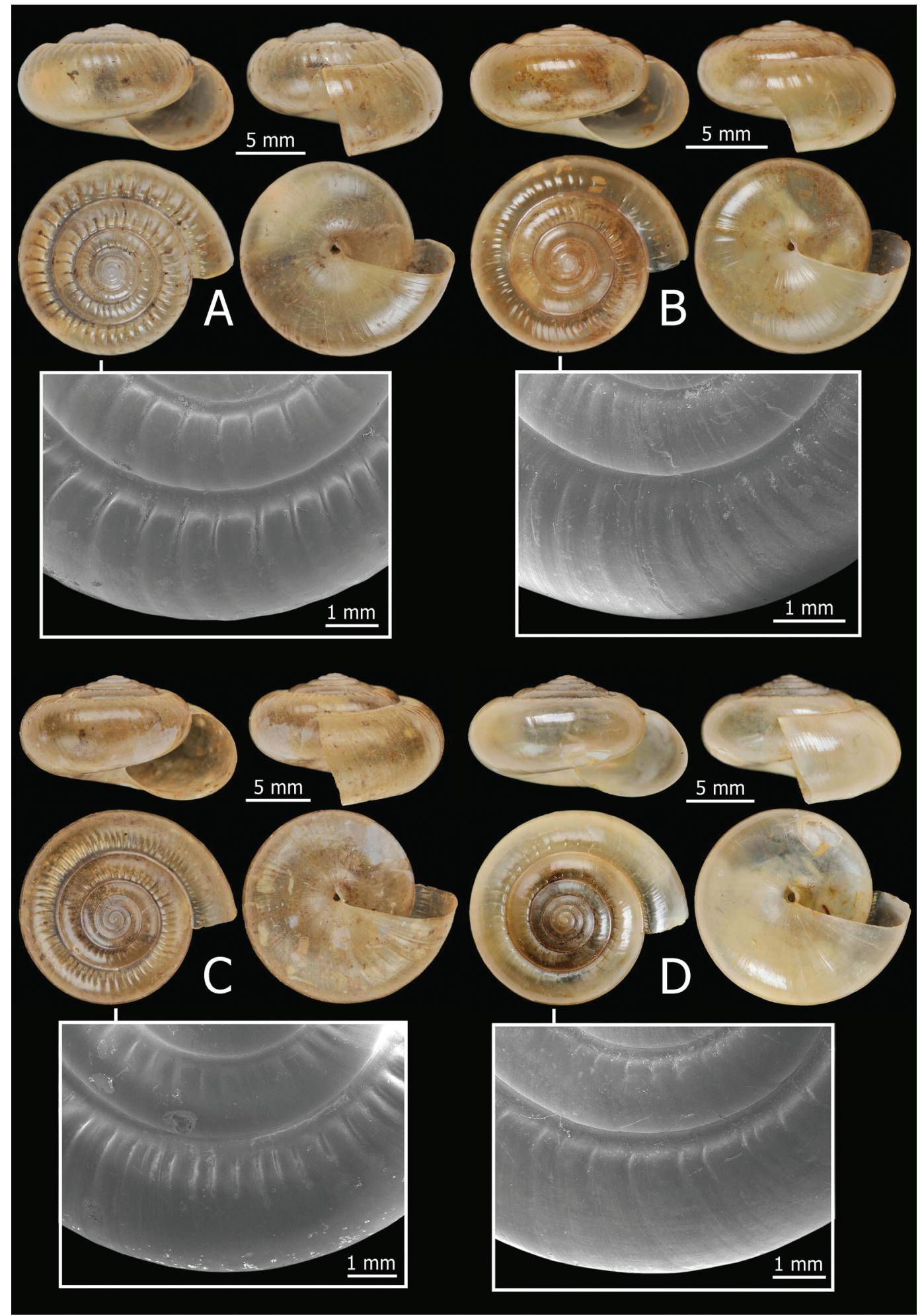

FIGURE 10 Shells. A. Taphrenalla corona sp. nov. holotype CUMZ 7191. B. T. parversa sp. nov. holotype CUMZ 7199. C. T. conformis sp. nov. holotype CUMZ 7202. D. Taphrenalla incilis sp. nov. holotype CUMZ 7207. Inset SEM image showing shell sculpture of each species. 


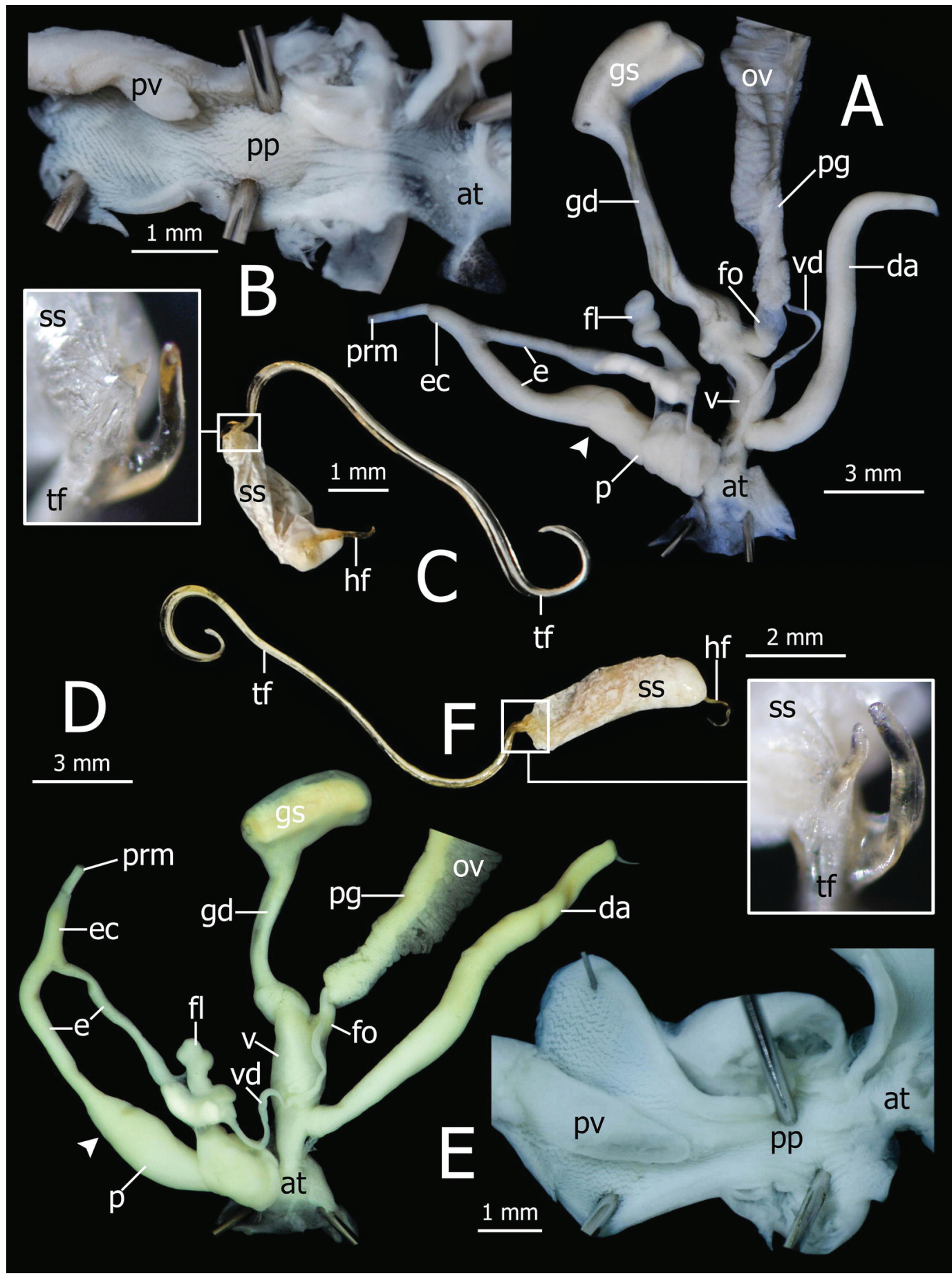

FigurE 11 Genitalia and spermatophore. A-C. Taphrenalla corona sp. nov. paratype CUMZ 7192. A. whole reproductive system. B. internal wall of penis with penial verge. C. spermatophore; inset showing two spines located close to the sperm sac. D-F. T. parversa sp. nov. paratype CUMZ 720o. D. whole reproductive system. E. internal wall of penis with penial verge. F. spermatophore; inset showing two spines located close to the sperm sac. White arrowheads indicate the position of penial verge. 
7226 ( 15 shells). Tham Namlod Bureau of Monks, Phrasaeng District, Surat Thani $\left(8^{\circ} 40^{\prime} 40.2^{\prime \prime N}\right.$ $9^{\circ} 5^{\circ} 6^{\prime} 41.9$ "E): CUMZ 7227 (six shells).

Type locality. Limestone outcrops near Than Bok Khorani, Ao Luek District, Krabi, Thailand $\left(8^{\circ} 22^{\prime} 28.7^{\prime \prime} \mathrm{N} 98^{\circ} 44^{\prime} \mathrm{O} 7.9^{\prime \prime} \mathrm{E}\right)$.

Etymology. The specific epithet "corona" is from the Latin word "corona" meaning "crown" and is in reference to the characteristic radial grooves on the shell sculpture of this genus.

Diagnosis. Shell with wide channel-shaped suture, and slightly deep and short radial grooves. Penis with thick penial sheath. Penial caecum absent. Epiphallic caecum straight. Inner sculpture of proximal penis with fine irregular longitudinal folds and then with obliquely longitudinal folds distally. Dart apparatus connected on vagina. Spermatophore with two spines on tail filament close to sperm sac.

\section{Description}

Shell (fig. 10A). Shell depressed conic, medium-sized (width up to $16.0 \mathrm{~mm}$; height up to 9.3 $\mathrm{mm}$ ) and slightly milky to brownish. Whorl $5^{-6}$; suture wide and deep groove, channel-shaped. Upper shell surface with rather strong and short radial grooves continuing from suture to inconspicuous at periphery and disappears below periphery. Radial grooves starting between whorl 3 to 4 and having $26-47$ grooves at last whorl (n = 26; fig. 5). Spire slightly depressed conic; apex raised with a spire angle of about $140-155^{\circ}$. Last whorl barely shouldered and well-rounded at periphery. Aperture lip simple; umbilicus narrowly opened.

Genital organs (figs $11 \mathrm{~A}-\mathrm{C}$ ). Atrium short. Penis enlarge cylindrical and same length as vagina; penial caecum absent. Inner sculpture of proximal penis with fine irregularly longitudinal penial pilasters, gradually transforming to obliquely longitudinal folds surrounding penial verge. Epiphallus slender tube, about two and a half times total penis length and smaller diameter than penis. Epiphallic caecum short, and attached with thick penial retractor muscle. Flagellum prolonged with irregular cylindrical tip. Vas deferens slim tube. Vagina prolonged, cylindrical-shaped and distal part larger diameter than proximal part. Dart apparatus located on proximal vagina away from penis joining to atrium. Spermatophore long and needle-shaped. Tail filament very long tube; region near sperm sac bearing two spines, spine close to sperm sac very small and shorter than the other.

External features (fig. 3). Animal very dark gray in body colour with one creamy to pale orange stripe in middle of body running from head to caudal horn; stripe on tail wider than on body to head.

Remarks. Although the shell morphology of this new species is close to those of T. diadema and $T$. dalli sp. nov., its genitalia is unique. The absence of a penial caecum and presence of a thick penial sheath covering a proximal portion of penis distinguished T. corona sp. nov. from the other Taphrenalla species.

Taphrenalla parversa Pholyotha \& Panha, sp. nov. (figs 1, 3, 10B, 11D-F, table 6)

Type material examined. Holotype: CUMZ 7199 (fig. 10B). Paratypes. Same data as holotype: CUMZ 7200 (one shell and five specimens in ethanol), CUMZ 7201 (five shells), NHMUK (two shells), and SMF (two shells).

Type locality. Tham Suwan Khuha, Takua Thung District, Phang-nga, Thailand $\left(8^{\circ} 25^{\prime} 45.0^{\prime \prime} \mathrm{N}\right.$, $\left.98^{\circ} 28^{\prime} 19 \cdot 6^{\prime \prime} \mathrm{E}\right)$.

Etymology. This species is derived from 'parv' (the Latin word 'parvus') meaning 'little' and 'versa' 
(the Latin word 'versus') meaning 'line, furrow' with reference to the characteristic numerous little radial grooves on the shell sculpture.

Diagnosis. Shell with shallowly impressed suture and very weakly radial grooves. Penis with thick penial sheath. Penial caecum absent. Epiphallic caecum straight. Inner sculpture of proximal penis with fine, irregular and longitudinal folds, and then trasition to irregular and zig-zag, longitudinal folds distally. Dart apparatus connected on vagina. Spermatophore with two spines on tail filament close to sperm sac.

\section{Description}

Shell (fig. 10B). Shell comparatively depressed conic, medium-sized (width up to $14.4 \mathrm{~mm}$; height up to $8.1 \mathrm{~mm}$ ) and pale brown. Whorls $5^{-6}$; suture shallowly impressed. Upper shell surface with numerous weak radial grooves continuing from suture and disappear before periphery. Spire depressed conic; apex raised with a spire angle of about $142-164^{\circ}$. Last whorl barely shouldered and rounded periphery. Aperture lip simple; umbilicus narrowly opened.

Genital organs (figs $11 \mathrm{D}-\mathrm{F}$ ). Atrium very short. Penis stout cylindrical and about same length as vagina; penial caecum absent. Inner sculpture of proximal penial wall with fine irregular longitudinal penial pilasters and then gradually irregular, zig-zag, longitudinal folds in middle and surrounded penial verge. Epiphallus slender tube, around two times total penis length, and smaller diameter than penis; proximal epiphallus larger than distal portion. Epiphallic caecum short, same diameter as proximal epiphallus, and attached with thick penial retractor muscle. Flagellum short with irregular shape. Vas deferens small tube. Vagina very enlarged, cylindrical-shaped, and distal part enlarged. Dart apparatus located on proximal vagina away from penis joining to atrium. Spermatophore elongate and needle-shaped. Tail filament very long tube; region close to sperm sac bearing two spines; spine located close to sperm sac smaller and shorter than the other.

External features (fig. 3). Animal dark gray colour on head to body with three bright orange stripes running from head to body (two stripes near foot sole and one at middle of body), and then gradually only bright orange stripes on body to tail.

Remarks. Taphrenalla parversa sp. nov. is similar to T. corona sp. nov. because of the absence of the penial caecum and a thick penial sheath. However, they can be discriminated by their flagellum, epiphallus, vagina, and shell morphology. Taphrenalla parversa sp. nov. has a shorter flagellum, longer epiphallus, and larger vagina than T. corona sp. nov. In shell comparison, T. parversa sp. nov. has a weakly impressed suture and very weakly radial grooves on the shell sculpture, whereas T. corona sp. nov. exhibits a wide and deep groove at suture and deep radial grooves on the shell sculpture.

Taphrenalla conformis Pholyotha \& Panha, sp. nov. (figs 1, 3, 10C, 12A-C, table 6)

Type material examined. Holotype: CUMZ 7202 (fig. ${ }_{10 C}$ ). Paratypes. Same data as holotype: CUMZ 7203 ( 15 shells and 52 specimens in ethanol), CUMZ 723 O (three specimens in ethanol), CUMZ 7204 (eight specimens in ethanol), CUMZ 7205 (11 shells and six specimens in ethanol), CUMZ 7206 (24 specimens in ethanol), NHMUK (two shells), and SMF (two shells).

Type locality. Tham Phung Chang, Mueang District, Phang-nga, Thailand $\left(8^{\circ} 26^{\prime} 33.0^{\prime \prime} \mathrm{N}, 98^{\circ} 30^{\prime} 55 \cdot 4^{\prime \prime} \mathrm{E}\right)$.

Etymology. The specific name is from the Latin 'conformis' meaning "like" or "similar" and name refers to the new species possessing a superficially similar shell to T. parversa sp. nov. 


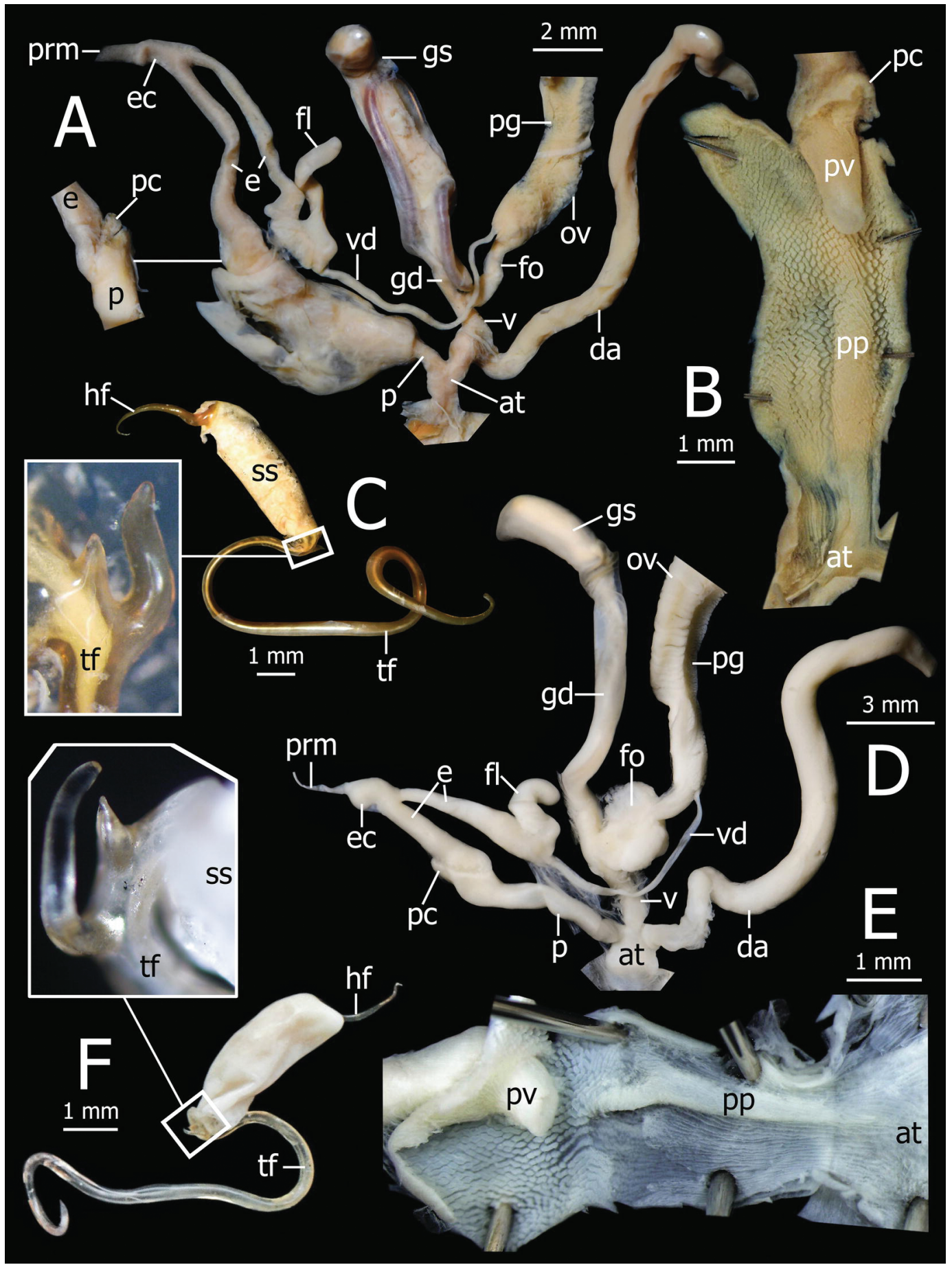

FigurE 12 Genitalia and spermatophore. A-C. Taphrenalla conformis sp. nov. paratype CUMZ 723o. A. whole reproductive system; inset showing a small penial caecum. B. internal wall of penis with penial verge. C. spermatophore; inset showing two spines located close to thesperm sac. D-F. T. incilis sp. nov. paratype CUMZ 7208. D. whole reproductive system. E. internal wall of penis with penial verge. F. spermatophore; inset showing two spines located close to the sperm sac. 
Diagnosis. Shell having shallowly impressed suture, weakly radial grooves. Penis covered with thick penial sheath. Epiphallic caecum short and bent at tip. Penial caecum short. Inner sculpture of proximal penis with very small longitudinal folds; distally narrow and obliquely cuboidal folds. Dart apparatus connected on vagina. Spermatophore with two spines on tail filament close to sperm sac.

\section{Description}

Shell (fig. 10C). Shell comparatively depressed conic, medium-sized (width up to $17.7 \mathrm{~mm}$; height up to $10.3 \mathrm{~mm}$ ) and pale brown. Whorls $5^{-6}$; suture shallowly impressed. Upper shell surface with numerous weak radial grooves continuing from suture to gradually disappear before periphery. Spire depressed conic; apex raised with a spire angle of about $138-148^{\circ}$. Last whorl well-rounded periphery. Aperture lip simple; umbilicus narrowly opened.

Genital organs (figs 12A-C). Atrium slightly prolonged. Penis cylindrical and nearly three times total vagina length; penial caecum present. Inner sculpture of proximal penis with small longitudinal folds; distal portion with narrow obliquely cuboidal pilasters, then reduced in size and surrounding penial verge. Epiphallus slender tube, around two times total penis length and smaller diameter than penis. Epiphallic caecum short and bent at the tip; thick penial retractor muscle connecting near the tip. Flagellum short, tapering and irregular slender tube. Vas deferens thin tube. Vagina long and cylindrical-shaped. Dart apparatus located near proximal vagina away from penis join to atrium. Spermatophore long and needle-shaped. Tail filament very long tube; region close to sperm sac bearing two spines; spine close to sperm sac small and shorter than the other.

External features (fig. 3). Animal dark gray in body colour with three pale milky yellow stripes running from head to caudal horn. One stripe at middle of the body and other two stripes above foot sole.
Remarks. Shell characters in T. conformis sp. nov. and $T$. parversa sp. nov. are very similar. They have a weakly impressed suture and weakly radial grooves on shell sculpture. However, the body colouration and reproductive organ can be used to separate them. In T. conformis sp. nov., the body has three pale milky-yellow bands running from the head to caudal horn, and the genitalia have a penial caecum. Whereas, the body colouration of T. parversa sp. nov. contains three bright orange stripes running from head to body, and only bright orange stripes on the body to tail. The genitalia of T. parversa sp. nov. do not have a penial caecum.

Taphrenalla incilis Pholyotha \& Panha, sp. nov. (figs 1, 3, 10D, 12D-F, table 6)

Type material examined. Holotype: CUMZ 7207 (fig. 10D). Paratypes. Same data as holotype: CUMZ 7208 (four shells and five specimens in ethanol), CUMZ 7209 (six shells and six specimens in ethanol), NHMUK (two shells), and SMF (two shells).

Type locality. Tham Khao Ting, Palian District, Trang, Thailand ( $7^{\circ} \circ 9^{\prime} 3$ o.o"N, $\left.99^{\circ} 48^{\prime} \circ 6.0^{\prime \prime} \mathrm{E}\right)$.

Etymology. The specific epithet "incilis" is from the Latin word "incile" meaning "ditch, trench", which referrs to the characteristic small radial grooves in the shell sculpture.

Diagnosis. Shell with narrow and deep channel-shaped suture, and weak and short radial grooves. Epiphallic caecum short and bent at tip. Penial caecum short. Inner sculpture of proximal penis with very small longitudinal folds; distally narrow and obliquely cuboidal folds. Dart apparatus located at vagina and penis junction. Spermatophore with two spines on tail filament close to sperm sac.

\section{Description}

Shell (fig. 1oD). Shell comparatively depressed conic, moderate-sized (width up to $16.1 \mathrm{~mm}$; height 
up to $8.8 \mathrm{~mm}$ ) and pale to dark brown. Whorls $5^{-6}$; suture narrow, deep grooved, and channel-shaped. Upper shell surface with numerous, very short and weak radial grooves near suture and then suddenly disappear. Spire depressed conic; apex raised with a spire angle of about $134-151^{\circ}$. Last whorl barely shouldered, and periphery almost rounded. Aperture lip simple; ummbilicus narrowly opened.

Genital organs (figs 12D-F). Atrium short. Penis cylindrical and around three times total vagina length; penial caecum present. Inner sculpture of proximal and middle part of penis with fine longitudinal folds; distal portion with narrow obliquely cuboidal penial pilasters surrounding penial verge. Epiphallus slender tube and slightly longer than penis. Epiphallic caecum short and bent at tip; thick penial retractor muscle connecting near the tip. Flagellum short, irregular curved and with obtuse tip. Vas deferens thin tube. Vagina prolonged, cylindrical-shaped. Dart apparatus located at junction of vagina and penis. Spermatophore long and needle-shaped. Tail filament very long tube; region close to sperm sac bearing two spines; spine near sperm sac very small and shorter than the other.

External features (fig. 3). Animal dark gray in body colour with a pale milky yellow stripe at middle of the body running from head to caudal horn. Posterior part (body to tail) with pale milky yellow colour and wider stripe than anterior part (head to body).

Remarks. The weak radial grooves on the upper shell surface of T. incilis sp. nov. is similar to T. parversa sp. nov., T. conformis sp. nov., and T. pygmaea sp. nov. However, together with the suture shape and genitalia, T. incilis sp. nov. have a deeper and wider suture than T. parversa sp. nov. and T. conformis sp. nov. The dart apparatus of T. parversa sp. nov. and T. conformis sp. nov. is located on the proximal vagina away from the penis junction, while T. incilis sp. nov. has the dart apparatus joining at the junction of vagina and penis.

While the suture shape and position of dart apparatus of $T$. incilis sp. nov. is similar to $T$. pygmaea sp. nov., T. incilis sp. nov. have a bent epiphallic caecum, and short flagellum and vagina, whereas T. pygmaea sp. nov. have a straight epiphallic caecum, and long flagellum and vagina.

Taphrenalla pygmaea Pholyotha \& Panha, sp. nov. (figs 1, 3, 13A, 14A, B, table 6)

Type material examined. Holotype: $\mathrm{CUMZ}_{7210}$ (fig. 13A). Paratypes. Same data as holotype: CUMZ 7211 (19 shells and 12 specimens in ethanol), NHMUK (two shells), and SMF (two shells).

Other material examined. Wat Sathit Khirirom, Khiri Rat Nikhom District, Surat Thani ( $9^{\circ}$ ol' $48.2^{\prime \prime} \mathrm{N}$ $98^{\circ} 59^{\prime} 12.5^{\prime \prime E}$ ): CUMZ 7212 (75 shells and nine specimens in ethanol).

Type locality. Tham Wang Badan Priest's Camp Site, Khiri Rat Nikhom District, Surat Thani, Thailand $\left(8^{\circ} 54^{\prime} 21.99^{\prime \prime} 9^{\circ}{ }^{\circ} 6^{\prime} 53 \cdot 9^{\prime \prime} \mathrm{E}\right)$.

Etymology. The specific epithet 'pygmaea' is from the Latin word 'pygmaeus' meaning 'dwarf', which referrs to it being the smallest sized snail in this genus.

Diagnosis. Shell small to medium-sized, narrow and deep channel-shaped suture, and weak, diminutive radial grooves. Epiphallic caecum straight. Penial caecum short. Inner sculpture of proximal penis with very fine longitudinal folds and then transition to oblique and transverse folds distally. Dart apparatus located at junction of vagina and penis.

\section{Description}

Shell (fig. 13A). Shell moderately depressed conic, small to nearly medium-sized (width up to 12.3 


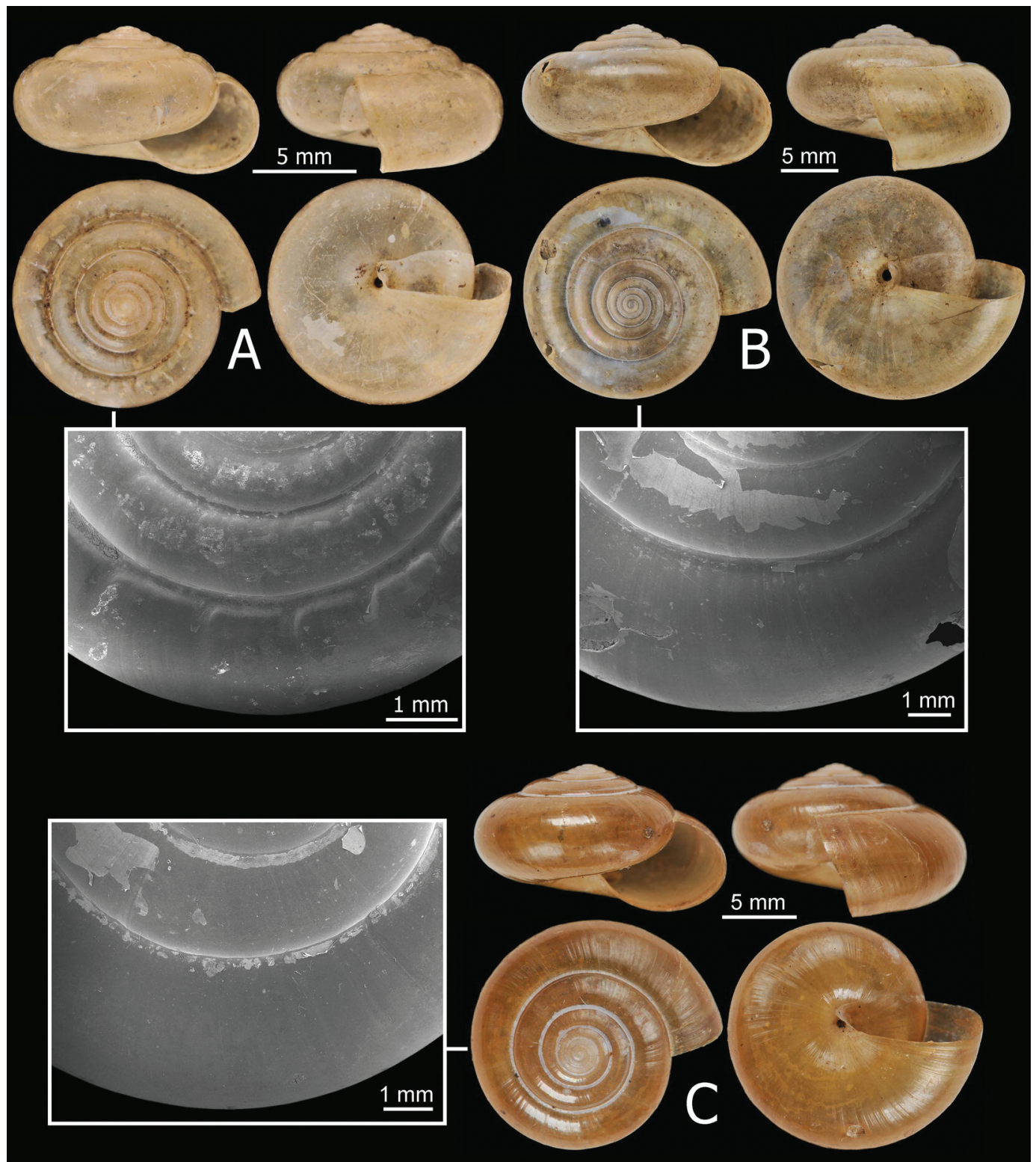

FIgUrE 13 Shells. A. Taphrenalla pygmaea sp. nov. holotype CUMZ 7210. B. T. zemia sp. nov. holotype CUMZ 7213. C. T. alba sp. nov. holotype CUMZ 7217. Inset SEM image showing shell sculpture of each species.

$\mathrm{mm}$; height up to $6.8 \mathrm{~mm}$ ) and pale brown. Whorls $5^{-6}$; suture narrow, deep, and channel-shaped. Upper shell surface with weak and diminutive radial grooves that appear only near suture. Spire deressed conic; apex raised with a spire angle of about $131-151^{\circ}$. Last whorl barely shouldered and periphery almost rounded. Aperture lip simple; umbilicus narrowly opened.

Genital organs (figs 14A, B). Atrium short. Penis funnel-shaped and slightly longer than vagina; penial caecum present. Inner sculpture of proximal penis 


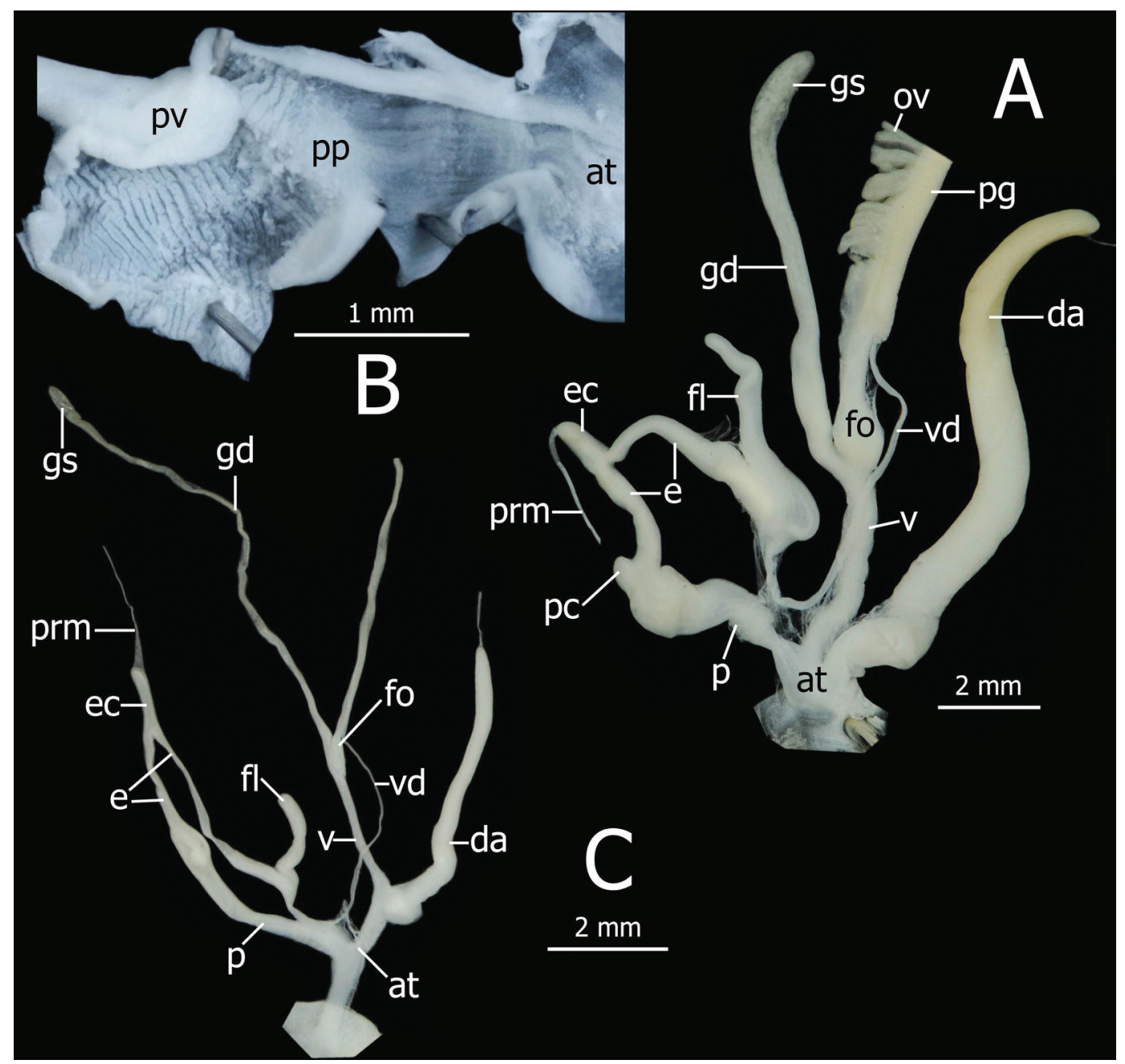

Figure 14 Genitalia. A, B. Taphrenalla pygmaea sp. nov. paratype CUMZ 7211. A. whole reproductive system. B. internal wall of penis with penial verge. C. T. zemia sp. nov. paratype CUMZ 7214, whole reproductive system from juvenile specimen.

with very fine longitudinal penial pilasters, gradually transforming to oblique and transverse folds surrounding penial verge. Epiphallus cylindrical-shaped, about one and half times total penis length. Epiphallic caecum short, and attached with thin penial retractor muscle. Flagellum prolonged and cylindrical with blunt tip. Vas deferens small tube. Vagina long and cylindrical-shaped. Dart apparatus located at junction of proximal vagina and proximal penis.
External features (fig. 3). Animal very dark gray in body colour with indistinct pale milky stripe at middle of the body running from head to caudal horn.

Remarks. Taphrenalla pygmaea sp. nov. is distinctive in being the smallest of the known Taphrenalla species. Compared to T. incilis sp. nov., this new species is distinguished by a small shell with narrow body whorl. Moreover, the internal distal 
penial surface of T. pygmaea sp. nov. has oblique and transverse folds whereas the distal portion of $T$. incilis sp. nov. has narrow obliquely cuboidal pilasters.

Taphrenalla zemia Pholyotha \& Panha, sp. nov. (figs 1, 3, 13B, 14C, table 6)

Type material examined. Holotype: CUMZ 7213 (fig. $\left.{ }_{13} B\right)$. Paratypes. Same data as holotype: CUMZ 7214 (25 shells and 30 specimens in ethanol), NHMUK (two shells), and SMF (two shells).

Other material examined. Tham Pha Sua Bureau of Monks, Mueang District, Phang-nga $\left(8^{\circ} 28^{\prime} 30.9^{\prime \prime N}\right.$ $98^{\circ} 3^{\prime} 20.8^{\prime \prime} \mathrm{E}$ ): CUMZ 7215 (five specimens in ethanol). Wat Tham Bang Toei, Mueang District, Phang-nga $\left(8^{\circ} 27^{\prime} 47.9^{\prime \prime N} 98^{\circ} 34^{\prime} 11.6\right.$ "E): CUMZ 7216 (five specimens in ethanol).

Type locality. Wat Khiriwong, Thap Put District, Phang-nga, Thailand $\left(8^{\circ} 31^{\prime} 53 \cdot 2^{\prime \prime} \mathrm{N} 98^{\circ} 34^{\prime} 41.4\right.$ "E).

Etymology. The specific epithet is from the Greek word 'zemia' meaning 'loss', which referrs to the shell being without radial grooves on the upper surface.

Diagnosis. Shell moderate to large-sized, shallowly impressed suture, and without radial groove. Epiphallic caecum straight. Dart apparatus located on vagina.

\section{Description}

Shell (fig. 13B). Shell globosely depressed, moderate to nearly large (width up to $21.3 \mathrm{~mm}$; height up to $11.9 \mathrm{~mm}$ ) and yellowish-brown. Whorls $5^{-6}$; suture shallowly impressed. Upper shell surface smooth without radial grooves. Spire moderately elevated; apex raised with a spire angle of about $137-151^{\circ}$. Last whorl slightly shouldered and almost rounded periphery. Aperture lip simple; umbilicus narrowly opened.
Genital organs (fig. 14C). Atrium long. Penis slender tube and slightly longer than vagina. Epiphallus cylindrical tube, nearly one and a half times total penis length. Epiphallic caecum short, and attached with penial retractor muscle. Flagellum large and slender tube. Vas deferens thin tube connected between distal end of epiphallus and free oviduct. Vagina long and cylindrical-shaped. Dart apparatus located near proximal vagina away from penis joining to atrium.

External features (fig. 3). Animal dark gray in body colour with three pale milky yellow stripes running from head to caudal horn. One stripe at middle of the body and two stripes close to foot sole.

Remarks. Taphrenalla zemia sp. nov. is distinguished from all other Taphrenalla species by the shell having a shallowly impressed suture without a subsutural band and no radial grooves on shell sculpture. Although we surveyed three localities during the wet season, only juvenile specimens were found for the examination and illustrated herein.

Taphrenalla alba Pholyotha \& Panha, sp. nov. (figs 1, 3, 13 C, 15, table 6)

Type material examined. Holotype: $\mathrm{CUMZ}_{7217}$ (fig. $\left.{ }_{13} \mathrm{C}\right)$. Paratypes. Same data as holotype: CUMZ 7218 (12 shells and 22 specimens in ethanol), CUMZ 7219 (13 specimens in ethanol), NHMUK (two shells), and SMF (two shells).

Other material examined. Limestone outcrops at Khlong Thom Nuea, Khlong Thom District, Krabi ( $7^{\circ} 55^{\prime} 47.9^{\prime \prime} \mathrm{N} 99^{\circ}{ }^{\prime} 6^{\prime} 23.3^{\prime \prime} \mathrm{E}$ ): CUMZ 7220 (six shells). Limestone outcrops at Ao Luek Tai, Ao Luek District, Krabi ( $8^{\circ} 24^{\prime}$ og.9” $\left.\mathrm{N}, \quad 98^{\circ} 44^{\prime} 16.3^{\prime \prime} \mathrm{E}\right)$ : CUMZ 7221 (four specimens in ethanol). Limestone outcrops near Than Bok Khorani, Ao Luek District, Krabi $\left(8^{\circ} 22^{\prime} 28.7^{\prime \prime} \mathrm{N} 98^{\circ} 44^{\prime} \mathrm{O} 7.9\right.$ "E): CUMZ 7222 (one shell), CUMZ $_{7223}$ (10 shells and four specimens in ethanol), and CUMZ 7224 (five specimens in ethanol). Tham 


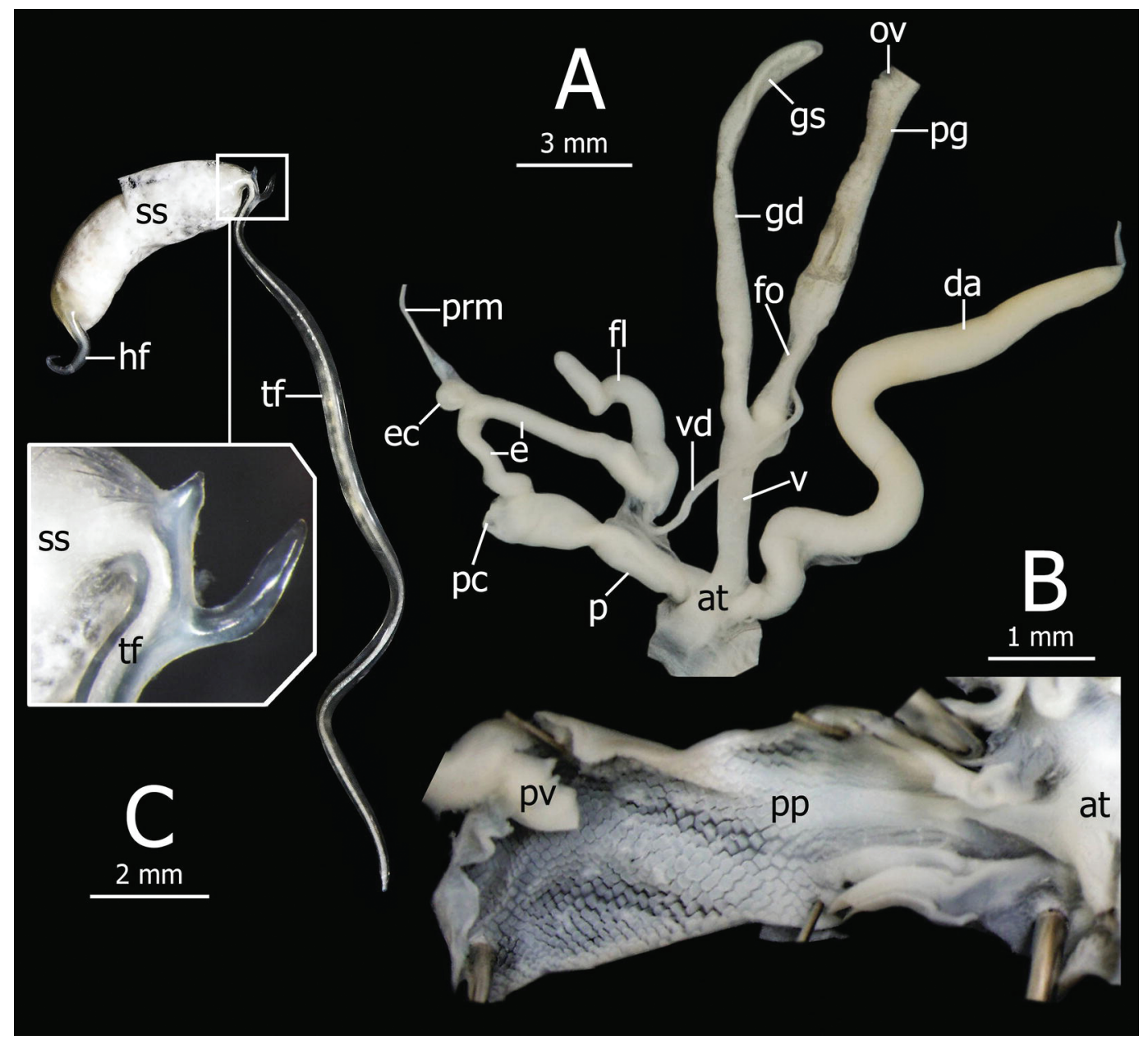

FIGURE 15 Genitalia and spermatophore of Taphrenalla alba sp. nov. specimen CUMZ 7223. A. whole reproductive system. B. internal wall of penis with penial verge. C. spermatophore; inset showing two spines located close to the sperm sac.

Nalakiring Bureau of Monks, Plai Phraya District, Krabi $\left(8^{\circ} 33^{\prime} 35 \cdot 3^{\prime \prime} \mathrm{N} 98^{\circ} 51^{\prime} 37 \cdot 5^{\prime \prime E}\right)$ : CUMZ 7228 (two specimens in ethanol). Wat Khao Phra, Phrasaeng District, Surat Thani $\left(8^{\circ} 37^{\prime} 33.0^{\prime \prime} \mathrm{N} 98^{\circ} 56^{\prime} 53.5^{\prime \prime E}\right)$ : CUMZ $_{7229}$ (one specimen in ethanol).

Type locality. Wat Tham Seua (Tiger Cave Temple), Mueang District, Krabi, Thailand ( $8^{\circ} \mathrm{O} 7^{\prime} 32.9^{\prime \prime} \mathrm{N}$, $\left.98^{\circ} 55^{\prime} 27 \cdot 1^{\prime \prime} \mathrm{E}\right)$.

Etymology. The specific epithet 'alba' is from the Greek word 'albus' meaning 'white, whitish', and refers to the characteristics of the shell having a white line or white subsutural band below the suture.

Diagnosis. Suture shallowly impressed and with white subsutural band. Epiphallic caecum short and bent at tip. Penial caecum short. Inner sculpture of proximal penis with very soft longitudinal folds then transition to small cuboidal pilasters distally. Dart apparatus located at vagina and penis junction. Spermatophore with two spines on tail filament close to sperm. 


\section{Description}

Shell (fig. ${ }_{13}$ ). Shell globosely depressed, medium-sized (width up to $18.5 \mathrm{~mm}$; height up to 10.6 $\mathrm{mm}$ ) and reddish-brown. Whorls $5^{-6}$; suture shallowly impressed and with narrow whitish subsutural band. Upper shell surface smooth and without radial grooves. Spire conic; apex raised with a spire angle of about $126-144^{\circ}$. Last whorl well-rounded at periphery. Aperture lip simple; umbilicus narrowly opened.

Genital organs (fig. 15). Atrium short. Penis cylindrical and nearly one and a-half times total vagina length; penial caecum present. Internal sculpture of proximal penis with thin longitudinal folds then transformed to small cuboidal penial pilasters in middle and surrounding penial verge in distal penis. Epiphallus slender tube, slightly longer than total penis length. Epiphallic caecum short and bent at the tip, and penial retractor muscle connected near tip. Flagellum slightly long (about half-length of epiphallus) with blunt tip. Vas deferens small and tube-shaped. Vagina prolonged and cylindrical-shaped. Dart apparatus located at junction between vagina and penis. Gametolytic sac elongate bulbous; gametolytic duct long and tube-shaped. Spermatophore elongate and needle-shaped. Tail filament very long tube; region close to sperm sac bearing two spines; furthest spine from sperm sac large and longer than the other.

External features (fig. 3). Animal very dark gray in body colour with three milky yellow stripes running from head to caudal horn. One stripe at middle of the body and the other two above foot sole.

Remarks. Taphrenalla alba sp. nov. is similar to $T$. zemia sp. nov., but can be distinguished by having a reddish-brown shell with narrow whitish subsutural band, whereas T. zemia sp. nov. has a yellowish-brown shell and without subsutural band. Furthermore, the dart apparatus of T. alba sp. nov. is located at the vagina and penis junction, whereas in T. zemia sp. nov. it is located on vagina away from the vagina and penis junction. 